\title{
Integrating Natural Gas Hydrates in the Global Carbon Cycle
}

\author{
Final Scientific/Technical Report \\ submitted by David Archer ${ }^{1}$ and Bruce Buffett ${ }^{2}$
}

\author{
Submitted 4-10-2012 \\ ${ }^{1}$ Department of the Geophysical Sciences \\ University of Chicago \\ Chicago IL 60637 \\ ${ }^{2}$ University of California, Berkeley \\ Earth \& Planetary Science \\ 383 McCone Hall \\ Berkeley, CA 94720-5800
}

Agency Award Number: DE-NT0006558

Award Dates 1/1/08 to 12/31/11

Disclaimer: This report was prepared as an account of work sponsored by an agency of the United States Government. Neither the United States Government nor any agency thereof, nor any of their employees, makes any warranty, express or implied, or assumes any legal liability or responsibility for the accuracy, completeness, or usefulness of any information, apparatus, product, or process disclosed, or represents that its use would not infringe privately owned rights. Reference herein to any specific commercial product, process, or service by trade name, trademark, manufacturer, or otherwise does not necessarily constitute or imply its endorsement, recommendation, or favoring by the United States Government or any agency thereof. The views and opinions of authors expressed herein do not necessarily state or reflect those of the United States Government or any agency thereof. 


\begin{abstract}
We produced a two-dimensional geological time- and basin-scale model of the sedimentary margin in passive and active settings, for the simulation of the deep sedimentary methane cycle including hydrate formation. Simulation of geochemical data required development of parameterizations for bubble transport in the sediment column, and for the impact of the heterogeneity in the sediment pore fluid flow field, which represent new directions in modeling methane hydrates. The model is somewhat less sensitive to changes in ocean temperature than our previous 1-D model, due to the different methane transport mechanisms in the two codes (pore fluid flow vs. bubble migration). The model is very sensitive to reasonable changes in organic carbon deposition through geologic time, and to details of how the bubbles migrate, in particular how efficiently they are trapped as they rise through undersaturated or oxidizing chemical conditions and the hydrate stability zone. The active margin configuration reproduces the elevated hydrate saturations observed in accretionary wedges such as the Cascadia Margin, but predicts a decrease in the methane inventory per meter of coastline relative to a comparable passive margin case, and a decrease in the hydrate inventory with an increase in the plate subduction rate.
\end{abstract}




\section{Table of Contents}

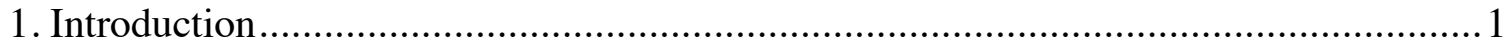

2. Passive Margin Model Formulation ................................................................... 3

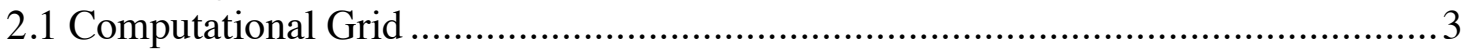

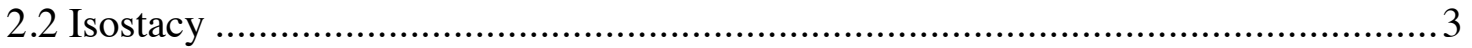

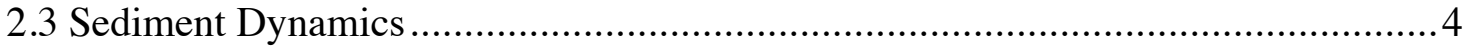

2.3.1 Deposition .................................................................................... 4

2.3.2 Slope-Driven Offshore Transport ........................................................... 4

2.3.3 Sea Level Changes ................................................................................. 5

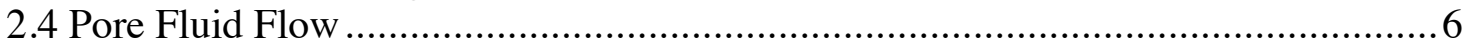

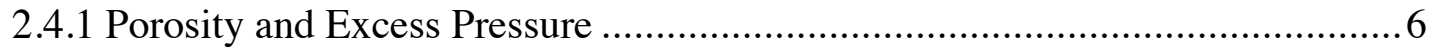

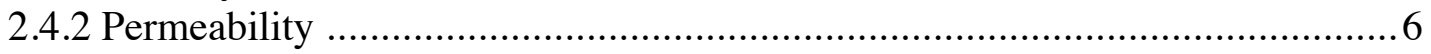

2.4.3 Darcy flow ................................................................................... 7

2.4.4 Vertical Flow Relative to the Seafloor .................................................. 8

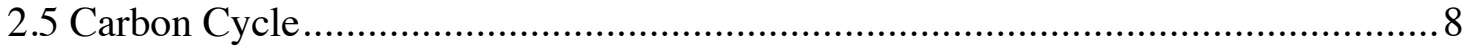

2.5.1 Deposition ...................................................................................... 8

2.5.2 Biological Degradation ........................................................................ 9

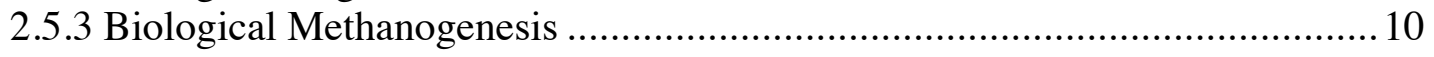

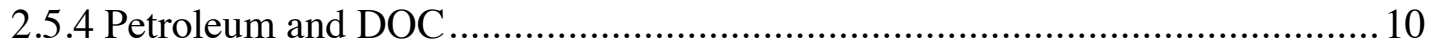

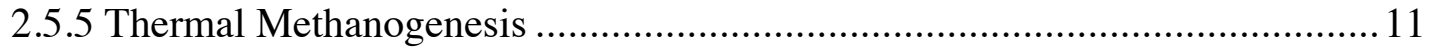

2.5.6 Methane Bubbles and Hydrate .............................................................. 11

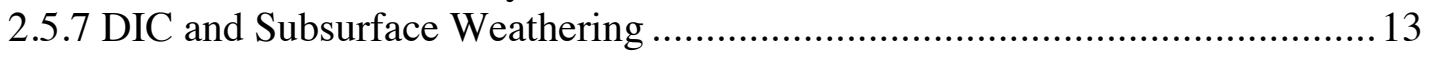

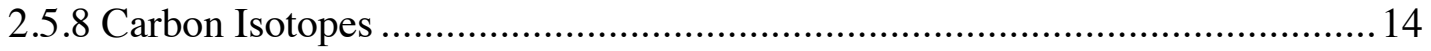

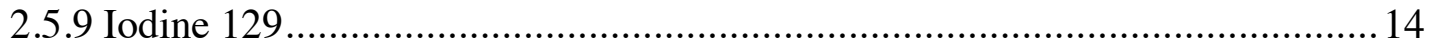

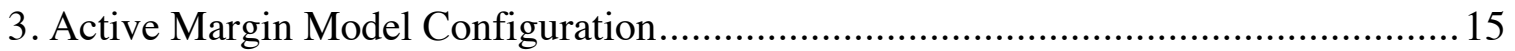

3.2 Deformation of the sediment column ........................................................... 15

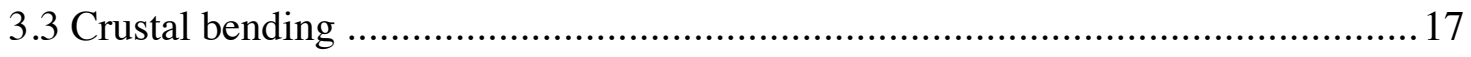

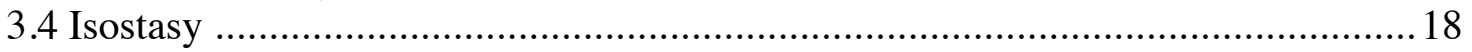

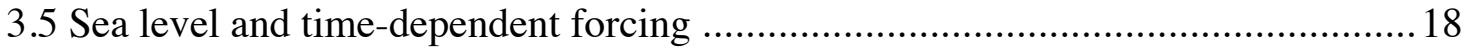

3.6 Sediment Erosion and Landslides ............................................................... 18

3.7 Pore Fluid Flow .................................................................................... 19

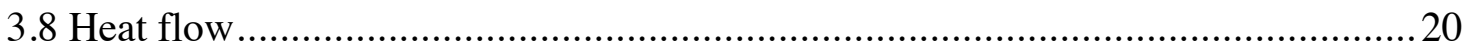

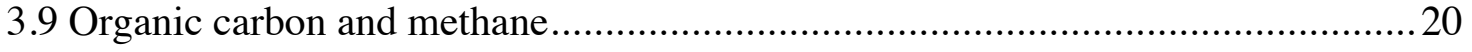

4. Gulf of Mexico Model Configuration ................................................................... 21

5. Arctic Margin Model Configuration ..................................................................... 22

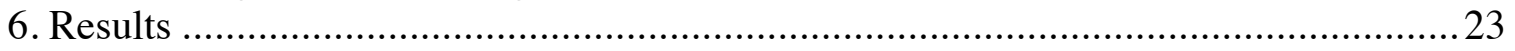

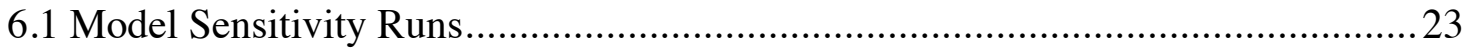

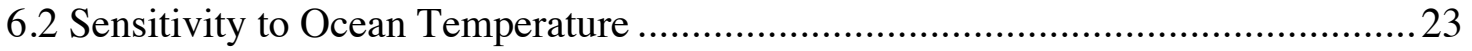

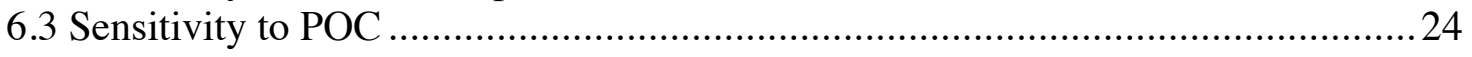

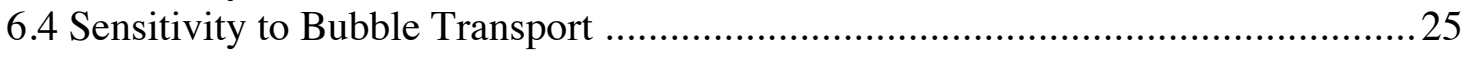

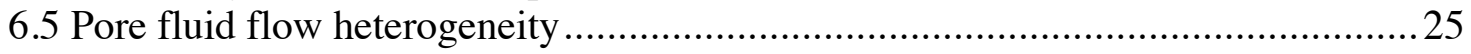

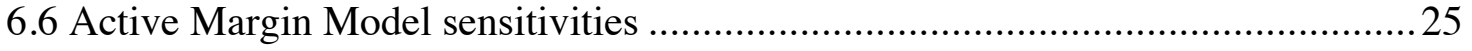

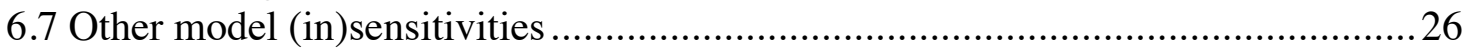

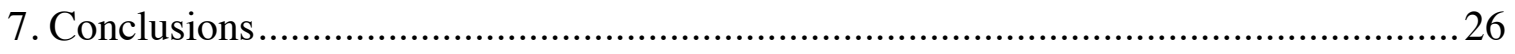

8. Publications Resulting from this project so far .............................................. 27 
Citations.

Table 1. Passive Model scenarios with uniform sea level and POC deposition state (ocean oxic state $=3$ ).

Table 2. Passive margin simulations with a time-varying sea level and ocean oxic state (POC deposition) 34

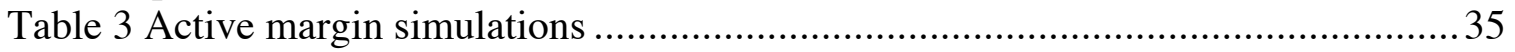

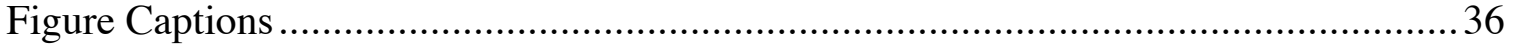




\section{Executive Summary}

We have developed a geologic-time and basin-spatial scale model of the continental margin methane cycle. The model, SpongeBOB, is used to simulate evolution of the carbon cycle in a passive sedimentary continental margin in response to changing oceanographic and geologic forcing over a time scale of 140 million years. The model is somewhat less sensitive to temperature than our previous results with a one-dimensional model, but is more sensitive to reasonable changes in POC than it is to reasonable changes in temperature. This behavior could lead to higher inventories of hydrate during hothouse climate conditions, rather than lower as generally assumed, due to the enrichment of the sediments in organic carbon. The hydrate inventory in the model is extremely sensitive to the ability of methane bubbles to rise within the sediment column, and how far gas-phase methane can get through the sediment column before it redissolves when it reaches undersaturated conditions. Hydrate formation is also sensitive to deep respiration of migrating petroleum in the model. The geochemistry of the sediment column is altered by the addition of vertical high-permeability chimneys intended to mimic the effects of heterogeneity in the real sediment column due to faults and chimneys, and produces results consistent with measured pore-water tracers $\mathrm{SO}_{4}{ }_{4}^{2-}$ and ${ }^{129}$ I. Pore water DIC concentrations are consistent with chemical weathering at depth within the sediment column. The carbon isotopic composition of the DIC is consistent with a methane production efficiency from POC of 50\%, which is somewhat lower than redox balance with the $\mathrm{H} / \mathrm{C}$ of organic matter in the model. Other phenomena which we simulated had only small impact on the hydrate inventory, including thermogenic methane, dissolved organic carbon, and sediment transport characteristics.

The two-dimensional model of sediment column geophysics and geochemistry has been adapted to the problem of an accretionary wedge formation, patterned after the margin of the Juan de Fuca plate as it subducts under the North American plate. Many aspects of the active margin model are similar to the passive margin model. The main differences are related to the deformation of the deforming sediment wedge as it approaches the subduction zone. The active margin configuration of the model shares sensitivities with the passive margin configuration, in that sensitivities to organic carbon deposition and respiration kinetics, and to vertical bubble transport and redissolution in the sediment, are stronger than the sensitivity to ocean temperature. The active margin simulation also shows a sensitivity to plate subduction velocity, with higher plate velocities producing less hydrate per meter of coastline than slower velocities or the passive margin configuration. However, the local hydrate concentrations, as pore volume saturation, are higher in the active setting than the passive, as generally observed in the field.

\section{Introduction}

Models of methane hydrate formation in sediments of the deep-sea have tended to follow the example of early diagenesis modeling in adopting a one-dimensional formulation [Davie and Buffett, 2001; Davie and Buffett, 2003a; Davie and Buffett, 2003b]. For the top meter of the sediment column [Archer et al., 2002], the 1-D approximation is a good 
one, because vertical diffusion is far faster than any possible lateral pore fluid transport or diffusional effects. The methane cycle challenges a 1-D formulation, however, because the relevant chemical processes occur hundreds of meters below the sea floor, and clearly show the impact of pore fluid and gas phase migration in more than one dimension. Onedimensional models of the upper sediment require fluid flow imposed as a bottom boundary condition, and the hydrate inventory of the model is very sensitive to this parameter [Buffett and Archer, 2004]. The methane cycle is also impacted by timedependence of the sediment and organic carbon deposition rates, which are governed by onshore-offshore processes, another benefit of incorporating the second dimension into the model formulation.

SpongeBOB is formulated in the onshore-offshore dimension laterally, and to bedrock in the vertical, to internalize the entire coastal margin carbon and methane cycle, of which the methane hydrates near the sea floor are just one manifestation. Many of the processes and mechanisms, such as all the different means of downslope sediment transport, or pathways for subsurface fluid flow, are impossible to represent accurately given our present state of knowledge, but by representing them as best we are able, we hope to gain some qualitative picture of the relative importances of the various driving factors and processes.

The model is set up to simulate an accumulating passive continental margin such as the East coast of the United States, which has been accumulating sediment since rifting of the Atlantic about 200 million years ago. One of the best-studied locations for methane hydrates is the Blake Ridge, a "drift deposit" ridge jutting out into the Atlantic [Borowski, 2004]. The Blake Ridge owes its existence to the hydrodynamics of particle sedimentation, presumably driven by existing topography and the energetic western boundary flow of the Atlantic. Although Blake Ridge is attached to the continental slope of the U.S., our model results (which only represent the slope, with no drift-deposit ridge) suggest that Blake Ridge might not be entirely typical of slope sediments in general, and thus might be deceptive jumping-off point for global extrapolation.

There have been fewer models of the methane cycle in accretionary wedge sediment complexes, because of the greater complexity of the underlying physics [Carson et al., 1990]: instead of ongoing sediment accumulation onto a collapsing but essentially onedimensional sediment column, in an accretionary wedge complex the sediment is actively deformed by compression associated with the scrape-off of the sediment complex from the underlying subducting oceanic crust. An accretionary wedge sediment complex is an example of a "structural" hydrate deposit, which comprise a smaller fraction of the hydrate inventory globally but which form hydrate in higher concentrations, even forming massive hydrate blocks, and forming them closer to the sediment surface than the stratigraphic deposits, which tend to concentrate hydrate at the base of the stability zone, often hundreds of meters below the sea floor. In particular, the model is applied to the case of the Cascadia margin [Spence et al., 2000].

We gauge the sensitivities of this complex model by showing a variety of sensitivity model runs, varying critical parameters or turning process on and off. The characteristics 
of the runs will be described as they come up in the model formulation section, and they are summarized in Tables 1,2, and 3.

\section{Passive Margin Model Formulation}

\subsection{Computational Grid}

SpongeBOB is formulated on a free-form grid sigma-type vertical coordinate system in depth (Figure 1), in which the grid cells expand to fill the sediment column as it expands through time. The grid cell thicknesses are controlled through the simulation by the bookkeeping strategy of advecting sediment (solid plus associated pore fluid and other phases) through the interior of the model domain. Initially all grid cells contain enough solid material to fill a thickness of 1 meter at a "drained" porosity. Sediment is deposited on the top face of the top cell, and a material flow rate is calculated for the bottom face of the cell, such that the cell keeps some of the new material for itself, but passes most of it on fill the subsurface cells. The process continues through the sediment column, and the boxes all expand uniformly.

A few grid cells in the top of the domain are restricted, such that they cannot expand beyond a thickness of 200 meters, in order to maintain a minimum computational resolution in the region of the hydrate stability zone. After enough model time has passed that a restricted cell reaches its maximum thickness, it passes along the entire incoming advective flux from above into the cell below.

\subsection{Isostacy}

The sediment column elevation is determined by a time-dependent, laterally smoothed isostasy calculation, based on the idea that the crust and all the material sitting on top of it are all floating in a denser fluid of mantle material. The model domain spans between continental crust and ocean crust, with a stipulation that only the ocean crust is affected by a time-dependent cooling.

The continental crust is $13 \mathrm{~km}$ thick and its density is $3.0 \mathrm{~g} / \mathrm{cm}^{3}$. Any sediment load also contributes to the mass of the column, and the equilibrium elevation of the bedrock. Cooling of the ocean crust takes place with a time-dependent thermal boundary layer, in which temperature varies linearly with depth, and the thickness of which increases according to $\mathrm{dz}=\operatorname{sqrt}(\kappa \mathrm{T})$ [Parson and Sclater, 1977$]$. The temperatures of the ocean crust and the mantle boundary layer are found by interpolation between the time-evolving temperature at the base of the sediment column, and a generic mantle temperature of $1600{ }^{\circ} \mathrm{C}$. A temperature of $1600 \mathrm{~K}$ would have been more realistic, but the impact of this coding error on the buoyancy of the crust is small. The ocean end-member sediment column is taken as the sum of the sediment column, the ocean crust, and the thermal boundary layer as it thickens and thermally contracts through time. 
The blending of domains is done by calculating pure end-member continental and ocean crust scenarios at each model grid point, and then scaling between them using an ad-hoc ocean fraction variable, ranging from 0 for continent to 1 for the ocean end member. The transition is set up with a horizontal length scale of $50 \mathrm{~km}$. For each end member, continental and oceanic, the masses and heights of the column are computed. The two scenarios are blended together at this stage, taking a composite column mass that scales between the two end members, and a composite column height.

The position of local isostatic equilibrium is determined by mass displacement of generic mantle material, taking a hypothetical mantle "water line" defined such that the nominal elevation of the top of a generic ocean crust falls at about 4000 meters below sea level. The equilibrium heights for the top of bedrock are smoothed horizontally through the grid using a diffusion algorithm that achieves a spatial scale of a few 10's of kilometers. Flexure and rigidity of the plates becomes important in accretionary margins, but for this study the lateral interaction in isostacy is rudimentary, merely setting the stage for the sediment column.

\subsection{Sediment Dynamics}

\subsubsection{Deposition}

The goals of the sedimentation scheme are to create appropriate sedimentation rates and grain sizes, in adaptive response to a time-evolving submarine landscape. The existence of a shelf break, and the prograding clinoform pattern of sediment deposition, requires the existence of a region of fast sediment accumulation just off the shelf break, a sediment depocenter. Sediment input from the continent is also sorted by grain size, with largest grains depositing closer to shore and finer grain sediments offshore (Figure 2).

Offshore sediment transport and deposition in SpongeBOB is parameterized in an approach following Pirmez et al [1998]. The ocean margin is treated as a giant river carrying suspended particles from continental runoff, from left to right in our configuration. As the water depth increases, the flow velocity decreases as a plug flow. Suspended particles settle out following Stokes' law according to their grain size. Particles deposit only if the shear stress at the bed, calculated from the hypothetical river velocity multiplied by a fudge factor, is too slow to lift the particles faster than they sink. The critical shear velocity depends on particle radius, as does the settling speed, effectively sorting the particles by size with offshore distance.

\subsubsection{Slope-Driven Offshore Transport}

Turbidites in abyssal sediments attest to the importance of slope failure to the margin sediment dynamics. These processes are handled as a function of the sea floor grade. If the grade exceeds a critical value, here taken to be $6 \%$, the material that would deposit according to the shear / sinking speed criterion is instead classified as "resuspended". 
Also, if the sea floor slope ever manages to exceed the critical slope, surface sediment is eroded into the resuspended pool. The resuspended material redeposits using the same settling speed / offshore transport criterion as used for the primary settling material, but resuspended material only begins to deposit where the sea floor slope is less than $1 \%$, reflecting the difference between a turbidity flow which only stops on the plain as opposed to individual sinking particles assumed in the primary sedimenting material [Koeve, 2005].

When material is resuspended, its POC concentration is specified as a function of the water depth at the point of its initial potential deposition. Because the offshore transport is assumed to be turbidites, we assume it escapes the degradation that individual settling particles, the primary deposition, are subject to (in other words, the POC fraction of sedimenting material is specified in the code as a function of depth of original deposition, not redeposition). Resuspended organic carbon is assumed to be distributed among the grain size fractions of the resuspended material according to surface area, selectively concentrated (according to mass) the organic carbon into the smaller size fractions.

The sediment transport scheme is intended to be a utilitarian parameterization of sediment transport processes, rather than a mechanism-resolving model such as Sedflux [Syvitski, 2001]. The scheme as we have tuned it achieves the goal of a well-defined shelf break, driven by a strong sediment depocenter just off the shelf break, and response to sea level changes that mimics the Sedpak model [Koeve, 2002]. The accumulation rate at $2 \mathrm{~km}$ depth in the model is close to that of Blake Ridge, about $2 \mathrm{~cm} / \mathrm{kyr}$. Total sediment thicknesses and extents are comparable with a seismic images of the Atlantic margin from Kennett [1982] (Figure 4). Model sensitivity to these sediment transport processes was gauged by altering the critical sea floor slope in sensitivity simulation $L o$ Slope.

\subsubsection{Sea Level Changes}

Sedimentation is heavily impacted by eustatic changes in sea level, with highest rates close to shore but in water that not too shallow. Sea level changes are imposed on the simulation as a 160 million-year cycle, peaking at high sea level in the middle of the simulation and dropping the final 20-30 million years (Figure 3) [Haq et al., 1987]. Two sets of simulations were done, one which neglected time-dependent sea level and POC rain forcing (Table 1), and another set which included these effects (Table 2). Results in this paper will be presented as time slices from various points in the simulations, but animations of the entire runs are available as links from the figure captions. 


\subsection{Pore Fluid Flow}

\subsubsection{Porosity and Excess Pressure}

Fluid flow follows Darcy's law in response to the pore fluid excess pressure gradient [Athy, 1930]. The pressure formulation of the model is based on a constitutive equation in which the excess pore fluid pressure can be calculated from the porosity and the mass load overhead [Flemings et al., 2002]. The idea is that there is a one-to-one relationship between the porosity of the sediment and the amount of solid load it can support, akin to a bulk compressibility. We find that to fit the entire sediment column requires a double exponential decay, in effect two $\beta$ values, analogous to two springs of different weights and lengths connected in serial. Coefficient $\beta_{1}$ represents ductile flows and recrystalization of mineral grains, on a depth scale of about $10 \mathrm{~km}$, while $\beta_{1}$ represents the collapse of clays that occurs on a depth scale of about $2 \mathrm{~km}$ (Figure 5),

$$
\phi=0.38 \mathrm{e}^{-0.0312 \mathrm{~S}_{\text {sup }}}+0.32 \mathrm{e}^{-0.2 \mathrm{~S}_{\text {sup }}}
$$

where $S_{\text {supp }}$ is the supported solid load. Because of the double exponential form of the constitutive equation, this is an iterative calculation.

The excess pressure, which drives the Darcy flow, is calculated as

$$
\mathrm{P}_{\text {excess }}=\mathrm{S}_{\mathrm{v}}-\mathrm{P}_{\text {hydro }}-\mathrm{S}_{\text {sup }}
$$

where $S_{v}$ is the total load of the sediment column from all phases, and $P_{\text {hydro }}$ is the hydrostatic pressure (the load due to the fluid phase).

\subsubsection{Permeability}

The permeability $\mathrm{k}$ in the vertical direction is parameterized as

$\mathrm{k}=\frac{\overline{\mathrm{r}}^{2} \phi^{3}}{180(1-\phi)^{2}}$

where $\overline{\mathrm{r}}$ is the mean grain radius and $\phi$ the porosity. A factor of 100 anisotropy is imposed [Daigle and Dugan, 2011], such that the permeability along the horizontal grid is 100 times higher than the vertical permeability, to parameterize for the effect of layers like sandy turbidites, that are unresolved in the model.

We show results of two model permeability formulations, one as presented so far, and the other with added vertical chimneys of enhanced permeability, such as faults, pipes, chimneys, and similar structures (cases No Chimneys and Base, respectively). The chimneys are situated every 5 grid cells throughout the model domain, and remain 
stationary as the continental margin progrades offshore through the simulation. The chimneys are meant to suggest the impact of faults and heterogeneities in the sediment column. The horizontal grid spacing is $3.15 \mathrm{~km}$, the vertical permeability in the chimney is 10 times higher than given above. This is only a crude representation of a realistic flow regime through faults and permeable chimneys which seem to dominate subsurface flows [Flemings et al., 2003]. The intent is to gauge in a qualitative way the sense and potential magnitude of the impact of heterogeneity on the flow and chemical evolution of the sediment column.

The permeabilities and the excess pressures of the two simulations at the end of the simulations are shown in Figure 6.

\subsubsection{Darcy flow}

The excess pressures drive flow following Darcy's law

$$
\phi \quad \mathrm{w}_{\text {Darcy }}=\frac{\mathrm{k}}{\mu} \nabla \mathrm{P}_{\text {excess }}
$$

where $\mathrm{w}_{\text {Darcy }}$ is the Darcy velocity, $\mathrm{k}$ is the permeability, $\mu$ the interstitial fluid viscosity, $\phi$ the porosity, and $\mathrm{P}_{\text {excess }}$ is the pressure in excess of hydrostatic in the pore fluid. The fluid velocity is defined here relative to the solid grains, but the solids also move from one grid cell to another vertically as the vertical grid in the model stretches to fill the expanding sediment column. The vertical motion of pore fluid within the numerical grid is taken as the sum of the Darcy flow plus the "accounting" flow to accommodate the stretching coordinate system

$\mathrm{w}_{\text {bur }}=\mathrm{w}_{\text {Darcy }}-$ Burial $_{\text {fluid }}$

where $\mathrm{w}_{\text {bur }}$, like $\mathrm{w}_{\text {Darcy }}$, is defined as relative to the moving cell faces of the numerical grid.

A flow limiter in the vertical protects the calculation from numerically overstepping, for thin, permeable layers, by testing for the change in fluid pressure that would result from unimpeded Darcy flow each time step. If the pressure change exceeds a threshold, a stand-in vertical velocity is calculated that generates a prescribed, limited change in the pressure gradient (and hence also the porosity). The idea is that a thin sandy layer would quickly drain, reaching zero excess pressure gradient, and the velocity is designed to achieve that end in a stable way even if the time step for Darcy flow would need to be much shorter. Most of the vertical flow in the model however is well-resolved in time, leaving the flow limiter for a few "emergency" grid points and times. 


\subsubsection{Vertical Flow Relative to the Seafloor}

Formation of methane hydrate in 1-D models is very sensitive to upward vertical flow of pore fluid carrying methane into the stability zone. A measure for the net vertical flow is the fluid flow rate relative to the moving sediment water interface, defined throughout the sediment column as

$\mathrm{w}_{\text {seafloor }}=\mathrm{w}_{\text {bur }}+\frac{\mathrm{d}}{\mathrm{dt}}\left(\mathrm{z}-\mathrm{z}_{\text {seafloor }}\right)$

Like $\mathrm{w}_{\text {bur }}$ and $\mathrm{w}_{\text {Darcy }}, \mathrm{w}_{\text {seafloor }}$ is defined on the cell faces, but at any moment in time the subsurface $\mathrm{w}_{\text {seafloor }}$ velocities are defined as relative to the moving sea floor, so that if a subsurface parcel were flowing upward just quickly enough to remain at a constant depth below the seafloor, its $\mathrm{w}_{\text {seafloor }}$ would be defined as zero. Sections of $\mathrm{w}_{\text {Darcy }}$ and $\mathrm{w}_{\text {seafloor }}$ are shown in Figure 7, and values at the sediment surface in Figure 8.

When vertical permeable chimneys are added to the simulation, the chimneys take most of the compaction flow. The horizontal anisotropy applied to the permeability allows the sediment columns in between the chimneys to vent fluid into the chimneys for expulsion. Interestingly for the formation of methane hydrate discussion to come, the chimneyed simulation finds strongly downward $\mathrm{w}_{\text {seafloor }}$ in the grid cells in between the chimneys. These cells have vented their upward Darcy flow into the permeable chimneys, leaving the burial flux of fluid with sedimentation to drive $\mathrm{w}_{\text {seafloor }}$ in the downward direction, where it brings fluid from above into the hydrate stability zone, rather than fluid from below.

\subsection{Carbon Cycle}

\subsubsection{Deposition}

The carbon cycle of the deep biosphere is driven by the rain of particulate organic carbon (POC) to the sea floor, which depends on changes in sea level. The model encodes a generalization that periods of high sea level generally have enhanced carbon preservation due to low oxygen in the ocean, the Cretaceous being an important example [Hunt et al., 2002]. The POC concentration and $\mathrm{H} / \mathrm{C}$ and $\mathrm{O} / \mathrm{C}$ ratios of the depositing organic matter depend on water depth and the oxygen state of the ocean (Figure 3). The low sea-level ocean, with an oxygen minimum zone but no anoxia, deposits at most $2 \%$ dry weight $\mathrm{POC}$, with an $\mathrm{H} / \mathrm{C}$ ratio of 0.7 . The high-sea-level ocean, considered anoxic in the end member, buries up to 5\% POC, with an $\mathrm{H} / \mathrm{C}$ ratio of 2. The POC concentrations are specified as a function of water depth for each ocean state ( 1 to 4 , with 1 being fully oxic and 4 anoxic), and interpolated between ocean states so that carbon deposition can vary smoothly in time, in synchrony with changes in eustatic sea level. The "Atlantic" POC profile is comparable to sediment surface POC concentration off Cape Hatteras today 
[Mayer, 2002]. The impact of the ocean oxic state on hydrate abundance was gauged in simulations with time-uniform forcing, called Atlantic, Pacific, OMZ, and Anoxic.

As with the sea level forcing, the depositional trajectory of POC deposition is not intended to mimic any location in particular, but rather to give an indication of how typical deposition cycles might affect the methane cycle in continental margins in general: the sensitivity of the methane cycle to variability in time. High POC concentrations accumulate in a time of high sea level in the simulation, which becomes a buried feature by the end of the simulation (Figure 9 left).

\subsubsection{Biological Degradation}

2.Biological degradation is taken to be a function of temperature $\left(\mathrm{T},{ }^{\circ} \mathrm{C}\right)$, sediment age, and dissolved methane concentration.

$$
\begin{aligned}
\mathrm{k}_{\text {resp }}= & 0.5 \mathrm{yr}^{-1} \cdot \mathrm{e}^{(0.11 \mathrm{~T})} \cdot \mathrm{H}_{\text {smooth }}\left(50^{\circ} \mathrm{C}-\mathrm{T}, 10^{\circ} \mathrm{C}\right)^{6} \\
& \cdot \mathrm{e}^{-1.1 \log (\text { Age })-0.5} \cdot\left(\frac{35 \mathrm{M}}{\left[\mathrm{CH}_{4}\right]+35 \mathrm{M}}\right)
\end{aligned}
$$

The first exponential term represents the activation energy for respiration, tripling in rate with a temperature increase of $10^{\circ} \mathrm{C}$ [Antia, 2001]. The second represents inhibition of biological activity above a critical temperature of $50{ }^{\circ} \mathrm{C}$. The formulation uses a smoothed "Heaviside" function to shut down the respiration reactions above a threshold temperature of $50^{\circ} \mathrm{C}$. This function is used several times in the SpongeBOB formulation, defined as

$$
\mathrm{H}_{\text {smooth }}(\mathrm{x}, \Delta \mathrm{x})=\frac{1}{\pi}\left(0.5 \arctan \left(\frac{\mathrm{x}}{\Delta \mathrm{x}}\right)\right)
$$

The function provides a smooth transition between the on and off states ( 1 and 0$)$, rather than the discontinuous step function of the true Heaviside function. Raising the function to a power, as done here, tightens the transition, here intended to mimic a fairly strong shutdown of respiration rates when it gets too hot.

The age-dependence mimics the astonishingly wide correlation between carbon age and reactivity observed in nature [Hedges and Keil, 1995]. The effect of the "metabolite inhibition" effect as proposed by Wallmann et al. [Wallmann et al., 2006] is represented in the last term in the formulation. Wallmann included dissolved inorganic carbon concentration in addition to methane, but DIC concentrations are high in the model, perhaps too high (see below), so we took the simplifying liberty of excluding DIC inhibition of methanogenesis.

Respiration is concentrated in the top $2 \mathrm{~km}$ of the sediment column, limited by temperature (Figure 10). It is also generally focused offshore of the shelf break, except 
during periods of very high sea level, during which POC can accumulate in the shelf sediments. When sea level falls, the biologically available POC in the shelf sediment burns out, leaving most of the biological activity in slope sediments, and in particular in the sediment depocenter just off the shelf break. Model sensitivity to the respiration formulation was gauged by varying the "labile fraction" of the POC (cases Bio 10\%, Base (which is 50\%), and Bio $100 \%$ ).

\subsubsection{Biological Methanogenesis}

The respiring carbon is assumed to produce DIC and molecular hydrogen, a transient reducing agent. If sulfate is present in the pore water, the hydrogen reduces and consumes it; otherwise, it reacts with $\mathrm{CO}_{2}$ (DIC) to produce methane in reactions

$\mathrm{CH}_{\mathrm{x}}+2 \mathrm{H}_{2} \mathrm{O}->\mathrm{CO}_{2}+(2+\mathrm{x} / 2) \mathrm{H}_{2}$

followed by $\mathrm{CO}_{2}$ reduction

$1 / 2 \mathrm{CO}_{2}+2 \mathrm{H}_{2}->1 / 2 \mathrm{CH}_{4}+\mathrm{H}_{2} \mathrm{O}$

where the variable $\mathrm{x}$ denotes the relative concentration of $\mathrm{POH} / \mathrm{POC}$ in the reacting organic matter.

The maximum efficiency with which the biologically produced $\mathrm{CO}_{2}$ can be converted to $\mathrm{CH}_{4}$ is determined by conservation of carbon, hydrogen, and oxygen from the organic matter to methane plus $\mathrm{CO}_{2}$, realizing that supplemental oxygen and hydrogen comes from $\mathrm{H}_{2} \mathrm{O}$. This maximum $\mathrm{CH}_{4}$ production efficiency is

$\mathrm{R}_{\mathrm{CH}_{4}}=\frac{1}{2}+\frac{1}{8} \cdot \frac{\mathrm{POH}}{\mathrm{POC}}$

which works out to $62 \%$ if the $\mathrm{H} / \mathrm{C}$ ratio of the reacting organic matter is 1 . However, carbon isotopic systematics and data, described below, will restrict the efficiency of $\mathrm{CH}_{4}$ production somewhat, as if about $20 \%$ of the $\mathrm{H}_{2}$ reacts with oxidized mineral phases such as $\mathrm{Fe}_{2} \mathrm{O}_{3}$ rather than with $\mathrm{CO}_{2}$ to make methane, leaving an overall methane production efficiency of about $50 \%$.

\subsubsection{Petroleum and DOC}

The model produces petroleum based on chemical and thermal conditions. Petroleum formation in the real world is limited by the $\mathrm{H} / \mathrm{C}$ ratio of the organic matter, proceeding if the $\mathrm{H} / \mathrm{C}$ is greater than 1 , and continuing until the ratio approaches 1 . The temperature dependence of the rate constant is governed by an activation energy of $150 \mathrm{~kJ} / \mathrm{mol}$, with a pre-exponential constant of $1 * 10^{16} /$ year. These parameters confine petroleum generation to a temperature window of $60-150^{\circ} \mathrm{C}$, as inferred from the distribution of oil [Hunt, 1995]. 
Petroleum genesis temperatures are too warm to allow bacterial consumption, but $10 \%$ of the oil is assumed upwardly mobile at a rate of $1 \mathrm{~m}$ per thousand years. If it reaches cool enough conditions it is consumed by bacterial respiration, following the temperature and solute concentration dependence (but not the POC age dependence) of bacterial POC degradation kinetics above. The rate of methane production by this process of "secondary respiration" is shown in Figure 10b to be deeper than POC respiration, which is more confined to the upper sediment column. The model also assumes "sloppy feeding", in which $10 \%$ of biological POC consumption goes to dissolved organic carbon (DOC). Simulations to gauge the importance of these processes are called No Petro and No DOC.

\subsubsection{Thermal Methanogenesis}

Methanogenesis from thermal degradation of organic carbon proceeds according to an Arrhenius equation with an activation energy of $230 \mathrm{~kJ} / \mathrm{mol}$ and a pre-exponential rate constant of $4 \cdot 10^{21} \mathrm{yr}^{-1}$, which produces a lifetime of a million years at about $160{ }^{\circ} \mathrm{C}$. In contrast to the biological rate of methane production, the rate constant for thermal methane generation is very well constrained and consistent in field data, driven by the hunt for petroleum [Hunt, 1995].

The rate of methane production is taken to be this rate constant multiplied by the concentration of particulate organic hydrogen, $\mathrm{POH}$. The POC inventory decreases by $1 / 4$ of the decrease in $\mathrm{POH}$. The distribution of $\mathrm{H} / \mathrm{C}$ ratio in the sediment column (Figure 9 right) is primarily driven by the effects of changing ocean chemistry (anoxia) and thermogenic degradation. The $\mathrm{H} / \mathrm{C}$ ratio approaches zero as the carbon matures, and the decrease in $\mathrm{H}$ directly limits the production of methane in the model.

\subsubsection{Methane Bubbles and Hydrate}

The dissolved methane concentration is compared with the solubility of dissolved methane, relative to the two possible other phases of gas bubbles or hydrate, in Figure 11. Disequilibria in the three-phase methane system is restored toward equilibrium by conversion to bubbles or hydrate with a numerically-friendly time constant of 1000 years. Hydrate or bubbles both release or take up methane from the dissolved phase. When the precise depth of the stability boundary, determined by depth interpolation, falls within a grid cell, the non-gaseous $\mathrm{CH}_{4}$ is allocated into bubbles and hydrate in proportion to the volumes of the two zones, and the concentrations of the phases, for purposes of advection etc., are calculated using the partial grid cell volumes. This prevents a numerical artifact that otherwise appears as the depth of the stability boundary crosses through the numerical grid of the model.

A difficult issue to address within SpongeBOB is the mobility and fate of methane gas in the sediment column. The Davie and Buffett [2001] one-dimensional methane hydrate model covers a few hundred meters below the stability zone boundary and assumes that the bubbles are immobile. In the deeper domain of SpongeBOB, if bubbles are not 
allowed to migrate, gas completely fills some parts of the sediment column pore space (Figure 12c), so it is clear that gas must be allowed to escape the sediment column in the model. The view from petroleum geology is that, on geologic time scales, sediment columns are permeable to gas, except under permafrost soils and evaporites, which overlay the largest gas accumulations in the world in Siberia and the Middle East, respectively. Other parts of the world, for example the North Sea, are vastly enriched in oil relative to the expected amount of gas were it retained [Hunt et al., 2002].

Viewed from the perspective of an isolated bubble trapped in a pore space, it is not clear how to get that bubble to move [Jain and Juanes, 2009]. The difference in hydrostatic pressure between the top and bottom of a long, interconnected bubble network can be used to drive gas migration. Laboratory experiments find a critical gas saturation of about $10 \%$ where this mechanism begins to kick in [Leas et al., 1950], and values of 1$2 \%$ are often assumed in models for natural gas in wells [Reagan and Moridis, 2007]. SpongeBOB, without bubble transport, exceeds these values. But this is an incomplete explanation of bubble mobility in the deep sediment column because it would take an extremely tall bubble to break through the load of a few kilometers of sediment.

We have adopted a parameterization of bubble migration that depends on the bubble fraction in pores

$$
\mathrm{CH}_{4} \quad \text { loss }=\mathrm{H}_{\text {smooth }}\left(\mathrm{F}_{\mathrm{b}}-10 \%, 5 \%\right)^{3}
$$

where again the $\mathrm{H}_{\text {smooth }}$ is a smoothed version of a Heaviside function. The bubbles escape as their concentration approaches or exceeds a critical pore volume fraction of $10 \%$. In practical terms, the bubbles in SpongeBOB only fill at most $1-4 \%$ of the pore space, because the loss rate, however slow, is able to keep up with production, even when the saturation value is much less than the parameterized critical value.

Rather than resolving the pressures, permeabilities, and flow rates of the bubble phase, for reasons of simplicity, stability, and ease of manipulation, we parameterize the fate of the moving methane gas as an instantaneous redistribution of the moving methane back to the dissolved phase, following a negative exponential function of height in the sediment column. This approach is analogous to the treatment of sinking plankton in the water column of many ocean chemistry models, in which the sinking organic matter is assumed to reach some mean distance before redissolving. The bubbles once in motion rise instantaneously through the sediment until they encounter pore water that is undersaturated with respect to dissolved methane. Once they reach undersaturated conditions the upward flow is attenuated with height into the zone as

$$
\mathrm{CH}_{4} \text { flux }(\mathrm{z})=\mathrm{CH}_{4} \text { flux }(0) \cdot \mathrm{e}^{-\mathrm{z} / /_{\text {scale }}}
$$

where the value of the scale height parameter $z_{\text {scale }}$ is taken to be 500 meters in the highresolution run, but varied to 100 and $2000 \mathrm{~m}$ in two of the sensitivity runs (called $B u b b \_100 m$ and $\left.B u b b \_2 k\right)$. 
The distribution of bubbles resulting from these assumptions is shown in Figure 9. A standing crop of bubbles is sustained by respiration in the upper sediment column, and there is a chimney of bubbles carrying methane from the thermogenic zone up toward the sediment surface. Thermogenic methane in the model systematically evades the hydrate stability zone, because the sediment column is only deep enough to reach high enough temperatures when the top sediment column has nearly reached the sea surface, so that there is in general no hydrate stability zone over thermal methane production in the model (Figure 9).

\subsubsection{DIC and Subsurface Weathering}

Measurements of the concentration of dissolved inorganic carbon (DIC) reach ten times higher than the ocean value within the top few hundred meters (what we find to be the respiration zone), and then decrease to half that by the deepest samples measured, about 500 mbsf [Sivan et al., 2007]. The decrease can be explained as a chemical weathering reaction such as

anorthite $+\mathrm{CO}_{2}->$ kaolinite $+\mathrm{CaCO}_{3}$

Throughout the upper sediment column, the equilibrium concentration of dissolved $\mathrm{CO}_{2}$ is much lower than the measured concentrations.

We treated this chemistry as a first-order uptake in DIC. This neglects the impact of the alkalinity or $\mathrm{pH}$ of the solution on the $\mathrm{CO}_{2}$ concentration, but the constancy of porewater alkalinity / DIC ratios [Sivan et al., 2007] and pH make this seem a reasonable assumption. The kinetics are taken to be a function of temperature as

$\mathrm{k}_{\text {urey }}=10^{-9+\mathrm{T}(\mathrm{C}) / 0.062}$

which specifies a reaction timescale of about $10^{8}$ years at $15^{\circ} \mathrm{C}$, so that essentially nothing happens in surface sediments, to a time constant of 1000 years at $100{ }^{\circ} \mathrm{C}$. The effect of the parameterization is to deplete the DIC concentration in the deeper sediment column (Figure 13, top) relative to the case without the $\mathrm{CO}_{2}$ drawdown (Figure 13, bottom). The model DIC concentrations are higher than measured by Sivan et al [2007], and the penetration deeper, so if anything the model values are underestimates of the rates of $\mathrm{CO}_{2}$ consumption by the weathering reaction.

The concentration of dissolved inorganic carbon plays several roles in the sedimentary methane cycle. High concentrations of DIC seem to restrict biogenic methane production [Wallmann et al., 2006] although we didn't include that here because we couldn't allow the methane cycle to be a slave to a rather out-of-control DIC. The concentration of DIC affects the methane isotope systematics, although as it turns out, since uptake of by this reaction $\mathrm{CO}_{2}$ does not fractionate carbon isotopes, the value that emerges in the sediment column does not appear to be a strong function of weathering $\mathrm{CO}_{2}$ uptake. 


\subsubsection{Carbon Isotopes}

The model tracks parallel tracers representing the stable carbon isotopes in DIC and $\mathrm{CH}_{4}$. The isotopic boundary conditions are that the DIC in the ocean is assumed to be $0 \%$, and organic matter is assumed $-25 \%$. Organic matter is respired to DIC without fractionation. $\mathrm{CO}_{2}$ reduction carries a fractionation of $-90 \%$ at $0{ }^{\circ} \mathrm{C}$, dropping to about $-55 \%$ at $50{ }^{\circ} \mathrm{C}$ [Antia, 2001]. Thermogenic methane is assumed to have the isotopic composition of organic matter.

The isotopic composition of DIC in the sediment column (Figure 14) is lightened by degradation of organic matter, but then pulled heavier by extraction of isotopically light $\mathrm{CH}_{4}$. As a result, the isotopic composition of DIC in porewater samples [Sivan et al., 2007] starts near $0 \%$ at the sediment surface, then trends light in the near subsurface due to respiration in the non-methanogenesis zone, then gets heavier, reaching $+10 \%$, at a depth of $500 \mathrm{~m}$ (Figure 14). These authors interpreted the maximum $\delta^{13} \mathrm{C}$ of the DIC as an indicator of the rate of methanogenesis, but it turns out to be more sensitive in the model to the relative partitioning of respired carbon between DIC and methane. If the respired carbon has an isotopic composition of $-25 \%$, and the fractionation between $\mathrm{CH}_{4}$ and DIC at some temperature were $60 \%$, for example, then a balance of about $50 \%$ methane versus DIC would tend to produce DIC at an isotopic composition of $+10 \%$. In time, this source composition dominates the pore water value. Model experiments did not show a sensitivity of $\delta^{13} \mathrm{C}$ in DIC to the overall methaneogenesis rates, but it does respond to the relative $\mathrm{CH}_{4}$ production efficiency. The best-fit seems to require some loss of $\mathrm{H}_{2}$ in the pathway, as if by reduction of mineral phases.

\subsubsection{Iodine 129}

Iodine 129 has been used as a tracer for the age of the degrading organic matter in a sediment column [Fehn et al., 2000]. Iodine is incorporated into biological material, and it is released to the pore water as the carbon degrades biologically. Both stable and unstable iodine advect with the pore fluid and are subject to diffusion along with the rest of the dissolved tracers. Iodine 129 has a 22.8 million year e-folding lifetime and it is produced by cosmic ray spallation in the atmosphere. Iodine released by older organic carbon will have less Iodine-129 because of radioactive decay. Fehn et al [2000] measured $\mathrm{I}^{129}$ ages 55 million years old in pore waters of solid sediment that was 1.8 to 6 million years old, a difference of about 50 million years. Fehn et al [2000] interpreted this as indicative of 50 million year old carbon degrading.

Iodine 129 seems like a very rich tracer in the SpongeBOB model, indicative of the history of the accumulation of the sediment column and the expulsion of fluid from it. The iodine ages of the pore waters are higher than those of the solids, in near-surface sediments, while in the deepest sediment column the pore fluid iodine is much younger than the solid phase (Figure 15a). When permeable vertical conduits are available, the ages within the conduit are older than in the surrounding low-flow columns (Figure 15b), but the conduits do not change the fundamental pattern. These patterns are caused 
fundamentally by the compaction-driven upward flow of the pore water. When fluid flow is prevented in the model, the iodine ages collapse to the sediment ages (Figure $15 c)$.

The iodine ages in the depth range of Blake Ridge in SpongeBOB never get as old as Fehn et al [2000] measured at Blake Ridge. The values in the conduits reach 20 million years old, while Fehn measured 50 million years. It could be that Blake Ridge is affected by focused subsurface flow such as crudely approximated by the model, or it could be that a recent decrease in sedimentation rate has affected Blake Ridge.

\section{Active Margin Model Configuration}

\subsection{Deformation of the sediment column}

In the active model configuration, in addition to the processes in the passive margin model, the model grid in the horizontal dimension is manipulated to simulate the uniform compaction and thickening of the sediment column by lateral compression. The $x$ coordinate values of the grid cells are carried laterally by the moving crust, and the spacing between the grid points decreases, resulting in uniform vertical thickening of the sediment column.

The velocity of the incoming sediment column in the offshore edge of the model domain (the right) is the crustal velocity, specified as a parameter of the model scenario (for which there are sensitivity runs Fast Plate and Slow Plate). The plate velocity is taken to be $40 \mathrm{~cm} /$ year, from the subduction rate of the Juan de Fuca plate. The Juan de Fuca ridge is not orthogonal to the direction of plate motion, nor is it geographically stationary, but rather is moving slowly toward the trench. The model formulation as presented here simplifies this geometry into two dimensions by equating the spreading and subduction velocities, maintaining a constant distance between the ridge and the subduction zone throughout the model simulation. This simplification affects the plate velocity and also the amount of sediment that enters the wedge through time, and its impact can be assessed from the sensitivity to plate velocity and to sedimentation (simulation Pelagic).

At the onshore end of the domain, the sediment column velocity is held fixed at a value 10 times lower than the incoming sediment column velocity, representing a sediment column nearly stopped by collision into the other plate. The rate is specified at an extrapolated $x$ location at which the sea floor would rise above sea level. The velocities of the grid points offshore of this are determined by

$$
\mathrm{u}_{\text {sedcol }_{\mathrm{n}+1}}=\mathrm{u}_{\text {sedcol }_{\mathrm{n}}}-\mathrm{K}_{\text {deform }} \frac{\Delta \mathrm{x}}{\Delta \mathrm{z}_{\text {sedcol }}}\left(\mathrm{u}_{\text {plate }}-\mathrm{u}_{\text {sedcol }_{\mathrm{n}}}\right)
$$

where $\mathrm{K}_{\text {deform }}$ is a dimensionless deformation constant that controls the horizontal extent of the wedge relative to the thickness of the incoming sediments. The velocities are negative because they flow in the direction of decreasing x (Figure 16a). The horizontal 
extent of the deformation zone, in this simulation about $150 \mathrm{~km}$, is determined by the value chosen for $\mathrm{K}_{\text {deform }}$ (for which there is a sensitivity run called Wide Def).

The $\mathrm{x}$ coordinate (location in physical space) of each horizontal grid point is updated each time step according to its calculated velocity. As the sediment column slides landward, the state of the underlying ocean crust at the grid point is recalculated based on its new location, including in particular the flexure effect of the subducting plate in the trench. The sediment column rides but also isostatically steers the pathway of the subsiding ocean crust, as it thickens vertically due to the convergence horizontally.

As grid points move across the $\mathrm{x}=0$ origin, or as the sediment column begins to outcrop from the ocean, they are dropped from the model domain, and a new grid point is created on the far right-hand side of the domain. These sediment columns are initialized with a computationally-required minimum 1 meter thickness per each of 15 grid cells, a negligible fraction of the ultimate sediment wedge. The $400 \mathrm{~km}$ mark from the extrapolated coastline is taken to be the spreading center where ocean crust is created and begins to accumulate sediment. The grid points propagate through the domain, emerging on the right as new crust is formed at the spreading center, and accumulating sediment and deforming as they converge toward the left. The eventual model steady state has no stationary points in it, but it manages to reach a moving stationary solution.

By conservation of volume the thickness of the column $\Delta \mathrm{z}_{\text {sedcol }}$ increases as $\Delta \mathrm{x}$ decreases. The model is formulated in vertical columns, which mandates that the sediment column deforms strictly vertically. This has the effect of increasing the excess pressure in the fluid phase, driving an expulsion fluid flow [Yuan et al., 1994]. Real sediment column compression is generally focused on diagonal faults in the column, with a block of sediment from one side of the fault over-riding the other by sliding upward along the fault. The faults can dip onshore (normal) or offshore (abnormal), perhaps depending on the frictional state of the contact with bedrock [Davis et al., 1983].

Fortunately, previous models of sediment accretion have found a strictly vertical formulation to be an acceptable approximation, for modeling heat flow [Wang et al., 1993] and mineral closure ages [Batt et al., 2001]. The effect of slip motion along diagonal faults dipping in either direction would be to displace material laterally. A parcel of over-riding sediment over a fault dipping offshore, for example, would be moving shoreward somewhat as it rides the wedge upward toward shallow waters through the domain of the model. A parcel at the top of the undeformed incoming sediment column might progress into the wedge a bit before a contemporaneous parcel from the bottom of the incoming column. But the lateral displacements ought to be limited by typical fault geometry to be not much larger than the thickness of the sediment column, 5-10 km or so. This is a small displacement relative to the overall width of the wedge, which is about $100 \mathrm{~km}$. So we expect the effects of this mode of motion to be relatively small.

Ultimately the inventory of sediment in the model domain overall is determined by the balance of the sources and sinks, from lateral sediment advection into and out of the domain, and by sediment deposition from the adjacent continent. In the absence of 
deposition of new continental material, the factor of 10 difference in the velocities incoming and outgoing would ultimately drive the sediment column to contain 10 times more sediment per meter on the outgoing end, in the steady state (Figure 17). Adding continental material drives the outgoing column higher yet. Choosing the factor by which to impede the outgoing sediment column velocity (the factor of 10) essentially sets the model domain; a value of 10 achieves a solution in which the sediment column is close to outcropping at the sea surface, encompassing the entire hydrate stability zone but missing the complexities of sediment transport and erosion that produce the continental shelf, and erosion on land.

The model as described so far produces a smooth continental slope, but the sea floor in accretionary zones in reality are ridged, as blocks ride over each other. We attempt to simulate the effect of topography in the wedge by varying the deformation constant laterally, by $+/-40 \%$ on a wavelength of $100 \mathrm{~km}$, in a simulation called Bumpy. The zones of high and low deformability travel with the material through the domain, and new grid points are initialized by extrapolation, continuing the original wave into the new incoming model domain (Figure 17).

\subsection{Crustal bending}

Near the subduction zone, an oceanic plate is pressed downward by the load of the subducted lithosphere on the other side. The lithosphere deforms elastically, with the flexural rigidity determining the bending in response to a given torque. The situation is analogous to a floating dock with a person ready to dive in, standing at the edge. There is a zone next to the diver where the lateral cohesion of the crust pulls it downward, and then inshore of this, the dock rises out of the water somewhat, due to the requirement for overall isostatic equilibrium, and to the stiffness of the dock.

This situation is treated in the model based on an analytical solution to the case of a single point load at the subduction zone [Turcott and Schubert, 1982]. The differential equation is

$D \frac{d^{4} z}{d x^{4}}+\left(\rho_{m}-\rho_{s w}\right)$ g $z=0$

and its solution with application of appropriate boundary conditions

$$
\mathrm{dz}_{\mathrm{tq}}=\sqrt{2} \cdot \mathrm{e}^{\pi / 4} \cdot \mathrm{z}_{\mathrm{b}} \cdot \mathrm{e}^{-\frac{\pi \cdot \mathrm{x}_{\mathrm{s}}}{4}} \cdot \sin \left(\frac{\pi \cdot \mathrm{x}_{\mathrm{s}}}{4}\right)
$$

where

$$
\mathrm{x}_{\mathrm{s}}=\frac{\mathrm{x}-\mathrm{x}_{0}}{\mathrm{x}_{\mathrm{b}}-\mathrm{x}_{0}}
$$


There are three tunable parameters in this formulation (Figure 16b). One, $\mathrm{z}_{\mathrm{b}}$, corresponds to the height above isostasy of the forearc bulge, for which we use 100 meters. Two are horizontal space scales. One, $\mathrm{x}_{0}$, is from the edge of the plate (where the guy is standing, $\mathrm{x}=0$ ) to the boundary between the trench and the bulge (defined as the local isostatic equilibrium $\mathrm{z}=0$ line). The other, $\mathrm{x}_{\mathrm{b}}$, is the coordinate at the peak of the bulge. We use 125 and $175 \mathrm{~km}$, respectively. These horizontal scales have a huge impact on the eventual depth of the trench. The isostatic load of the sediment column, described next, greatly amplifies the eventual depth of bedrock in the trench. A "torque pulldown" of about 2000 meters at the left-hand side of the domain ultimately results in $10 \mathrm{~km}$ of trench (Figure 17).

\subsection{Isostasy}

The displacement of the crust near the subduction zone is implemented in the model as a deviation from the isostatic equilibrium condition to which the elevation of the crust relaxes. In this way, the mass of the sediment column still has an impact on the elevation of the crust, so that sedimentation can drive subsidence. The correct way to do this calculation would be to solve the differential equation (1) using the distributed load of the sediment column, allowing the load full interplay with the rigidity of the crust. SpongeBOB is formulated as a simpler approximation to this. The mass load effects the isostatic equilibrium value locally, without regard for the springiness of the crust, in order to benefit from the convenient analytical solution to the $\mathrm{x}=0$ point load case.

\subsection{Sea level and time-dependent forcing}

Because of the shorter simulation time (10 Myr) the 150 Myr sea level cycle, a fundamental driver to the passive margin simulations was neglected. We do however incorporate a +/- 20 meter sea level oscillation on a time scale of 1 Myr to simulate the turbulence that a tectonic regime must be experiencing. The sensitivity to this forcing is gauged by a simulation called No Sealevel.

\subsection{Sediment Erosion and Landslides}

The solution of the horizontal compression and deformation scheme, by itself, would tend toward ever-increasing sea floor slope in the shoreward direction (Figure 18). This tendency is balanced in the model by slope erosion and landslides. The grade of the sea floor is limited to a critical value ( $6 \%$ in the Base simulation) by two mechanisms. One is during sediment deposition; if the sea floor slope is supercritical the material that would have sedimented is instead added to a resuspended pool and advected offshore.

The other mechanism is an erosional term that is triggered when the sea floor slope exceeds critical. Sediment is removed from the top computational box by relaxation toward a value that would bring the grid point back to the critical slope with respect to its adjacent grid point, with a relaxation time constant of $10^{-5} \mathrm{yr}^{-1}$, sufficiently fast to hold the 
sea floor close to the critical value even while the sediment column, but slow enough to be kind to the numerics of the model. Solid material and pore fluid are advected upward through the computational grid, allowing the grid to contract as the sediment column erodes.

The resuspended material is assumed incorporated into a turbidity current that travels down slope without deposition of sediment until the sea floor slope is less than $1 \%$. Beginning at this point, the resuspended sediment deposits on the sea floor following the same criteria for deposition as used by the primary depositing continental material, with larger size classes falling out faster than small particles. The eroding material conserves the chemical and grain-size characteristics, but the redeposition of POC is fractionated by the size separation of the redepositing material. Snapshots of sediment accumulation/erosion rates and the fraction of redepositing material are shown in Figure 19.

The POC is distributed, in the model as well as in observations [Mayer, 1994], according to the surface area of the sediment, such that smaller size classes have a higher POC content by weight, due to their larger surface to volume (mass) ratio. The size fractionation of the POC can move the zone of highest POC content offshore; in particular this is evident in the Broad simulation, which has a shallow critical slope angle and hence a lot of sediment redeposition (Figure 20).

\subsection{Pore Fluid Flow}

Pore fluid flow in the model is driven by the accumulating mass of the sediment column, and governed by Darcy's law and a sediment permeability which depends on the grain size and the porosity of the local sediment. The derivation of excess pressure from the porosity, and the numerical advection scheme including flow limiter, are identical to that in the passive margin model.

Most of the fluid flow from the real ocean sediment column appears to make its way through high-permeability channels and pathways rather than flowing homogeneously through the bulk sediment column. The SpongeBOB model is too coarsely gridded to resolve faults and sandy turbidites in detail, but the overall impact of flow heterogeneity on the geochemistry of the sediment column is mimicked by creating vertical channels of high permeability within the SpongeBOB grid. The channels are placed every 5 model grid points, and their permeability is enhanced by a factor of 10 relative to the background grid points. The grid points are found to focus the upward flow, and result in significant changes in the pore water chemistry both within the channels and also in the background cells. For these active margin simulations, the permeable channels are carried horizontally with the computational grid, following the sediment material. Vertical flow velocities, relative to the sediment grains (Darcy flow, $\mathrm{w}_{\text {Darcy }}$ ) and relative to the sea floor $\left(\mathrm{w}_{\text {seafloor }}\right)$ are shown in Figure 21. 


\subsection{Heat flow}

The heat flow results are shown in Figure 22. The model captures the general trend of lower heat fluxes onshore, and by about the same magnitude of drawdown. The model fluxes are lower than the measurements from Hyndman and Wang [1993], driven by a model geothermal heat flow of $100 \mathrm{~mW} / \mathrm{m} 2$, compared to the offshore heat flux of 120$130 \mathrm{~mW} / \mathrm{m} 2$ in the data. The diffusive heat flow values are impacted by the permeable vertical channels, which appear as spikes of high heat flux. The simulations all appear to parallel each other in their decreasing heat flow with sediment column thickening, and parallel the trend in the data. The one curious model result comes from the Broad scenario, in which a shallow critical slope angle drives high rates of sediment erosion and redeposition (Figure 7b, dashed lines). In this scenario, removal of sediment by erosion increases the heat flux landward, counteracting the decrease landward seen in all the other simulations (and the data).

\subsection{Organic carbon and methane}

The model respiration and thermal degradation kinetics are the same as in the passive margin model. The production rates of methane from respiration and thermal degradation are shown in Figure 23. Methane concentrations from the simulations are shown in Figure 24. Bubbles are shown in Figure 25, and hydrate in Figure 26. The simulations are similar to the eye, but variations can be seen in the envelope of the sediment column, for example, due to plate velocity (Fast Plate and Slow Plate), sediment column deformation (Wide Def and Bumpy), and sediment transport and reposition (Pelagic and Broad Slope). Methanogenesis rates are affected by the labile fraction of POC (Bio 10\% and Bio 100\%), impacting the distribution of dissolved methane, bubbles, and hydrate.

Stable carbon isotopes provide a diagnostic window into the dynamics of the sedimentary carbon cycle. Profiles of the $\delta^{13} \mathrm{C}$ of dissolved methane and dissolved inorganic carbon (DIC) from the Base case are compared with the measurements of Pohlman et al [2009] in Figure 27, and results from the other scenarios are plotted in Figures 28 and 29. The primary driver of the isotopic compostions in the model is the efficiency with which POC is converted to methane as opposed to DIC. Variations in the model geophysical scenarios do not have a major impact on the isotopic compositions.

In broad brush the model captures the general isotopic compositions as measured, but the field data show a systematic dependence of the isotopic compositions that is not found in the model results. The isotopic compositions of both species are systematically heavier in the middle of the deformation wedge than they are near the toe? of the wedge (water depths ranging from 2200 meters near the two to about 1000 meters at their innermost profile). The heavier isotopic compositions could be explained as a gradient in the efficiencies of POC conversion into $\mathrm{CH}_{4}$ relative to DIC. For example, if the source POC is $-25 \%$, and the fraction on $\mathrm{CO}_{2}$ reduction $-60 \%$, then a conversion efficiency of POC to $\mathrm{CH}_{4}$ of $25 \%$ would explain the isotopic compositions of both tracers at the toe of 
the deformation zone, and an increase to $75 \%$ methanogenesis efficiency would explain the measurements in the mid-wedge. The low efficiency at the toe would have to be explained as the impact of sulfate reacting with $\mathrm{CH}_{4}$, while the high values in the mid wedge would require highly reduced organic carbon as a source, with an $\mathrm{H} / \mathrm{C}$ ratio of at least 2 , or perhaps an inorganic source of dissolved hydrogen to react with DIC.

\section{Gulf of Mexico Model Configuration}

The Gulf of Mexico is a passive margin analogous to the Atlantic coastal model configuration and utilizing all of the same machinery. The Gulf coast is subject to a considerably higher influx of sediment than the Atlantic margin, and deep sediment accumulation has been accommodated by stronger crustal subsidence than the Atlantic margin [Salvador, 1991]. This results in a stronger tendency for thermogenic methane to play a role in methane hydrate formation in the Gulf [Macdonald et al., 1994]. The horizontal domain of the Gulf scenario has been expanded by a factor of 4 relative to the Atlantic configuration, and the transition length scale between continental and oceanic crust has been stretched from 60 to $200 \mathrm{~km}$, representing the wide zone of transitional crust in the Gulf (Figure 30).

A parameterization for salt domes has been designed but not yet implemented. It will be based on the permeable conduits formulation used in the other simulations. There will be no solid salt domes per se within the grid of the SpongeBOB domain, but some of the vertical columns will be imagined to be affected by the presence of a salt dome nearby laterally (in front of or behind the 2-D slice). The impact of the nearby salt dome would be to increase the temperature of the sediment column, affecting the stability of methane hydrate and also pore fluid flow driven by the fluid density [Wilson and Ruppel, 2007]. Presumably the overall permeability of the sediment column near the rising salt plug will be increased by the disturbance, so we would presume that the sediment column heating from the salt domes would coincide with the permeable conduits in the existing SpongeBOB formulation. Salt domes form where salt deposits at the base of the sediment column exist, an extent limited to the relatively wide band of "transitional" crust (between continental and oceanic). The salt begins to rise when its density is exceeded by the bulk density of the sediment, which is to say, only when the surrounding sediment has been compacted to a very low porosity. Then it rises to its level of neutral buoyancy, or somewhat further due to the lateral transmission of the compressive stress in the salt layer [Nelson, 1991]. The impact of the salt domes will be restricted to the grid cells in which the geophysics are conducive in these ways. The sense of the potential impact of the salt domes will be assessed as the difference between the simulations with and without the parameterization. Neither those conduits nor the salt dome parameterization envisioned here resolve the details of the geophysics, so neither can be more than qualitative, but they can serve as a first indication of the potential relative importances of different processes and assumptions. 


\section{Arctic Margin Model Configuration}

The Arctic configuration of the model is also undergoing further development before it can be submitted to publication. The Arctic margin simulations include the Mackenzie Delta in Alaska and the Laptev Sea in Siberia. Both are passive margins analogous to the Atlantic and Gulf simulations, with more sedimentation and crustal subsidence in the Laptev Sea than in Mackenzie Delta (Figure 31). The distinguishing attribute of the Arctic is permafrost, resulting from the atmospheric exposure of the exposed sediment surface on the shelf during glacial stands of low sea level. Cold temperatures permeate high-salinity subsurface sediments, and also result in a fresh ground water ice cap near the sediment surface, producing a widespread highly saturated ice feature called the Ice Complex in Siberia. The ice is thought to serve as an impermeable barrier to gas migration, although elevated dissolved methane concentrations have been observed on the Siberian Shelf, leading to the conclusion that there must be holes in the permafrost, called "open taliks", left over from relict lakes or rivers on the exposed shelf, or resulting from geological fracturing. As sea level rises and falls through the glacial cycles, the frozen wedge of permafrost waxes and wanes, with a strong potential impact on the local methane cycle.

To top it off, the exposed coastal plains during glacial time accumulated windblown material (loess) that became enriched in organic carbon (these are called Yedoma deposits) [Zimov et al., 2006]. The deposits are syncryogenic, meaning frozen as they accumulated, resulting in efficient preservation of carbon deposits that can oxidize quickly if they are later thawed. When they thaw, the production efficiency of methane vs. $\mathrm{CO}_{2}$ is determined to a large extent by the water balance, with methanogenic conditions in the waterlogged periphery of lakes, for example [Walter et al., 2006].

Resolving these geophysical dynamics requires higher vertical grid resolution than the other simulations provoked us to provide, so the facility has been developed to read in a low-resolution output file from the model, and subdivide each of the grid cells in the expansion-restricted upper domain of the model into multiple grid points. There are 5 upper grid points in the low-resolution version of the passive margin scenarios, which are only allowed to expand to a maximum thickness of 200 meters. Each of these boxes is divided into 20 boxes for the Arctic simulations. The chemical concentrations are taken directly from each large cell to each of is sub-cells with no depth interpolation. The initial condition for the hi-resolution scenario is thus an unrealistic stair-step, but it quickly relaxes to the steady-state pore water and temperature profiles, at which point experiments with permafrost may begin.

Numerical simulations are ongoing, with number-crunching being the limiting factor. The most recent version of the Laptev Sea simulation, presented at the Gas Hydrates Gordon Conference, neglected the deposition of Yedoma, and it lacked the inhibition of gas migration from permafrost. But it showed a strong signal of methane degassing flux as a function of the climate cycle, and a strong impact of an extraordinary human-induced warming (Figure 32), but it must be noted that these methane fluxes are insignificant 
relative to tropical methane emissions, which dominate the atmospheric concentration and hence the climate impact.

\section{Results}

\subsection{Model Sensitivity Runs}

For the passive margin simulation, in addition to the "Base HR" and "No Conduits HR" cases, a series of sensitivity simulations were done, at lower spatial resolution of only 10 grid points horizontally instead of 40 . The setup, intent, and summary of the conclusions from the sensitivity runs are described in Tables 1 and 2. One suite of simulations was forced by time-invariant forcing, comprising sea level, ocean "oxic" state (POC deposition patterns), and temperature, with variations as described in Table 1. These allow a clearer diagnosis of the model sensitivity to these variables. Another suite of simulations imposes time-varying forcing shown in Figure 3, as described in Table 2. The time evolution of sea level, POC inventory, methanogenesis rates, and hydrate inventories are shown in Figure 33 for the two representative cases, the Base case, which including the sea level changes, and case TO, which does not. Active margin simulation variants are listed in Table 3 . In contrast to the passive margin simulations, the grid resolution is the same for all of the active margin simulations presented here.

\subsection{Sensitivity to Ocean Temperature}

The effect of ocean temperature on model hydrate inventory is shown in Figure 34a. These are from time-invariant suite of runs, with temperature a function of water depth only. The inventory of hydrate decreases roughly linearly with temperature, finally reaching zero hydrate with a warming of $10^{\circ} \mathrm{C}$. The active margin simulations have a similar temperature sensitivity to the passive case. The SpongeBOB model is significantly less sensitive to temperature than the Davie and Buffett [2001] onedimensional model (Figure 34a). These are essentially equilibrium calculations, comparable to those of Buffett and Archer [2004].

The difference is probably due to the fundamentally different processes controlling vertical methane fluxes between the two models. The 1-D model relies on the transport of dissolved-phase methane into the stability zone. In a warmer ocean, the stability zone gets thinner, which increases the diffusive loss of dissolved methane in that model by requiring the diffusive gradient to be steeper. This had the impact of restricting the formation of hydrate to regions of higher POC content, reducing the ocean's ultimate equilibrium inventory of methane nearly completely with $3{ }^{\circ} \mathrm{C}$ of warming. Methane trapping in the stability zone, when it is transported by bubbles in SpongeBOB, would also be affected by a change in the stability zone thickness, but the mechanism is different and so it is not surprising that the two models would have different temperature sensitivity. 


\subsection{Sensitivity to POC}

The model sensitivity to POC deposition was gauged using time-invariant forcing, by varying the "ocean oxic state" variable through the spectrum from "Atlantic" (low POC concentrations in surface sediments, state=1) to "Pacific" (2), "OMZ" (3), and "Anoxic" (4). The range in sediment surface POC concentrations is intended to bracket something of the range in the ocean, and Figure 34b shows the sensitivity to that range. These variations in POC deposition have a much stronger impact on the hydrate inventory than the temperature does. This is consistent with the recent finding of Gu et al [2011]

The sensitivity of the hydrate inventory can also be seen in the model response to changes in the labile fraction of the sedimenting POC (Figure 34c). In practice, the respiration zone is thin enough that the POC is not often limited by depletion of the labile POC fraction, so the labile fraction acts like a scaling of the apparent bulk POC degradation rate constant. With the tight correlation between organic carbon age and reaction rate [Middelburg et al., 1997], this range in effective POC degradation rate constants might optimistically be viewed as a range in the uncertainty in the POC degradation rates.

The sensitivity to biologically labile POC in particular shows that biogenic methane production is the important factor in the model. A model sensitivity run with thermogenic methane production disabled (called No Therm) corroborates this by the lack of much change in the hydrate inventory. Secondary respiration of migrating petroleum, simulation No Petro, produces no hydrate, a strong effect to be sure. However, the absence of hydrate without petroleum migration in the model does not mean that petroleum is the whole story. The hydrate inventory is so responsive to reasonable changes primary POC respiration that were we to neglect secondary petroleum respiration in the model, the primary respiration could be increased enough to tip back over to the point of preserving hydrate.

The time evolution of hydrate between the time-variant and -invariant configurations also demonstrates the primacy of POC forcing over temperature forcing for the model. In the time-variant configuration (Base), there is more hydrate in the middle of the simulation when sea level is high and the ocean warm than there at the end of the simulation, supposed to be cold and low-POC like today. The warm temperatures of the hothouse were more than offset by the increase in POC deposition. The hydrate inventory declines in the transition from the hothouse to the icehouse, rather than growing. In contrast, the time-invariant model hydrate inventory (the base case of which is called $T O$ ) peaks strongly at the end of the simulation, reflecting the larger sediment mass perhaps. The trajectories of hydrate inventory follow those of POC inventory and methanogenesis rates, rather than temperature or sea level (Figure 33).

All three indications of hydrate inventory sensitivity to biogenic methane production rates indicate that this variable is more important to get right than the temperature. 


\subsection{Sensitivity to Bubble Transport}

The hydrate inventory in the model depends critically on methane transport by rising bubbles through the sediment column, and redissolution if the bubbles enter an undersaturated condition. This mechanism is novel to SpongeBOB, not shared by the Davie and Buffett [2001] or other 1-D models. If bubble transport is disabled, hydrate disappears from the results (Figure 33). Figure 34d shows the extreme model sensitivity to the redissolution height scale, which determines what fraction of the methane will be recaptured by redissolution rather than escape directly to the sea floor. When a scale height of $2 \mathrm{~km}$ is imposed, hydrate again disappears from the simulation. Shortening the height scale from $500 \mathrm{~m}$ to $100 \mathrm{~m}$ increases the hydrate inventory by a factor of nearly 8 . Clearly this is a parameter to which the model is very sensitive, and which requires further work to capture the complexity of the real world in a numerical model.

\subsection{Pore fluid flow heterogeneity}

Old iodine 129 ages in pore waters at Blake Ridge, relative to the age of the solids, can only be reproduced in the model as resulting from heterogeneity in the pore fluid flow field, as crudely mimicked in the code by the vertical high-permeability chimneys. This conclusion is reinforced by the heterogeneity in penetration depth for dissolved sulfate, $\mathrm{SO}_{4}{ }^{2-}$ [Borowski et al., 1996], which seem to show a bimodal distribution, with some sites where the methane/sulfate boundary is just a few 10's of meters, and others where sulfate reaches hundreds of meters or more. The shallow sites correlate with the presence of methane hydrate, just like in the model where the hydrate is found. The importance of the chimneys justifies the imposition of an upward flow in the Davie and Buffett onedimensional model [2001], which was interpreted as representing a zone of upward flow, analogous to the chimneys here.

\subsection{Active Margin Model sensitivities}

Figure 35 shows the hydrate inventories of all the simulations, and the results are digested into specific model sensitivities in Figure 36. The temperature of the ocean does affect the inventory of methane hydrate (Figure 35a), although the temperature sensitivity of this and the passive margin model are both lower than that of the one-dimensional Davie and Buffett [2001] model as deployed globally by Buffett and Archer [2004]. The degradation kinetics of POC (Figure 36b) have a much stronger impact on the inventory of methane hydrate, as we also found for the passive margin simulations. And, also in common with the passive margin simulations, the ability of the sediment column to recapture rising bubbles, manifested in a bubble redissolution scale height, has a very strong impact (Figure 36c).

The most interesting new result from these simulations is the role of subduction in the methane cycle, and its sensitivity to the subduction velocity of the incoming plate (Figure 36d). In general, the hydrate concentrations (filled fraction of pore volume) are higher in 
the active margin simulation than they are in the passive margin simulation, with a fullscale of $10 \%$ for these plots but only $5 \%$ for the hydrate concentrations in the passive margin simulations. However, but the inventories of hydrate per meter of coastline are lower than the passive margin simulation (indicated in Figure $36 \mathrm{~d}$ as 0 plate velocity), and faster plate motion decreases the inventory of hydrate at the end of the simulation, everything else being equal. Perhaps this effect is due to the uplifting of the surface sediment due to the sediment convergence in the accreting wedge, continually depleting the stability zone of methane hydrate by advecting sediment through the stability zone. The highest hydrate saturations tend to be found at the toe of the wedge, similarly to observations from Cascadia [Malinverno et al., 2008].

Other insights into the functioning of the model can be gleaned by examination of a few more of the simulation results in Figure 35. The vertical permeable channels have only a minor impact on the overall abundance of methane hydrate (No Chan), in contrast with the passive margin simulation, in which the elimination of the channels decreased the hydrate inventory by about a factor of two. Thermogenic methane production is also found to be unimportant to methane hydrates (No Therm). Thermal methanogenesis alters the $\delta^{13} \mathrm{C}$ of methane in the deep sediment column, but it has limited impact on compositions in the shallower sediment column (Figure 13). Most of the geophysical variants had only a small impact on the hydrate abundance, for example the heterogeneous deformation scenario Bumpy, the altered sedimentation scheme Pelagic, or the No Erod scenario which prohibits sediment erosion. The one exception to this lack of sensitivity to model geophysical formulation is that the two scenarios with generally larger sediment envelopes, Slow Plate and Broad Slope (which erodes more aggressively to maintain a shallower sea floor slope than the base case) both have more hydrate per meter of coastline than the other cases. The simulation No Sealevel shows that the fluctuations in sea level that are imposed on the Base case had little effect on the hydrate inventory.

\subsection{Other model (in)sensitivities}

Most of the other scenarios had a fairly minor impact on the hydrate inventory. Thermogenic methane is not a significant contributor to the pelagic hydrate methane pool. The permeable chimneys do not determine the solution, nor does sediment erosion and redeposition, or the value of the critical seafloor slope that drives it.

\section{Conclusions}

Our attempt to capture the carbon and methane cycles of the entire sediment column have led us to make a choice in model formulation which might serve as a hypothesis for the real world. Bubble migration through the sediment column seems crucial to getting SpongeBOB to work, and appears to be important in the real sediment column, but it needs more attention both in the field and in the model. It turns out that the hydrate inventory in the simulations depended very strongly on the scale height for methane redissolution if a bubble enters an undersaturated zone. 
Heterogeneity in the vertical flow field, simulated very crudely in SpongeBOB as vertical chimneys of increased permeability, increases the global inventory of hydrate, determines where the hydrate will be found, and it will affect chemical tracers such as iodine 129, and the depth of $\mathrm{SO}_{4}{ }_{4}^{2-}$ penetration in the sediment column, which corroborate the conclusion that the hydrate distribution is steered by upward flow.

The model is also very sensitive to organic carbon rain to the sea floor; more sensitive to a reasonable range of sedimentary organic carbon concentrations than to the range of temperatures going back through geologic time.

Active margin coastal settings tend to have high concentrations of methane hydrate in surface and near-surface sediments, leading to a conceptualization of intense methane delivery to surface sediments by pore fluid flow, driven by the deformation of the thick sediment wedge. Our model confirms the general importance of geophysical forcing on the methane cycle in the wedge, but finds that horizontal motion of the sediment through the wedge flushes hydrate out of the stability zone, decreasing the global inventory of methane hydrate (moles per meter of coastline) relative to the case of no subduction (the passive margin).

Other uncertainties to which the hydrate inventory of the model are most sensitive echo the findings of the passive margin simulations. The model is sensitive to ocean temperature but less so than 1-D models of the near-surface sediment, probably due to the incorporation of bubble transport of methane included in this model but neglected in the smaller domain models. The bubble transport parameterization of the model has an enormous impact on hydrate inventories, providing incentive for future work to characterize the appropriate value for this parameter for bubbles in the real sediment column. The sensitivity of the models to POC degradation rate also appears to be stronger than that for temperature. Discussion of the possibility of hydrate degassing events in Earth's history, for example the PETM, has generally been based on the idea that there would be less hydrate in a warmer world [Archer, 2007]. However, it could be that higher organic carbon deposition rates in a hothouse climate could more than offset the impact of warmer temperatures on the hydrate inventory at that time.

In general, the model inventories of methane hydrate are still sensitive enough to uncertain parameters that the models provide no real strong new constraint on methane inventories of the real ocean, but rather the models can hope to diagnose what the sensitivities of the real ocean hydrate reservoir might be.

\section{Publications Resulting from this project so far}

Archer, D.E., B.A. Buffett, and P.C. McGuire, A two-dimensional model of the passive coastal margin deep sedimentary carbon and methane cycles, Earth Planet, Biogeosciences Discuss. 9, 1-46, 2012.

Archer, D.E. and B.A. Buffett, A two-dimensional model of methane cycle in a sedimentary accretionary wedge, Biogeosciences Discuss. 9, 1-36, 2012. 
Frederick, J.M. and B.A. Buffett, Topography- and fracture-driven fluid focusing in

layered ocean sediments, Geophys. Res. Lett., 38, L08614, doi:10.1029/GL046027, 2011.

Frederick, J.M., and B.A. Buffett, Fluid focusing in compacting marine sediments:

Implications for dating pore fluid with 129I, J. Geophys. Res., submitted.

\section{Citations}

Antia, A.N., Basin-wide particulate carbon flux in the Atlantic Ocean: Regional, Global Biogeochemical Cycles, 15 (4), 845-862, 2001.

Archer, D.E., Methane hydrate stability and anthropogenic climate change., Biogeosciences, 4, 993-1057, 2007.

Archer, D.E., B.A. Buffett, and P.C. McGuire, A two-dimensional model of the passive coastal margin deep sedimentary carbon and methane cycles, Earth Planet, submitted.

Archer, D.E., M. Eby, V. Brovkin, A.J. Ridgewell, L. Cao, U. Mikolajewicz, K. Caldeira, H. Matsueda, G. Munhoven, A. Montenegro, and K. Tokos, Atmospheric lifetime of fossil fuel carbon dioxide, Ann. Reviews Earth Planet Sci., 37, 117-34, 2009.

Archer, D.E., J.L. Morford, and S.R. Emerson, A model of suboxic sedimentary diagenesis suitable for automatic tuning and gridded global domains, Global Biogeochemical Cycles, 16, 10.1029/2000GB001288, 2002.

Athy, L.F., Density, porosity and compaction of sedimentary rocks, AAPG Bull., 14, 124, 1930.

Batt, G.E., M.T. Brandon, K.A. Farley, and M. Roden-Tice, Tectonic synthesis of the Olympic Mountains segment of the Cascadia wedge, using two-dimensional thermal and kinematic modeling of thermochronological ages, Journal of Geophysical Research-Solid Earth, 106 (B11), 26731-26746, 2001.

Borowski, W.S., A review of methane and gas hydrates in the dynamic, stratified system of the Blake Ridge region, offshore southeastern North America, Chemical Geology, 205 (3-4), 311-346, 2004.

Borowski, W.S., C.K. Paull, and W. Ussler, Marine pore-water sulfate profiles indicate in situ methane flux from underlying gas hydrate, Geology, 24 (7), 655-658, 1996.

Buffett, B., and D.E. Archer, Global inventory of methane clathrate: Sensitivity to changes in environmental conditions, Earth and Planetary Science Letters, 227, 185-199, 2004. 
Carson, B., E. Suess, and J.C. Strasser, Fluid-Flow and Mass Flux Determinations at Vent Sites on the Cascadia Margin Accretionary Prism, Journal of Geophysical Research-Solid Earth and Planets, 95 (B6), 8891-8897, 1990.

Daigle, H., and B. Dugan, Permeability anisotropy and fabric development: A mechanistic explanation, Water Resources Research, 47, 2011.

Davie, M.K., and B.A. Buffett, A numerical model for the formation of gas hydrate below the seafloor, J. Geophysical Res., 106 (B1), 497-514, 2001.

Davie, M.K., and B.A. Buffett, Sources of methane for marine gas hydrate: inferences from a comparison of observations and numerical models, Earth and Planetary Science Letters, 206 (1-2), 51-63, 2003a.

Davie, M.K., and B.A. Buffett, A steady state model for marine hydrate formation: Constraints on methane supply from pore water sulfate profiles, J. Geophysical Res., B10, doi:10.1029/2002JB002300, 2003b.

Davis, D., J. Suppe, and F.A. Dahlen, Mechanics of fold-and-thrust belts and accretionary wedges, J. Geophysical Res., 88 (B2), 1153-1172, 1983.

Fehn, U., G. Snyder, and P.K. Egeberg, Dating of pore waters with I-129: Relevance for the origin of marine gas hydrates, Science, 289 (5488), 2332-2335, 2000.

Flemings, B.P., X. Liu, and W.J. Winters, Critical pressure and multiphase flow in Blake Ridge gas hydrates, Geology, 31, 1057-1060, 2003.

Flemings, P.B., B.B. Stump, T. Finkbeiner, and M. Zoback, Flow focusing in overpressured sandstones: Theory, observations, and applications, Am. J. Sci., 302, 827-855, 2002.

Gu, G., G.R. Dickens, G. Bhatnagar, F.S. Colwell, G.J. Hirasaki, and A.G. Chapman, Abundant Early Palaeogene marine gas hydrates despite warm deep-ocean temperatures, Nature Geoscience, 4 (12), 848-851, 2011.

Haq, B.U., P.R. Hardenbol, and P.R. Vail, Chronology of fluctuation sea levels since the Triassic, Science, 235, 1156-1167, 1987.

Hedges, J.I., and R.G. Keil, Sedimentary organic matter preservation an assessment and speculative synthesis, Mar. Chem., 49, 81-115, 1995.

Hunt, J.M., Petroleum Geochemistry and Geology, 743 pp., Freeman, New York, 1995.

Hunt, J.M., R.P. Philp, and K.A. Kvenvolden, Early developments in petroleum geochemistry, Organic Geochemistry, 33 (9), 1025-1052, 2002. 
Hyndman, R.D., and K. Wang, Thermal Constraints on the Zone of Major Thrust Earthquake Failure - the Cascadia Subduction Zone, Journal of Geophysical Research-Solid Earth, 98 (B2), 2039-2060, 1993.

Jain, A.K., and R. Juanes, Preferential Mode of gas invasion in sediments: Grain-scale mechanistic model of coupled multiphase fluid flow and sediment mechanics, Journal of Geophysical Research-Solid Earth, 114, 2009.

Kennett, J.P., Marine Geology, Prentice-Hall, Englewood Cliffs, N.J., 1982.

Koeve, W., Upper ocean carbon fluxes in the Atlantic Ocean: The importance of the POC:PIC ratio, Global Biogeochemical Cycles, 16 (4), 2002.

Koeve, W., Magnitude of excess carbon sequestration into the deep ocean and the possible role of TEP, Marine Ecology-Progress Series, 291, 53-64, 2005.

Leas, W.J., L.H. Jenks, and C.D. Russell, Relative permeability go gas, Trans. AIME, 189, 65-72, 1950 .

Macdonald, I.R., N.L. Guinasso, R. Sassen, J.M. Brooks, L. Lee, and K.T. Scott, Gas Hydrate That Breaches the Sea-Floor on the Continental-Slope of the Gulf-ofMexico, Geology, 22 (8), 699-702, 1994.

Malinverno, A., M. Kastner, M.E. Torres, and U.G. Wortmann, Gas hydrate occurrence from pore water chlorinity and downhole logs in a transect across the northern Cascadia margin (Integrated Ocean Drilling Program Expedition 311), Journal of Geophysical Research-Solid Earth, 113 (B8), 2008.

Mayer, L., Mineral associations and nutritional quality of organic matter in shelf, DeepSea Research Part Ii-Topical Studies in Oceanography, 49 (20), 4587-4597, 2002.

Mayer, L.M., Surface area control of organic carbon accumulation in continental shelf sediments, Geochimica Et Cosmochimica Acta, 58, 1271-1284, 1994.

Middelburg, J.J., K. Soetaert, and P.M.J. Herman, Empirical relations for use in global diagenetic models, Deep-Sea Research I, 44, 327-344, 1997.

Nelson, T.H., Salt tectonics and listric-normal faulting, in The Gulf of Mexico Basin, edited by A. Salvador, pp. 73-90, GSA, Boulder, CO, 1991.

Parson, B., and J.B. Sclater, An analysis of the variations in ocean floor bathymetry and heat flow with age, J. Geophys. Res., 82, 803-827, 1977. 
Pirmez, C., L.F. Pratson, and M.S. Steckler, Clinoform development by advectiondiffusion of suspended sediment: Modeling and comparison to natural systems, Journal of Geophysical Research-Solid Earth, 103 (B10), 24141-24157, 1998.

Pohlman, J.W., M. Kaneko, V.B. Heuer, R.B. Coffin, and M. Whiticar, Methane sources and production in the northern Cascadia margin gas hydrate system, Earth and Planetary Science Letters, 287 (3-4), 504-512, 2009.

Reagan, M.T., and G.J. Moridis, Oceanic gas hydrate instability and dissociation under climate change scenarios, Geophysical Research Letters, 34 (22), 2007.

Salvador, A., The Gulf of Mexico Basin, in The Decade of North American Geology Project, pp. 568, GSA, Inc, Boulder, CO, 1991.

Sivan, O., D.P. Shrag, and R.W. Murray, Rates of methanogenesis and methanotrophy in deep-sea sediments, Geobiology, 5 (2), 141-151, 2007.

Spence, G.D., R.D. Hyndman, N.R. Chapman, R. Walia, J. Gettrust, and R.N. Edwards, North Cascadia deep sea gas hydrates, in Gas Hydrates: Challenges for the Future, pp. 65-75, 2000.

Syvitski, J.P.M., 2D SEDFLUX 1.0C: an advanced process-response numerical model for the, Computers \& Geosciences, 27 (6), 731-753, 2001.

Turcott, D.L., and G. Schubert, Geodynamics, 472 pp., Cambridge University Press, Cambridge UK, 1982.

Wallmann, K., G. Aloisi, M. Haeckel, A. Obzhirov, G. Pavlova, and P. Tishchencko, Kinetics of organic matter degradation, microbial methane generation and gas hydrate formation in anoxic marine sediments, Geochimica Et Cosmochimica Acta, 70 (15), 3905-3927, 2006.

Walter, K.M., S.A. Zimov, J.P.Chanton, D. Verbyla, and F.S. Chapin, Methane bubbling from Siberian thaw lakes as a positive feedback to climate warming, Nature, 443, doi:10.1028/nature05949, 2006.

Wang, K., R.D. Hyndman, and E.E. Davis, Thermal Effects of Sediment Thickening and Fluid Expulsion in Accretionary Prisms - Model and Parameter Analysis, Journal of Geophysical Research-Solid Earth, 98 (B6), 9975-9984, 1993.

Wilson, A., and C. Ruppel, Salt tectonics and shallow subseafloor fluid convection: models of coupled fluid-heat-salt transport, Geofluids, 7 (4), 377-386, 2007.

Yuan, T., G.D. Spence, and R.D. Hyndman, Seismic Velocities and Inferred Porosities in the Accretionary Wedge Sediments at the Cascadia Margin, Journal of Geophysical Research-Solid Earth, 99 (B3), 4413-4427, 1994. 
Zimov, S.A., E.A.G. Schuur, and F.S. Chapin, Permafrost and the global carbon budget, Science, 312 (5780), 1612-1613, 2006. 
Table 1. Passive Model scenarios with uniform sea level and POC deposition state $($ ocean oxic state $=3)$.

\begin{tabular}{|l|l|l|}
\hline Simulation name & Characteristics & Salient results \\
\hline T0 & No temperature offset & $\begin{array}{l}\text { Higher hydrate than the } \\
\text { Base case because of higher } \\
\text { POC rain in the last bits of } \\
\text { the simulation }\end{array}$ \\
\hline T2, T4 etc. & $\begin{array}{l}2,4,6,8, \text { and } 10{ }^{\circ} \mathrm{C} \\
\text { temperature increases }\end{array}$ & $\begin{array}{l}\text { Weaker temperature } \\
\text { sensitivity than the 1-D } \\
\text { models (Figure 17) }\end{array}$ \\
\hline Atl, Pac, Anoxic & $\begin{array}{l}\text { "Atlantic" (ocean state 1) } \\
\text { "Pacific" (state 2), and } \\
\text { "Anoxic" (state 4) POC rain } \\
\text { forcings, shown in Figure 3. } \\
\text { Default is state 3 in the T* } \\
\text { runs. }\end{array}$ & $\begin{array}{l}\text { Stronger POC dependence } \\
\text { for this range of conditions } \\
\text { than T dependence }\end{array}$ \\
\hline
\end{tabular}


Table 2. Passive margin simulations with a time-varying sea level and ocean oxic state (POC deposition)

\begin{tabular}{|c|c|c|}
\hline Simulation name & Characteristics & Salient results \\
\hline Base & Base case & \\
\hline Lores Base & $\begin{array}{l}\text { Lower resolution version of } \\
\text { the full base case for } \\
\text { comparison with sensitivity } \\
\text { runs }\end{array}$ & $\begin{array}{l}\text { Nearly } 50 \% \text { less hydrate } \\
\text { than the higher resolution } \\
\text { case }\end{array}$ \\
\hline No Conduits & $\begin{array}{l}\text { Vertical permeable } \\
\text { chimneys eliminated }\end{array}$ & $\begin{array}{l}\text { Similar hydrate inventory to } \\
\text { Lores Base }\end{array}$ \\
\hline $\begin{array}{l}\text { Labile } 10 \%, \\
\text { Labile } 100 \%\end{array}$ & $\begin{array}{l}\text { Changed the biologically- } \\
\text { available POC fraction from } \\
50 \% \text { in base to } 10 \% \text { and } \\
100 \%\end{array}$ & $\begin{array}{l}\text { Nearly linear dependence of } \\
\text { hydrate inventory on rate } \\
\text { constant. }\end{array}$ \\
\hline No Bubb Mig & Bubble migration disabled & Eliminates hydrate \\
\hline $\begin{array}{l}\text { Bubb Mig 100m, } \\
\text { Bubb Mig } 2 \mathrm{~km}\end{array}$ & $\begin{array}{l}\text { Redissolution height scale } \\
\text { for rising bubbles from } 500 \\
\mathrm{~m} \text { in base to } 100 \mathrm{~m} \text { and } 2 \mathrm{~km}\end{array}$ & $\begin{array}{l}\text { Strong impact on hydrate } \\
\text { inventory }\end{array}$ \\
\hline Lo Slope & $\begin{array}{l}\text { The maximum sea floor } \\
\text { slope is taken to be } 3 \% \\
\text { instead of } 6 \% \text { in base }\end{array}$ & $\begin{array}{l}\text { No strong hydrate inventory } \\
\text { impact }\end{array}$ \\
\hline No Slides & Landslides disabled & $\begin{array}{l}\text { No strong hydrate inventory } \\
\text { impact }\end{array}$ \\
\hline No Thermogen & $\begin{array}{l}\text { Thermal methanogenesis } \\
\text { disabled }\end{array}$ & $\begin{array}{l}\text { No strong hydrate inventory } \\
\text { impact }\end{array}$ \\
\hline No Petroleum & Petrogenesis disabled & Eliminates hydrate \\
\hline No DOC & $\begin{array}{l}\text { DOC production and } \\
\text { respiration disabled }\end{array}$ & $\begin{array}{l}\text { No strong hydrate inventory } \\
\text { impact }\end{array}$ \\
\hline
\end{tabular}


Table 3 Active margin simulations

\begin{tabular}{|c|c|}
\hline Model Name & Description \\
\hline Base & Baseline scenario \\
\hline $\begin{array}{l}\text { Bio } 10 \% \\
\text { Bio } 100 \%\end{array}$ & $\begin{array}{l}\text { Variation in the defined labile fraction of POC, } 10 \% \text { and } 100 \% \\
\text { respectively, within the context of the Base case which takes } \\
50 \%\end{array}$ \\
\hline $\begin{array}{l}\mathrm{T}-2 \\
\mathrm{~T}+2 \\
\mathrm{~T}+4\end{array}$ & Effect of ocean temperature, changes of $-2^{\circ} \mathrm{C}, 2^{\circ} \mathrm{C}$, and $4{ }^{\circ} \mathrm{C}$ \\
\hline No Bubb Mig & Bubble migration disabled \\
\hline $\begin{array}{l}\text { Bubb } 100 \mathrm{~m} \\
\text { Bubb } 2 \mathrm{~km}\end{array}$ & $\begin{array}{l}\text { Bubble redissolution scale height of } 100 \text { meters and } 2 \mathrm{~km} \text {, } \\
\text { relative to the Base case of } 500 \text { meters }\end{array}$ \\
\hline $\begin{array}{l}\text { Fast Plate } \\
\text { Slow Plate }\end{array}$ & $\begin{array}{l}\text { Plate subduction velocity of } 80 \text { or } 20 \mathrm{~mm} / \mathrm{yr} \text { instead of the Base } \\
\text { case of } 40 \mathrm{~mm} / \mathrm{yr} \text {. Slow plate simulation spun up for } 20 \mathrm{Myr} \\
\text { instead of Base } 10 \text { Myr. }\end{array}$ \\
\hline Broad Slope & Critical seafloor slope of $2 \%$ instead of default $6 \%$ \\
\hline Bumpy & $\begin{array}{l}\text { Heterogeneous sediment deformation constant imposed as } 100 \\
\mathrm{~km} \text { variations of } 40 \% \text { in the deformation constant. }\end{array}$ \\
\hline Wide Def & $\begin{array}{l}\text { Decreased sediment deformation constant, spreading the } \\
\text { deformation zone from } 8 . E-2 \text { in the Base scenario to a value of } \\
\text { 4.E- } 2 \text {. The change diminishes the need for erosion to maintain a } \\
\text { critical seafloor slope }\end{array}$ \\
\hline Pelagic & $\begin{array}{l}\text { Sedimentation dominantly "pelagic" (spatially uniform) rather } \\
\text { than continentally derived (doubled pelagic, halved continental) }\end{array}$ \\
\hline No Erode & Erosion disabled \\
\hline No Thermogen & Thermogenic methane production disabled \\
\hline No Chan & No vertical low-permeability chimneys. \\
\hline No Sealevel & $\begin{array}{l}\text { Sea level oscillations of }+/-20 \mathrm{~m} \text { on } 1 \mathrm{myr} \text { time cycle in Base } \\
\text { simulation disabled here }\end{array}$ \\
\hline
\end{tabular}




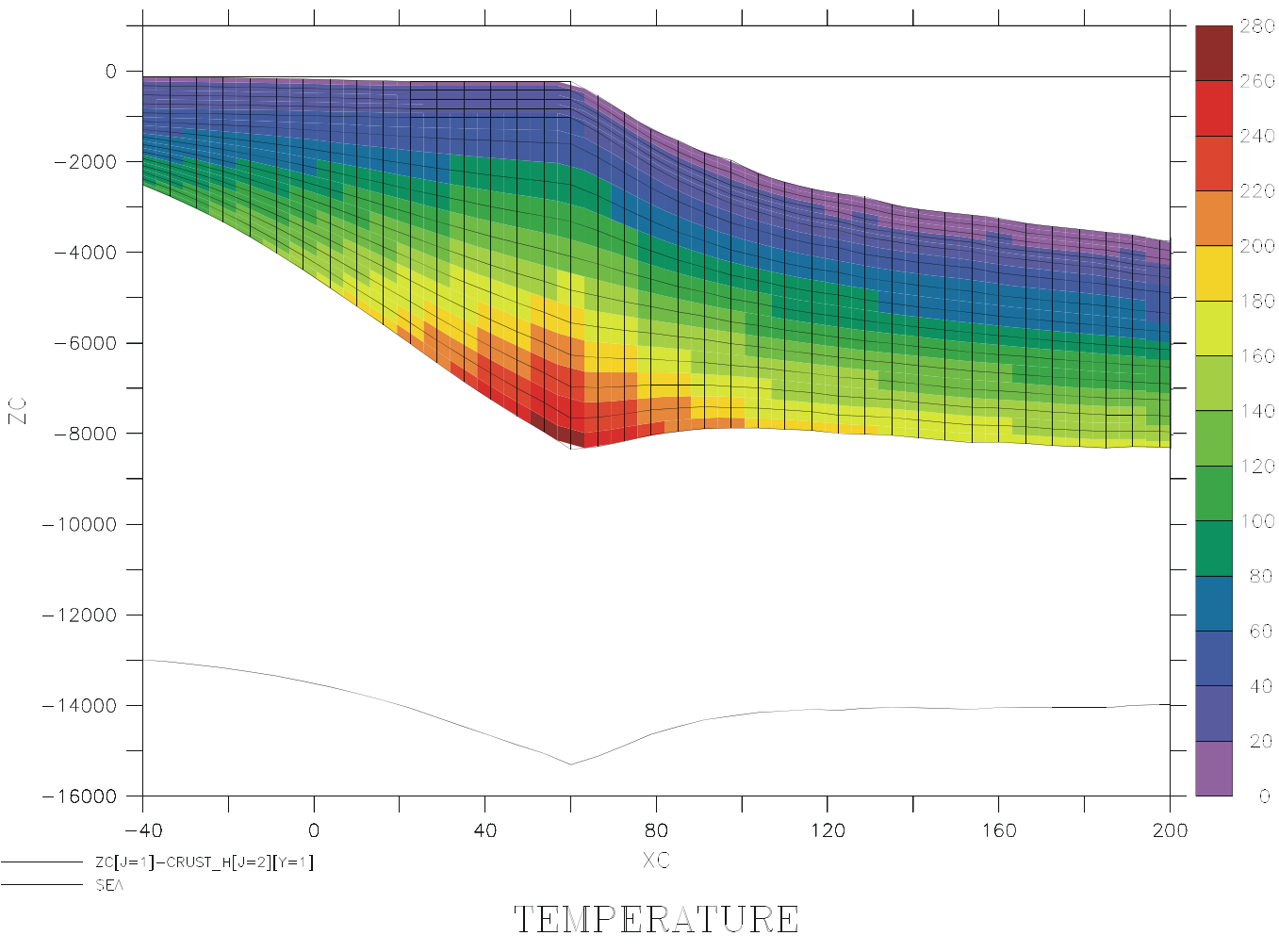

Figure 1. SpongeBOB in isostatic equilibrium. Colors are temperatures on the computational grid of the model, traced horizontally by the black lines. The thickness of the underlying crust grades from thin ocean crust on the right side of the domain into a thicker (and less dense) continental crust on the left. The transition between ocean and continental crust is smoothed over a spatial scale of $25 \mathrm{~km}$. Local isostacy applies, on a time scale of 10,000 years and with spatial smoothing over $20 \mathrm{~km}$. An animation of the simulation can be viewed at

http://geosci.uchicago.edu/ archer/spongebob_passiv e/fig1.atlantic.movie.gif 

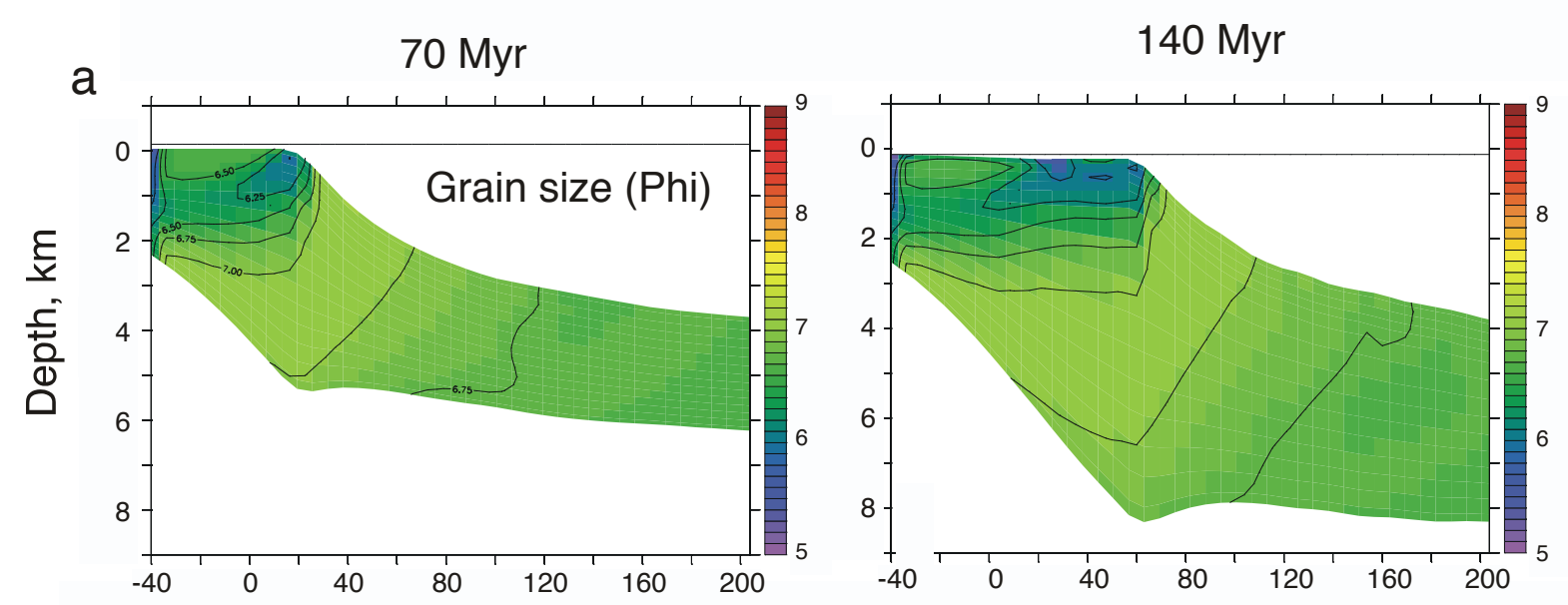

Figure 2. Sediment transport model results. A) Mean grain size $(\phi=\log 10(\mathrm{~mm}))$ in the sediment column half-way through (left) and at the end of the simulation (right). B) Snapshots of the sedimentation rate of particles of various sizes. C) Snapshots of the total sedimentation rate, with a depocenter just off the shelf break. An animation of this figure can be viewed at http://geosci.uchicago.edu/ archer/spongebob_ passive/fig2.atlantic.movie.gif
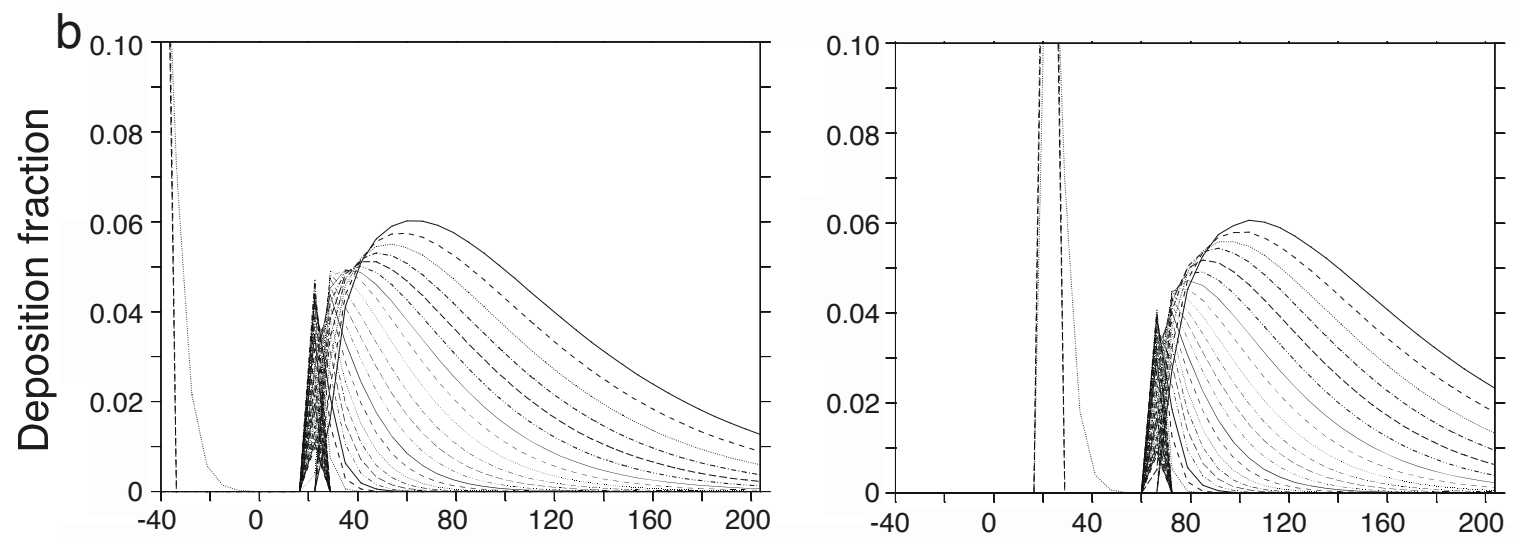

C
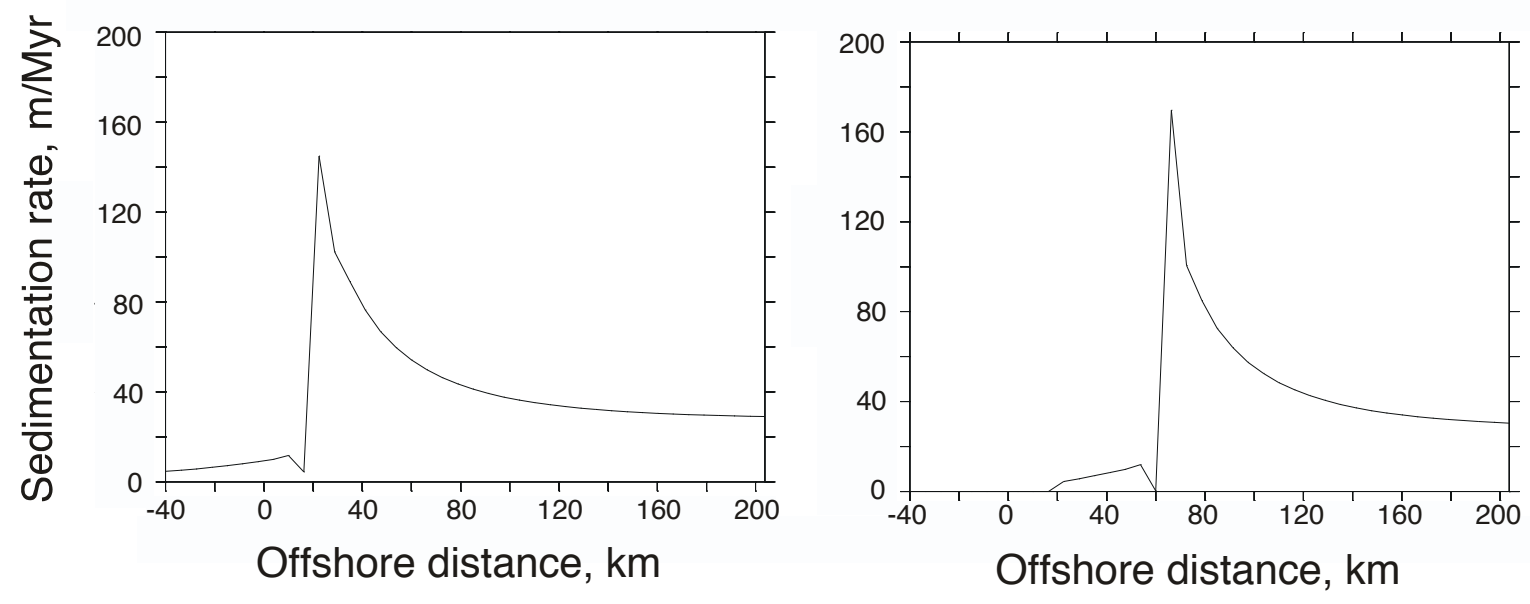
a

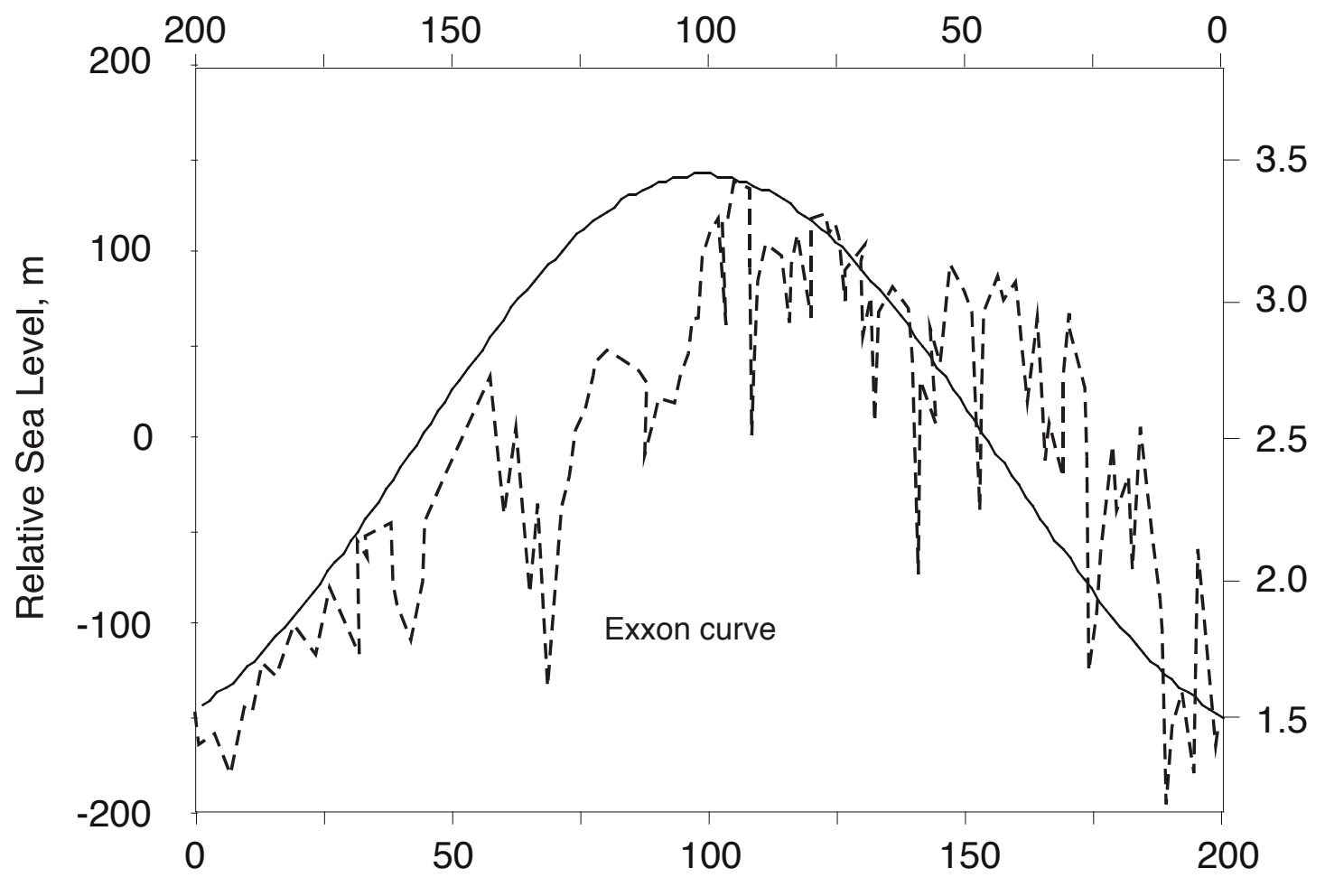

b

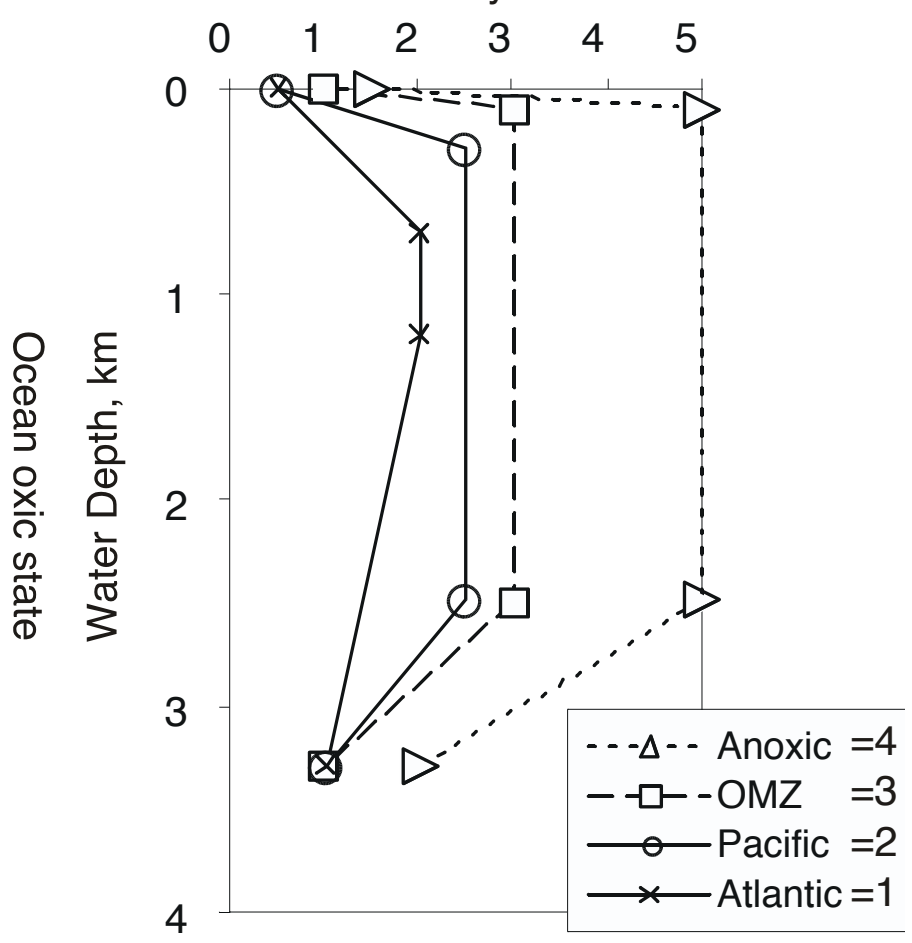

\section{Model time, Myr}

Figure 3. A) Sea level time variation with time imposed on the simulation, and corollary changes in the "ocean state", which drive POC deposition concentration patterns as in (B), where Atlantic and Pacific represent conditions typical of the East or Northwest coasts of United States, "OMZ" is stronger oxygen minimum conditions typical of the Eastern equatorial Pacific, and Anoxic refers to anoxic conditions. Concentrations of POC in ocean sediments vary through this range and beyond; the intent here is to allow for variations that span something like the observed range. 


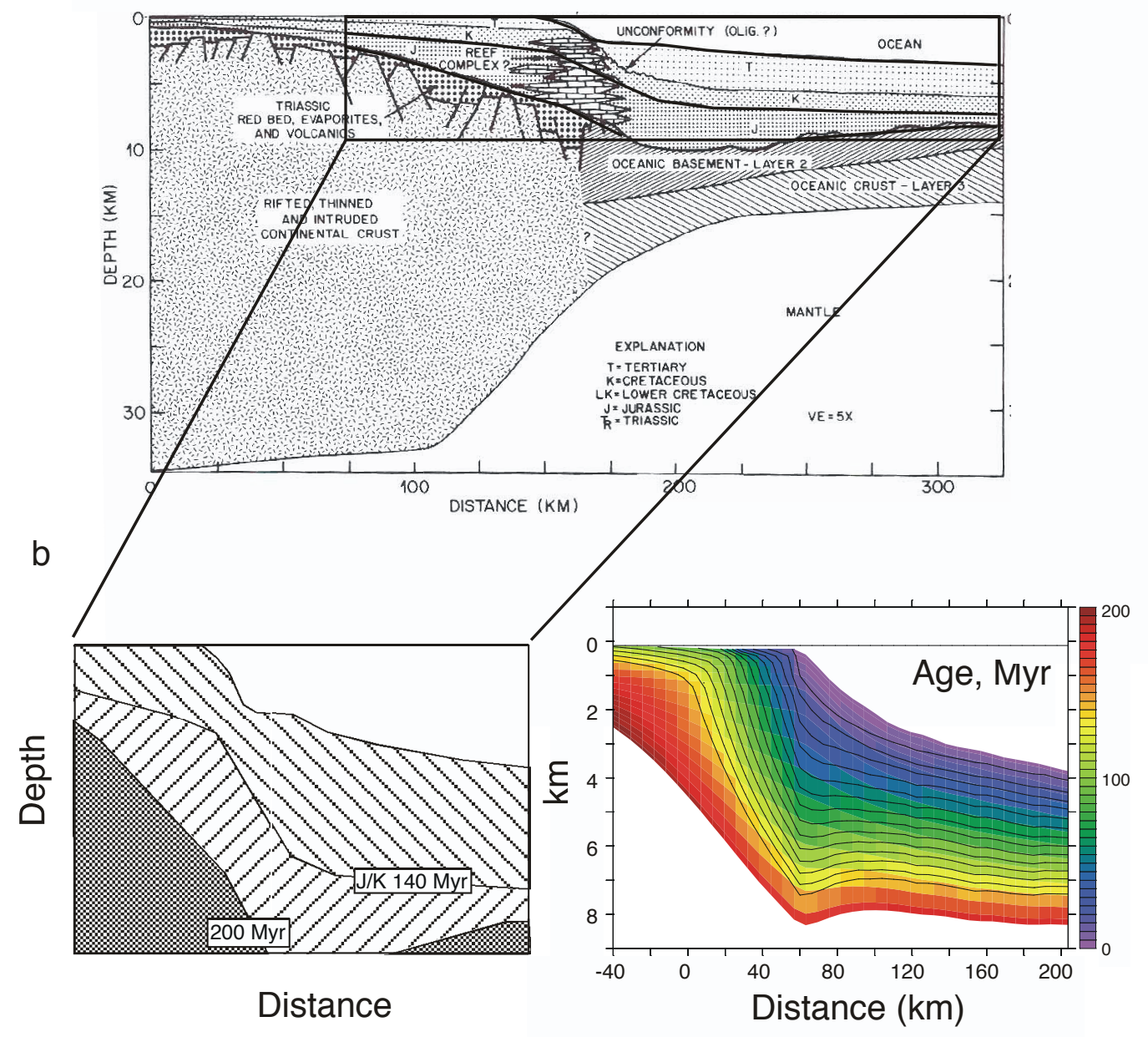

Figure 4. A) Sediment column constructed from a seismic section off Cape Cod, from Kennett [1982], with cutout (b) resized for comparison with model results (C). 


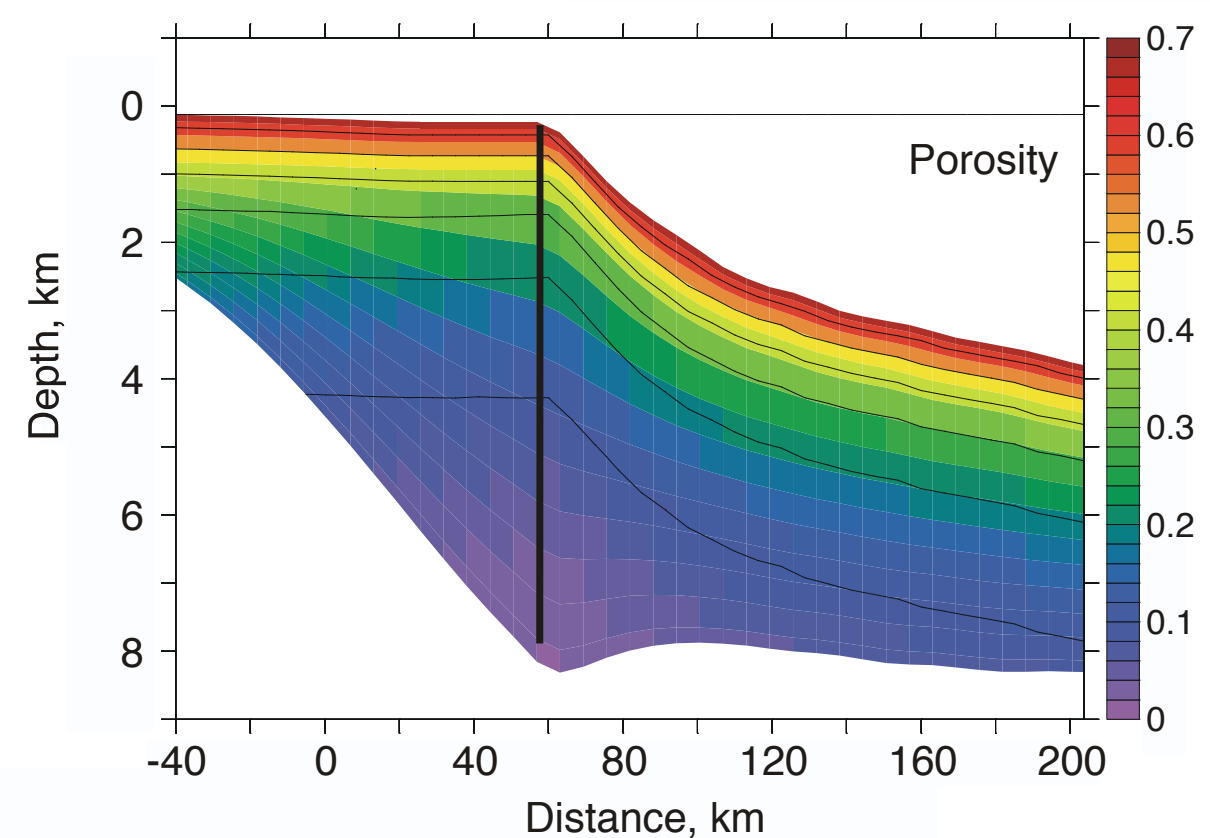

b

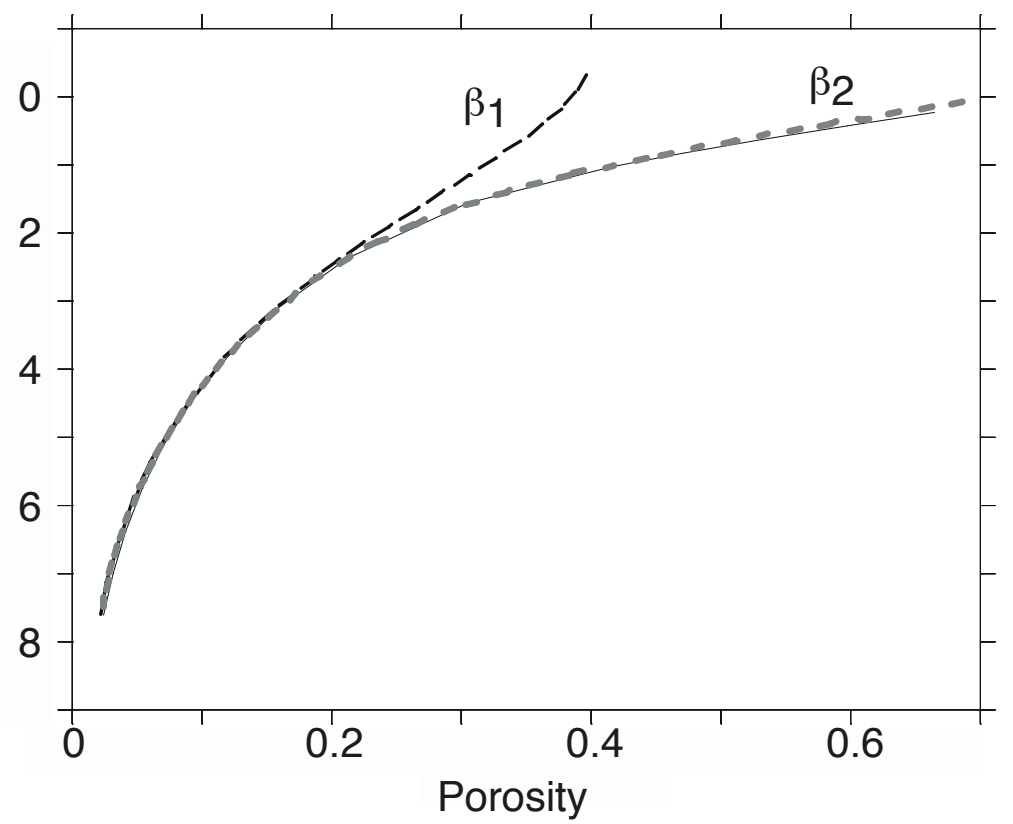

Figure 5. Porosity at the end of the simulation, section (A) and profile (B) taken on the heavy solid line in A: (solid line) full model solution, (long dashes) "drained" porosity contribution from $\beta 1$, (short grey dashes) sum of drained porosity contribution from $\beta 1+\beta 2$. 

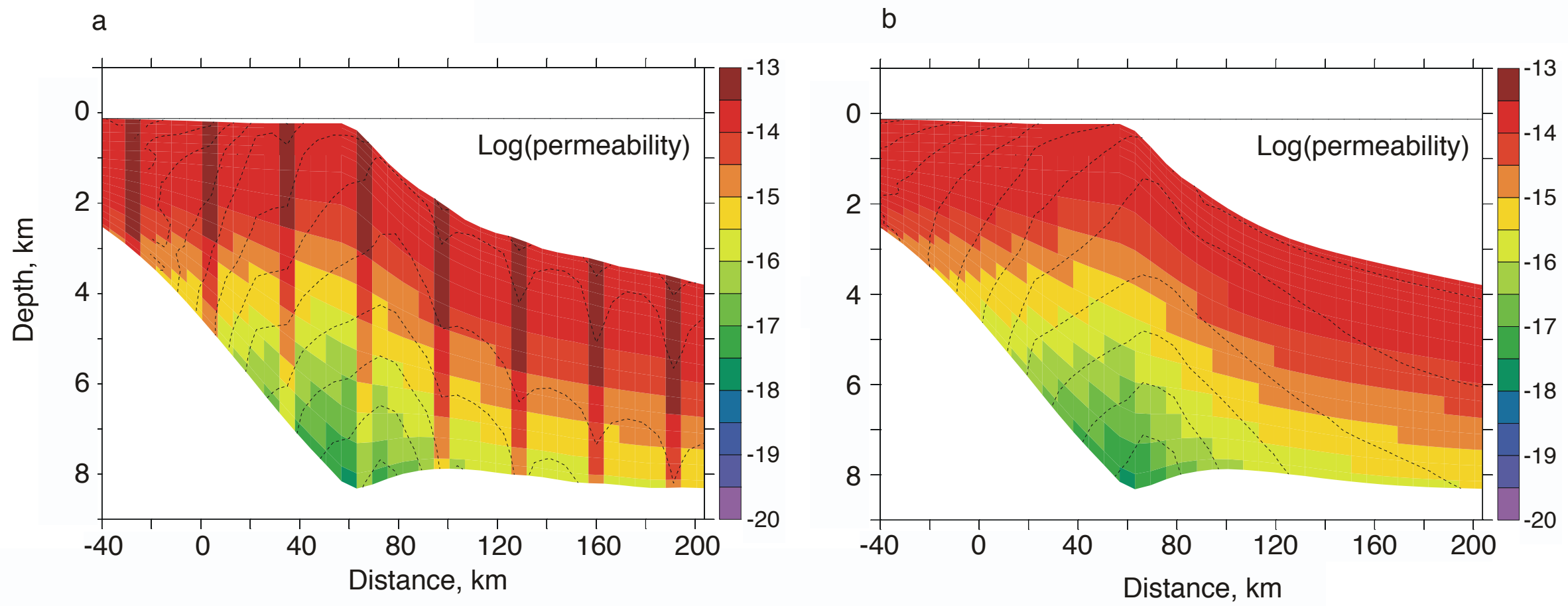

Figure 6. Log of the permeability from the end of the simulation, (A) from the Base case and (B) the No Chan case with the vertical permeable chimneys disabled and at lower horizontal resolution. 


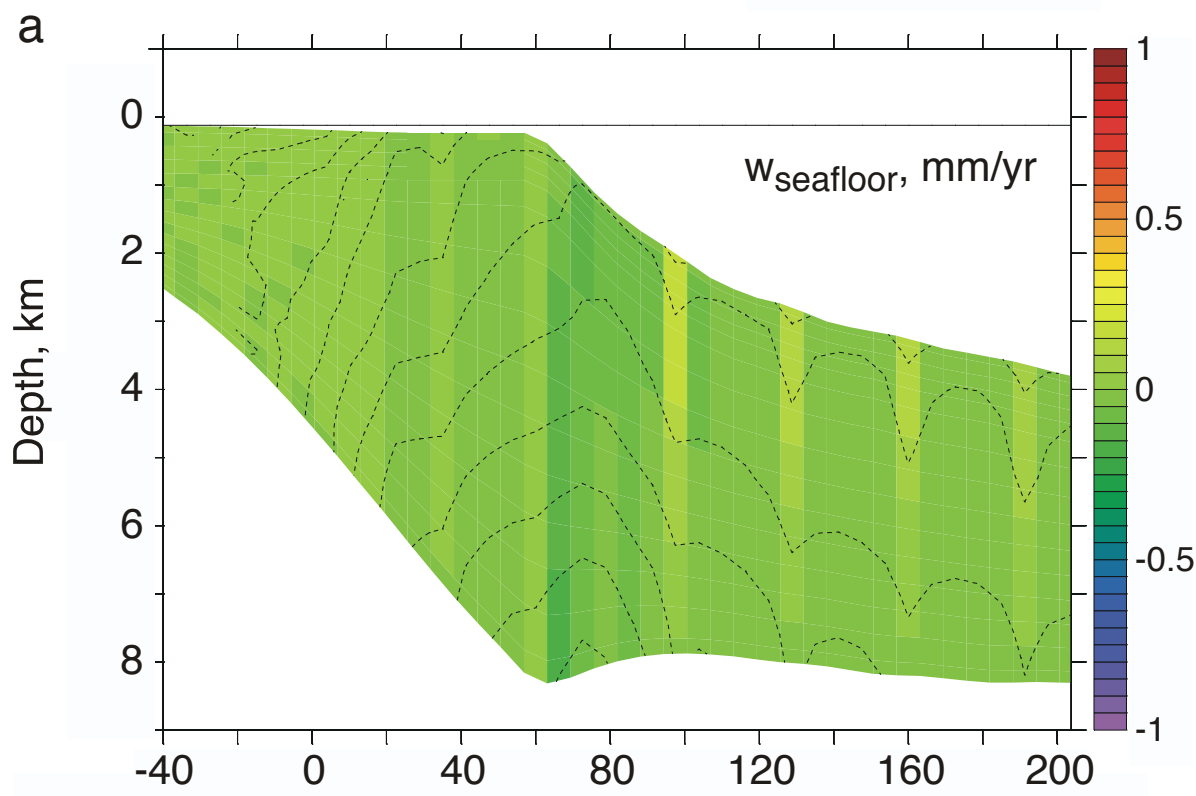

Figure 7. Vertical velocity relative to the moving sea floor (wseafloor) for the Base (A) and No Chimneys (B) cases, from the end of the simulation. An animation of the simulation can be viewed at

http://geosci.uchicago.edu/ archer/spongebob_ passive/w_seafloor.movie.gif

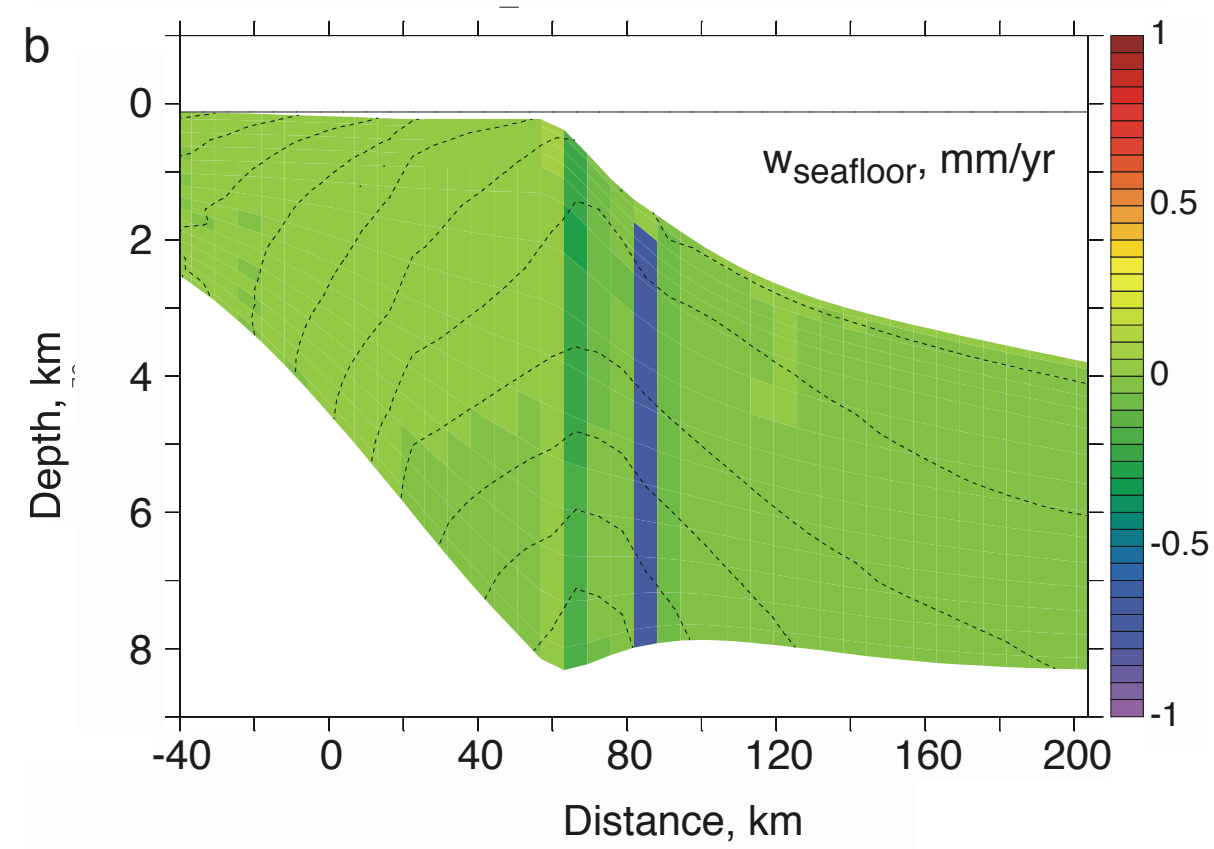




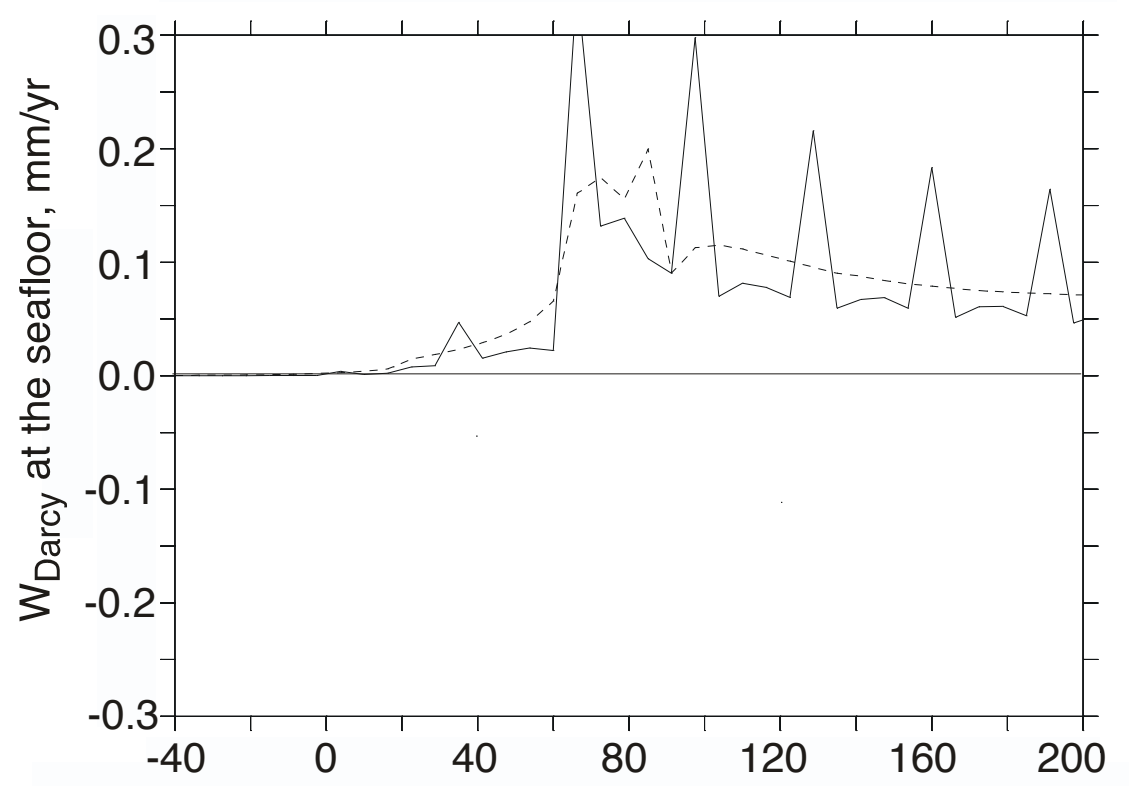

Figure 8. Rates of vertical flow at the sea floor. Solid lines are the Base scenario, dashed the No Chimney run. (A) Darcy flows (wDarcy) are upward, while (B) flows relative to the moving seafloor (wseafloor) can be found in both directions. An animation of the simulation can be viewed at

http://geosci.uchicago.edu/ archer/spongebob_passive/w_ seafloor_sf.movie.gif

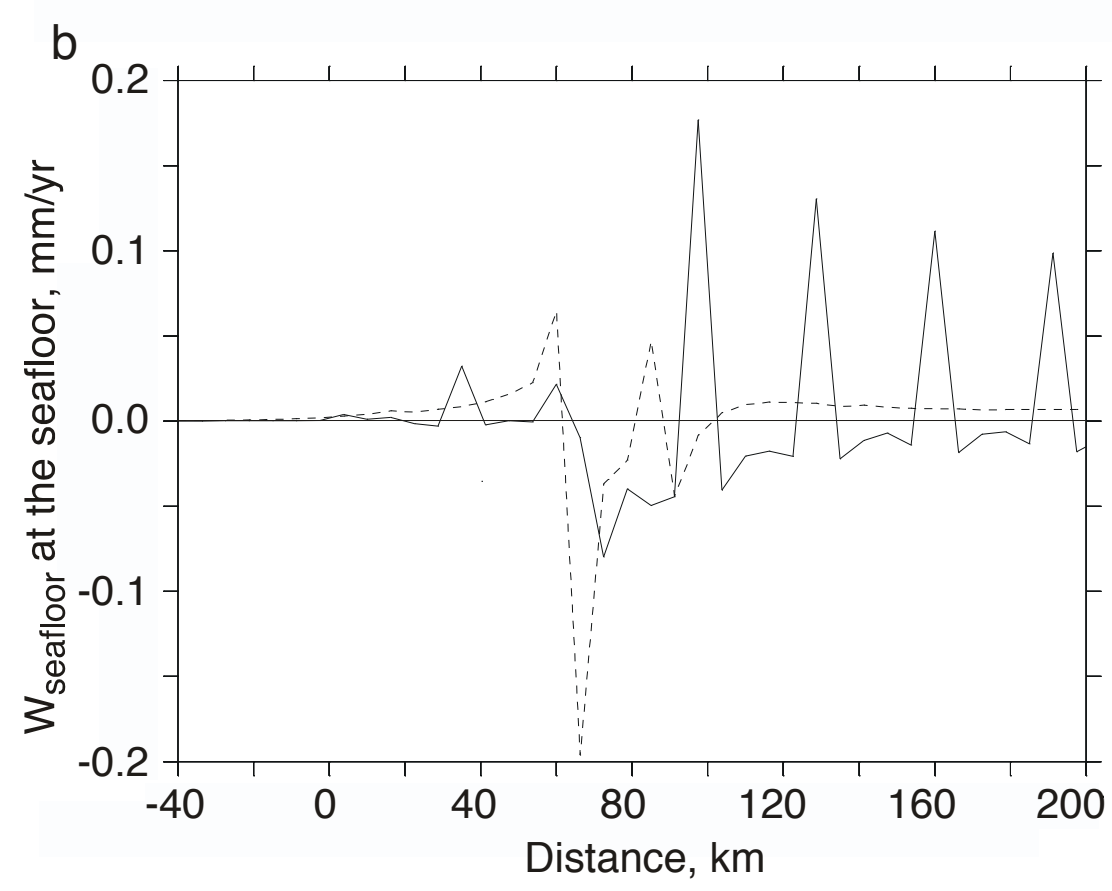


$70 \mathrm{Myr}$

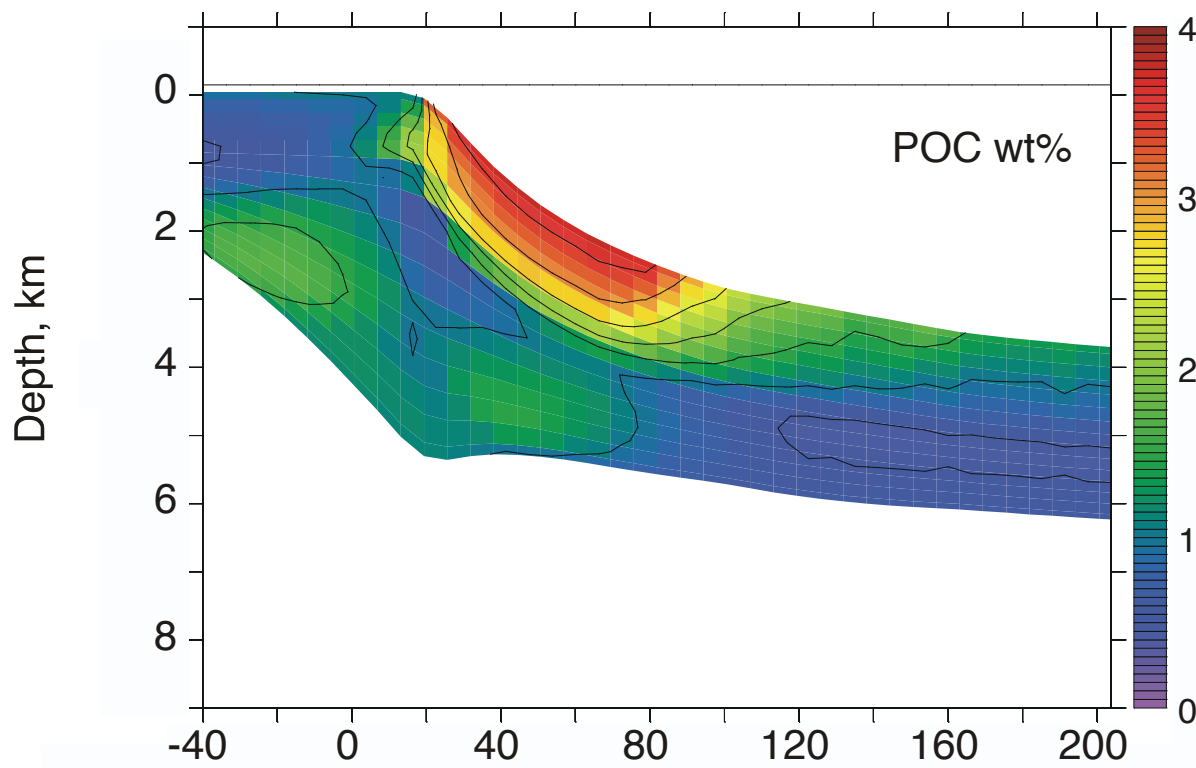

C

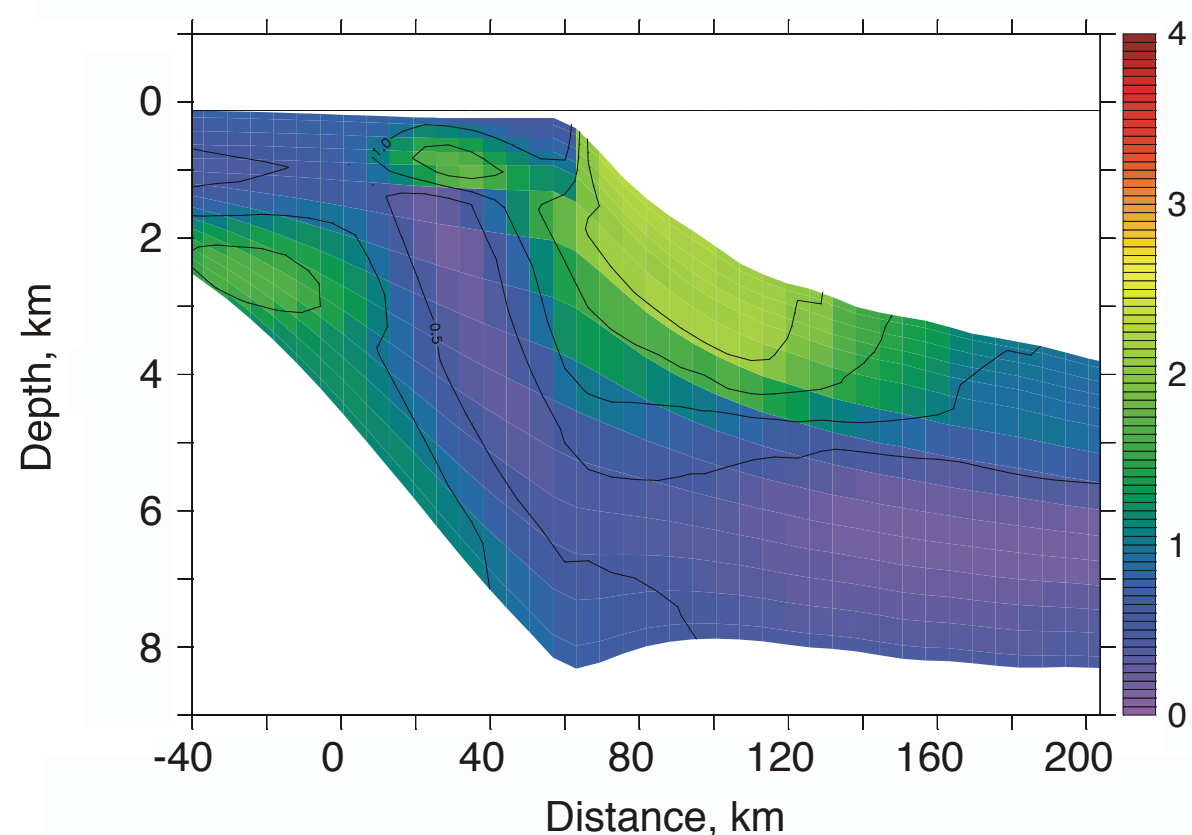

b

$140 \mathrm{Myr}$

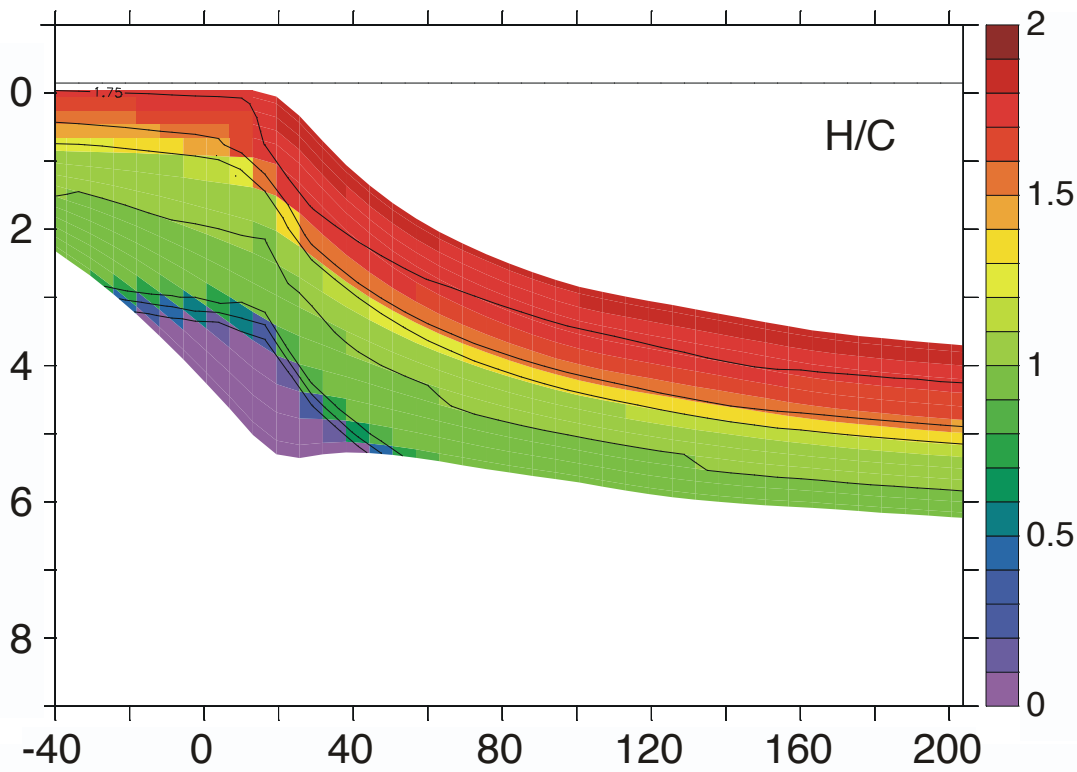

d

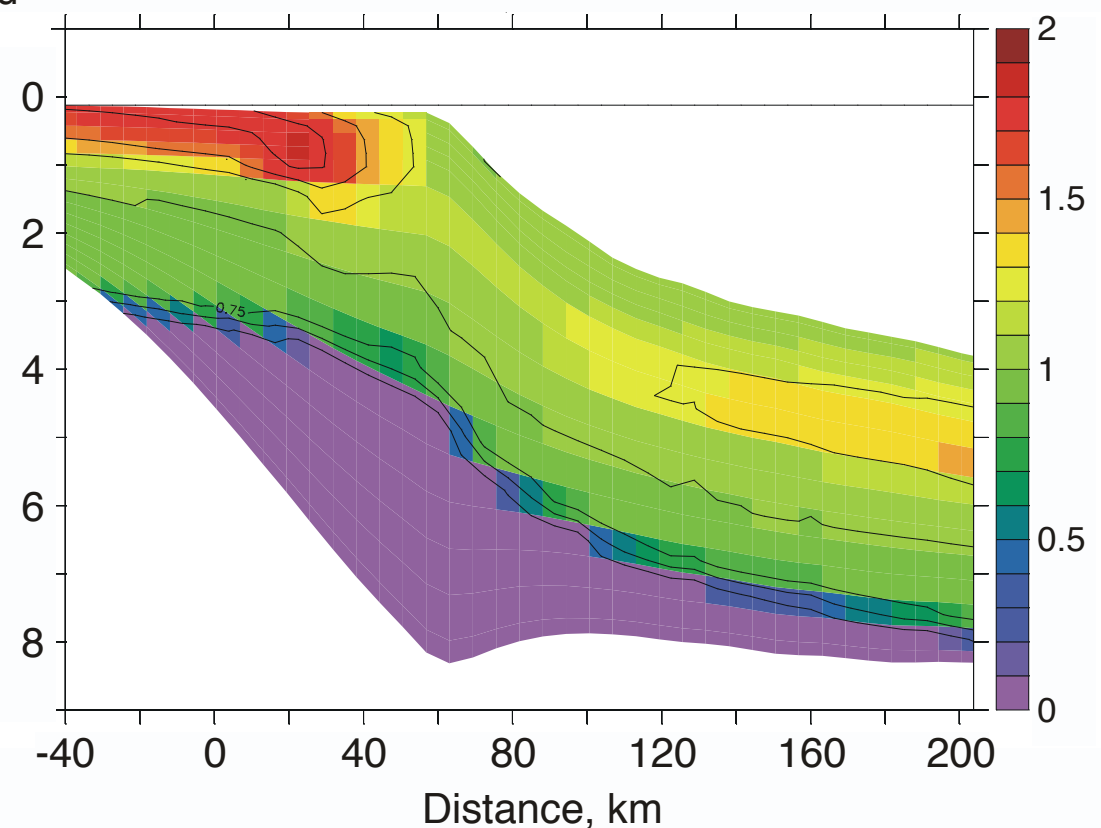

Figure 9. POC concentrations (dry weight percent) (A and C) and $\mathrm{H} / \mathrm{C}$ elemental ratio of organic matter (B and D). From half-way through (A and $\mathrm{B})$ the simulation, at a period of high sea level, and $(\mathrm{C}$ and $\mathrm{D})$ at the end of the simulation, when sea level is relatively low, as today. An animation of the simulation can be viewed at http://geosci.uchicago.edu/ archer/spongebob_passive/poc.movie.gif 
a

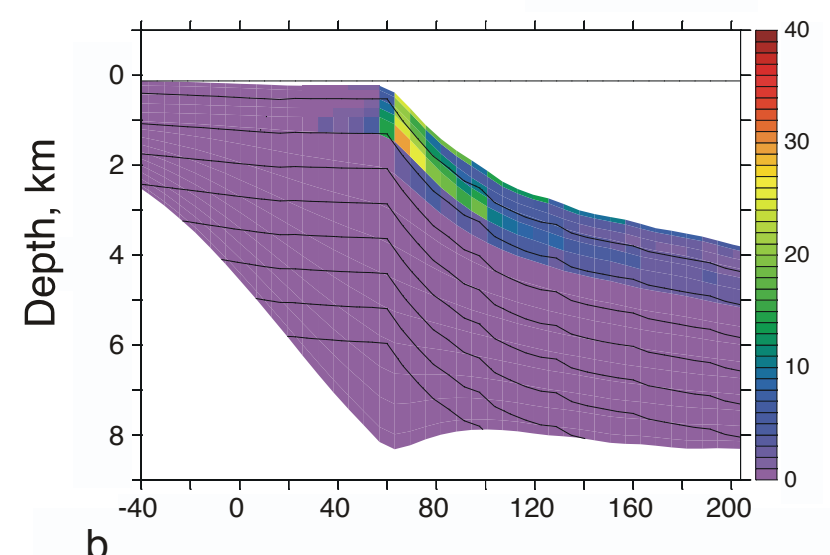

b

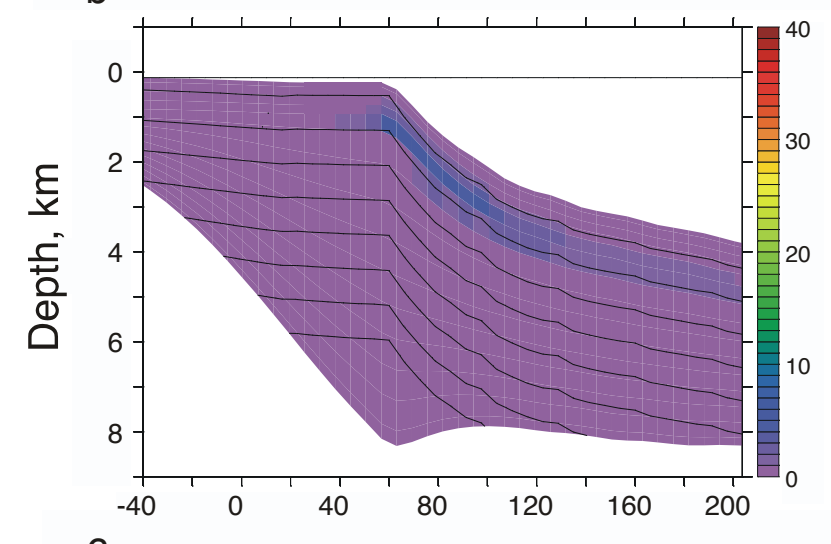

C

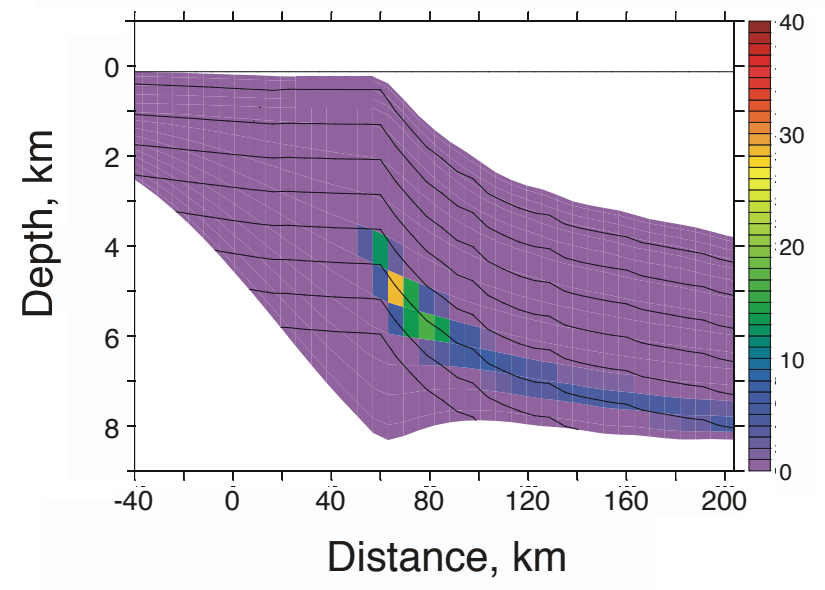

Figure 10. Methane sources in the sediment column. (A) From biological respiration of POC. (B) From biological degradation of migrating petroleum. (C) From thermal alteration of POC. An animation of the simulation can be viewed at

http://geosci.uchicago.edu/ archer/spongebob_passive/ch4_src.mo vie.gif 

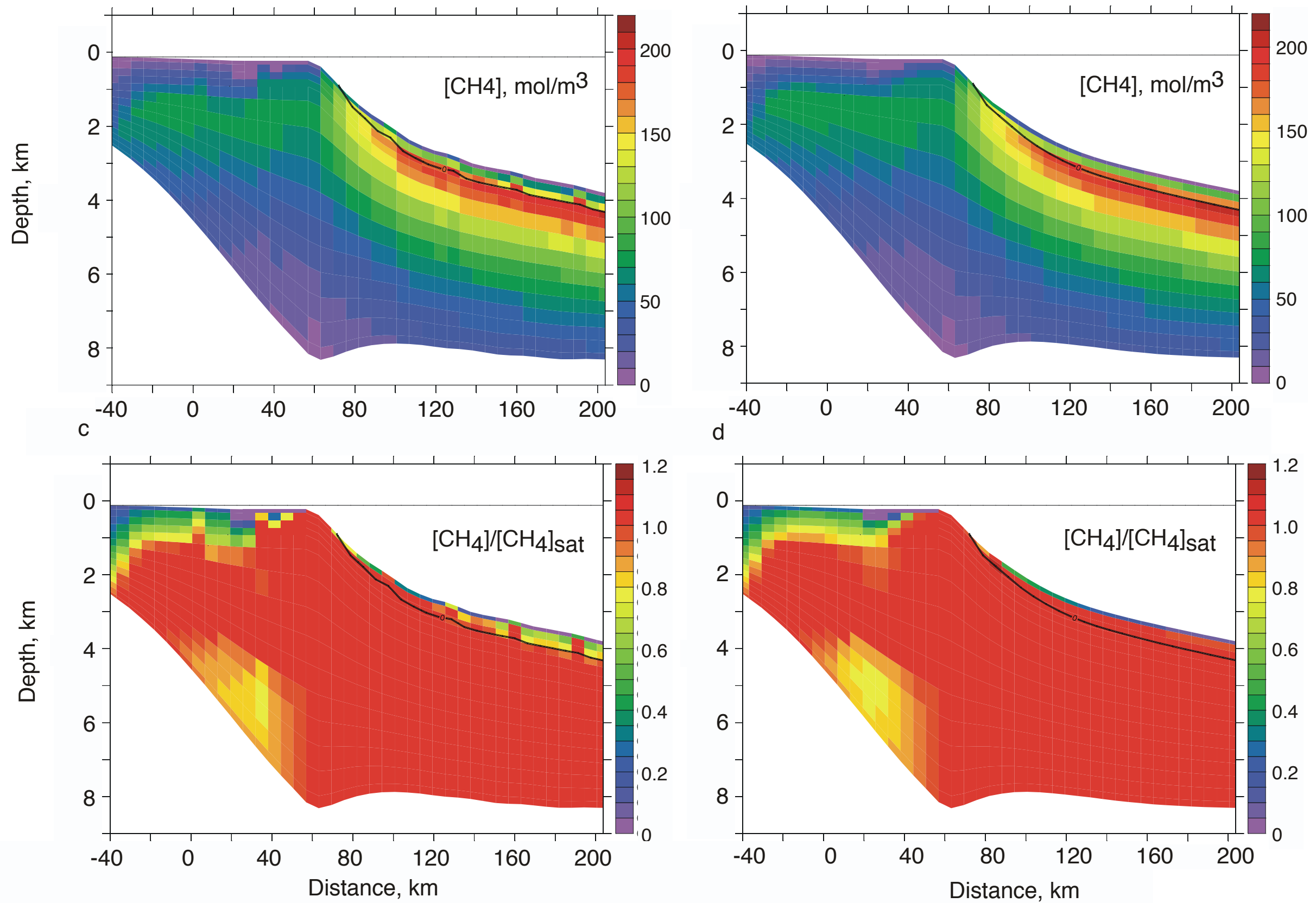

Figure 11. Concentration of dissolved methane plotted in moles / $\mathrm{m} 3$ (A and B), and relative to saturation (C and D). Base model run (A and C), and No Chimneys (B and D). An animation of the simulation can be viewed at http://geosci.uchicago.edu/ archer/spongebob_passive/ch4.movie.gif 
a
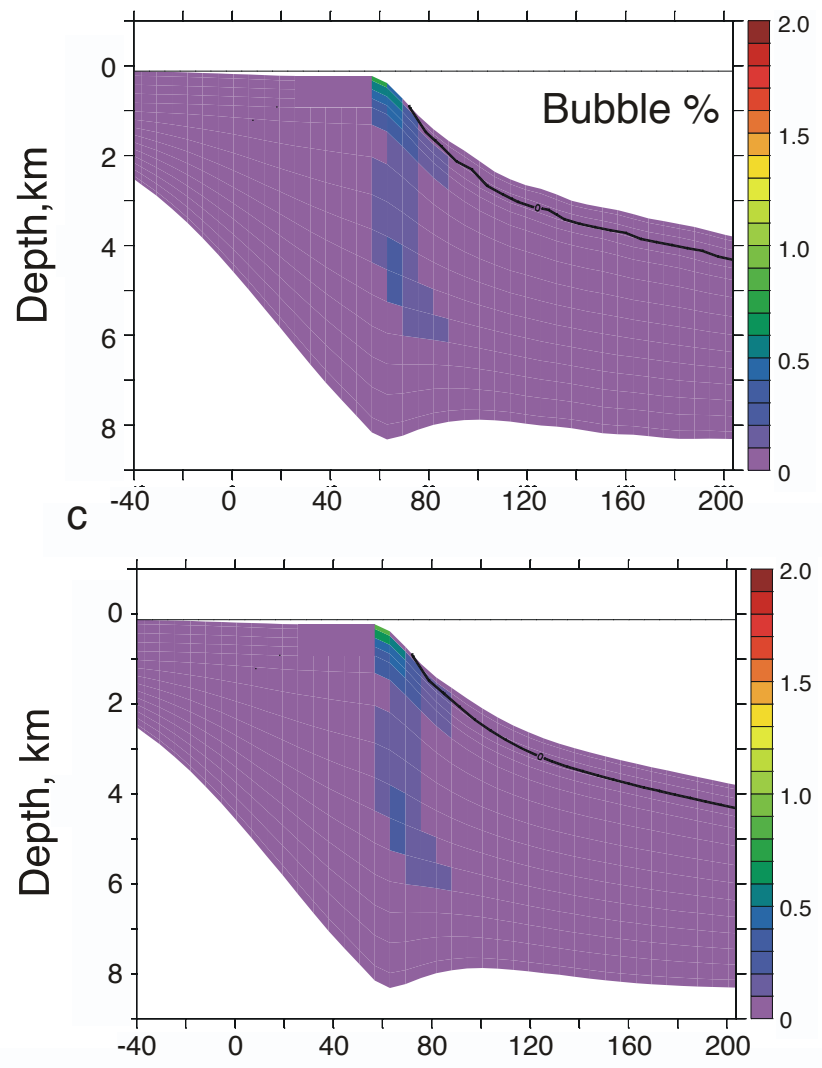

e

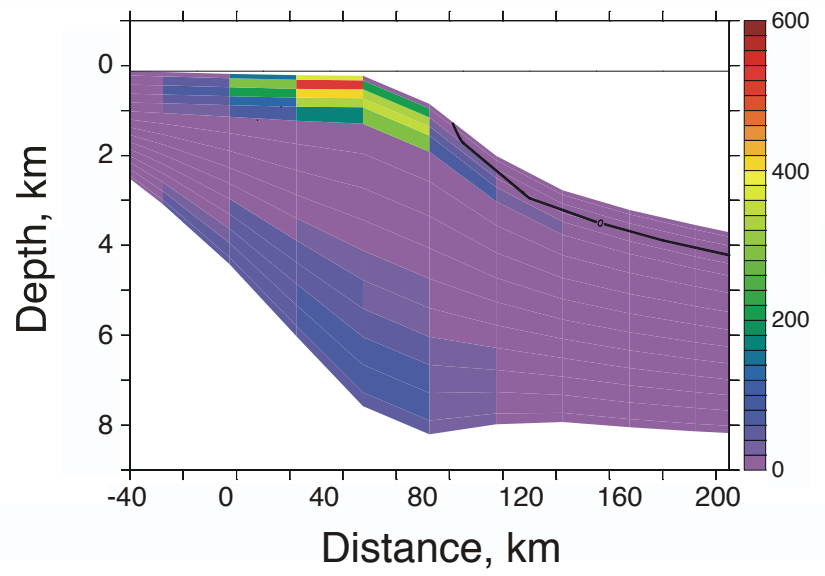

b

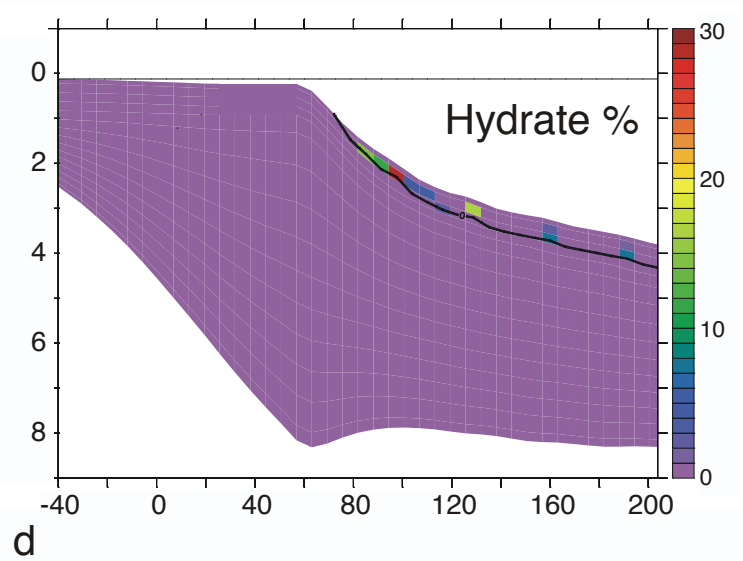

Figure 12. Bubbles (A, C, E) and hydrate $(\mathrm{B}, \mathrm{D}, \mathrm{F})$ (volume percent of pore space). From the Base model (A and B), the No Chimneys model $(\mathrm{C}$ and $\mathrm{D})$, and with bubble migration disabled ( $\mathrm{E}$ and $\mathrm{F})$. An animation of the simulation can be viewed at

http://geosci.uchicago.edu/ archer/s pongebob_passive/bubbles.movie.gi $\mathrm{f}$
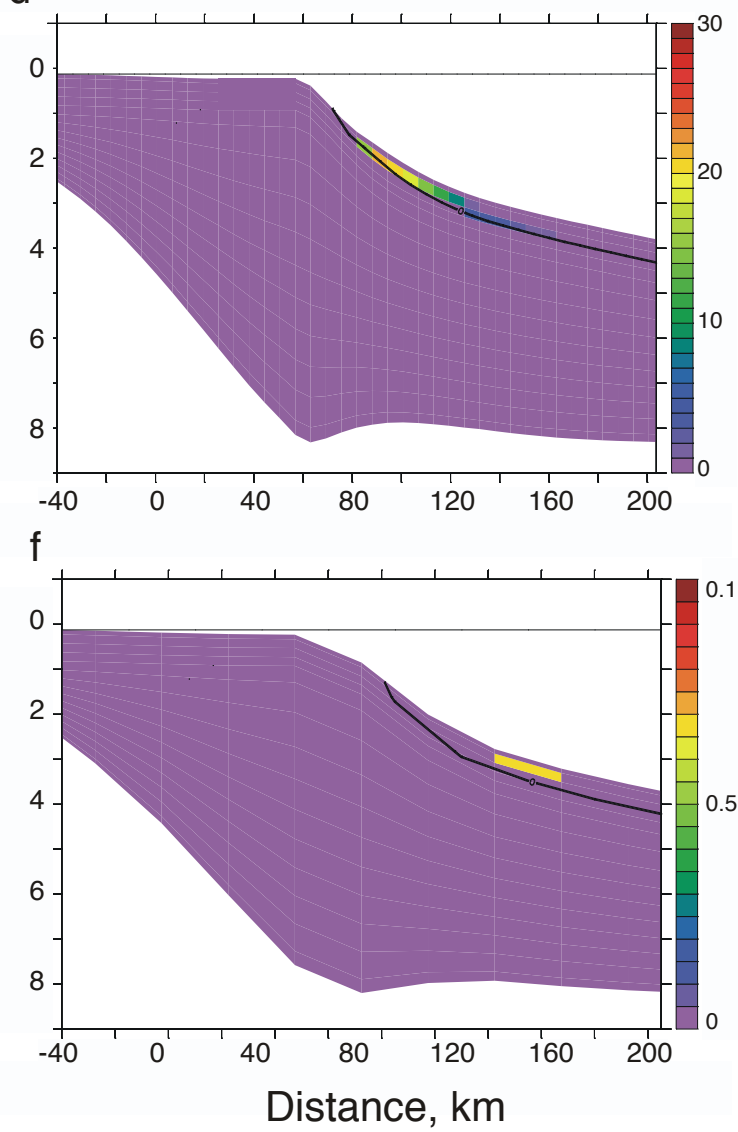
a
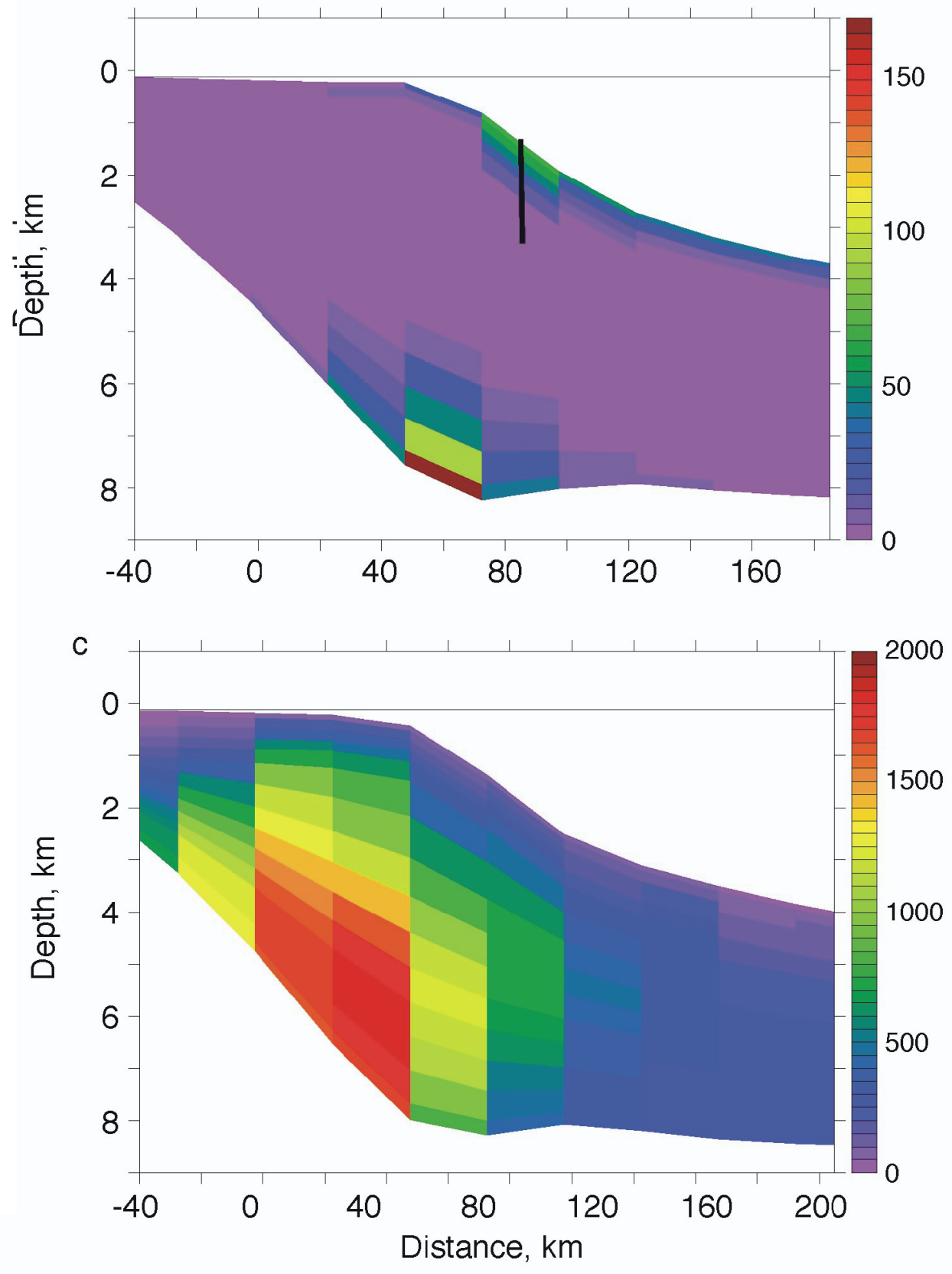

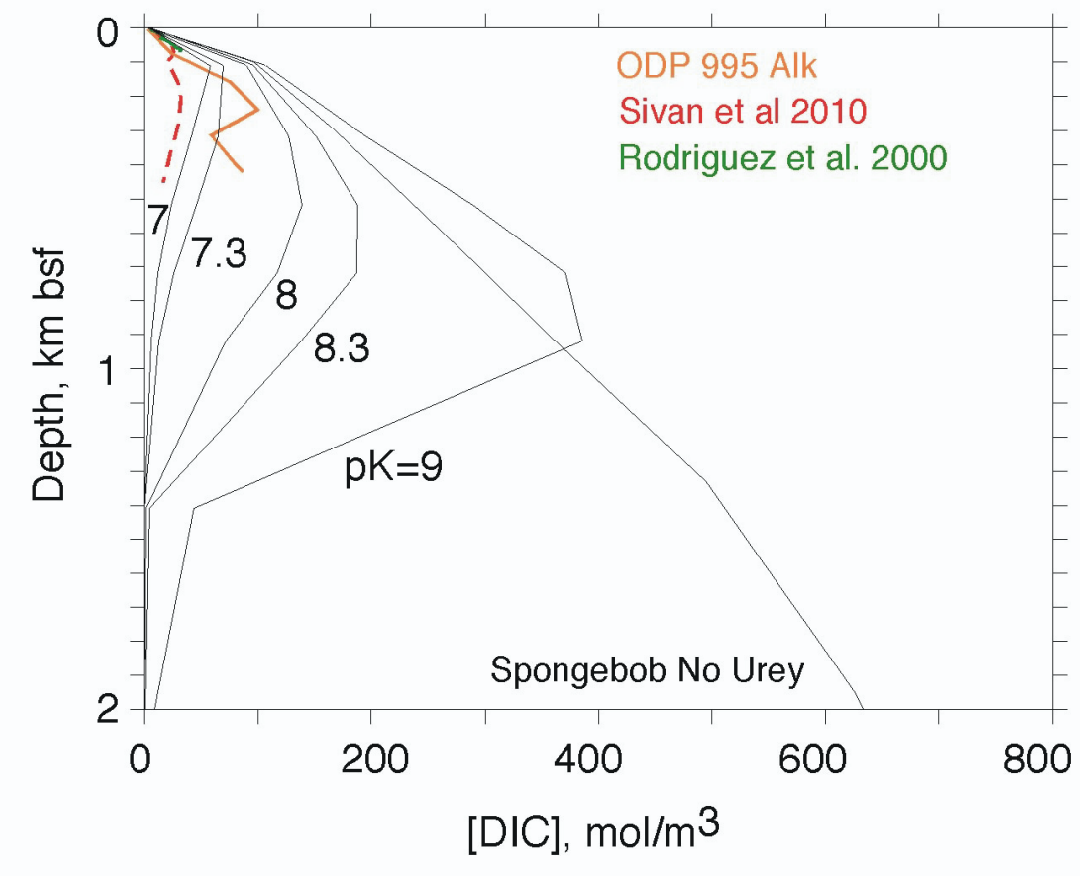

Figure 13. DIC concentrations, moles/m3. (A) Base case section, (B) Base case profile compared with data from Sivan et al [2007], dashed line, and (C) with Urey reactions that consume $\mathrm{CO} 2$ disabled (note change in color scale from A). An animation of the simulation can be viewed at

http://geosci.uchicago.edu/ archer/spongebob_passive /dic.movie.gif 

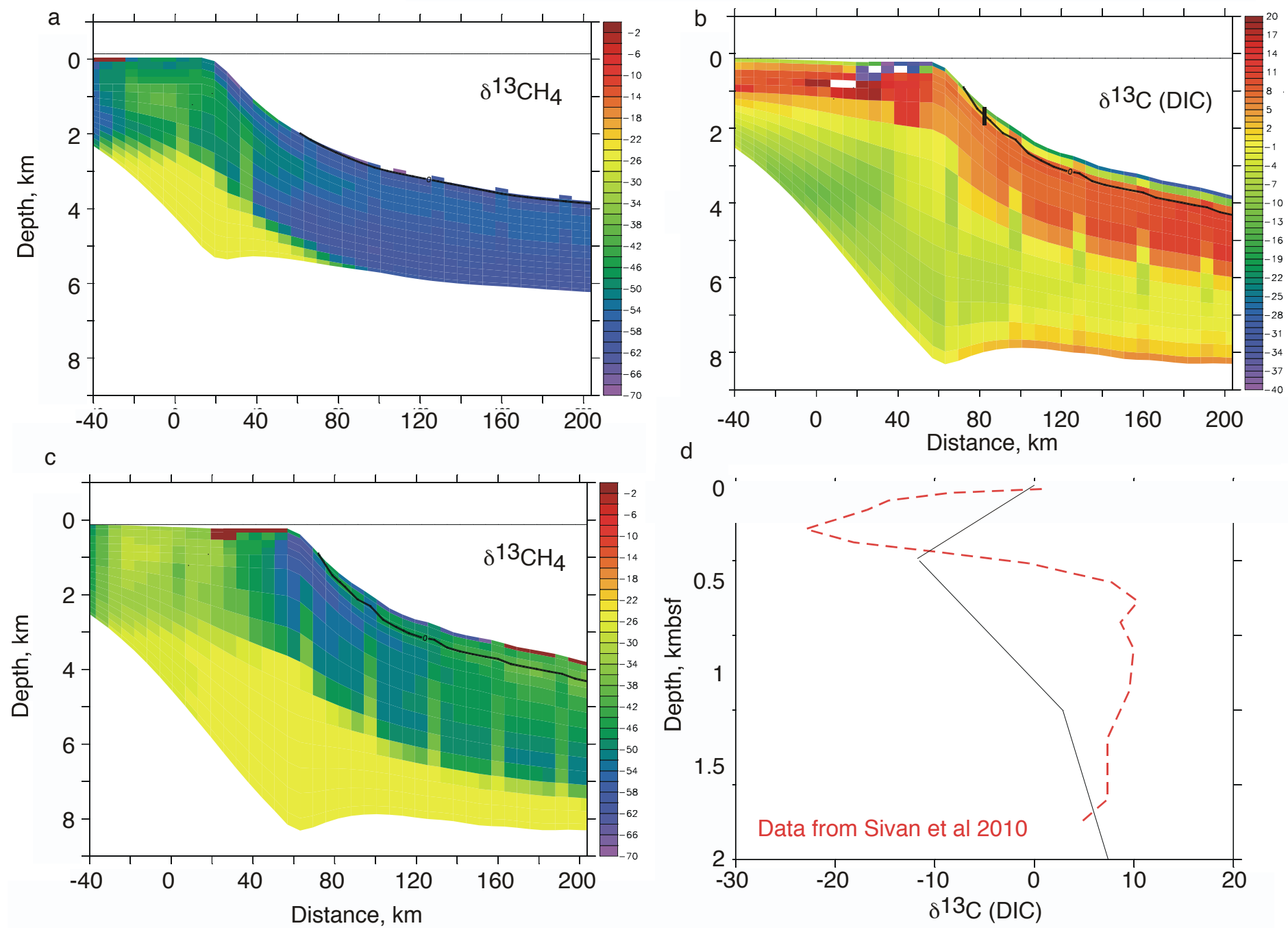

Figure 14. Carbon isotopic composition of methane from half-way through (A), where little influence of thermogenic methane can be seen, and at the end of the simulation (C), where thermogenic methane can clearly be seen. (B) is the $\delta 13 \mathrm{C}$ of DIC at the end of the simulation, compared with data from Sivan et al [2007] (dashed line) in profile (D). The model lacks the resolution to capture the isotopically light spike just below the sea floor, but the deep isotopic composition matches well. Animations of this plot can be viewed at http://geosci.uchicago.edu/ archer/spongebob_passive/del13.movie.gif. 

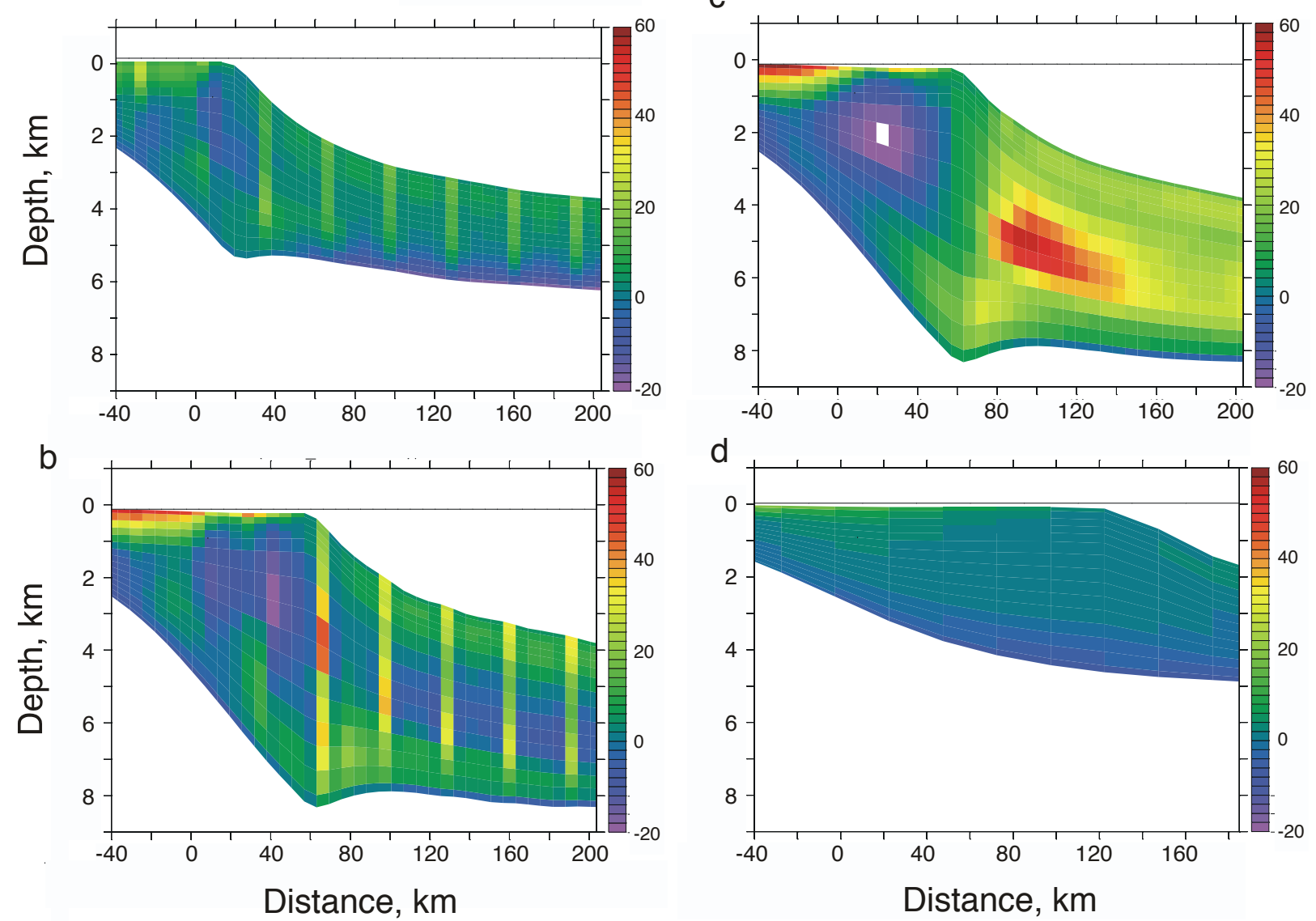

Figure 15. Iodine-129 porewater age - sediment age, in millions of years. With permeable chimneys half-way through the simulation, (A) and at the end of the sismulation (B). (C) Without permeable chimneys, and (D) with pore fluid flow disabled, $t=30$ myr instead of 140 myr for the other simulations. Animations of this plot can be viewed at

http://geosci.uchicago.edu/ archer/spongebob_passive/i129.movie.gif. 
a
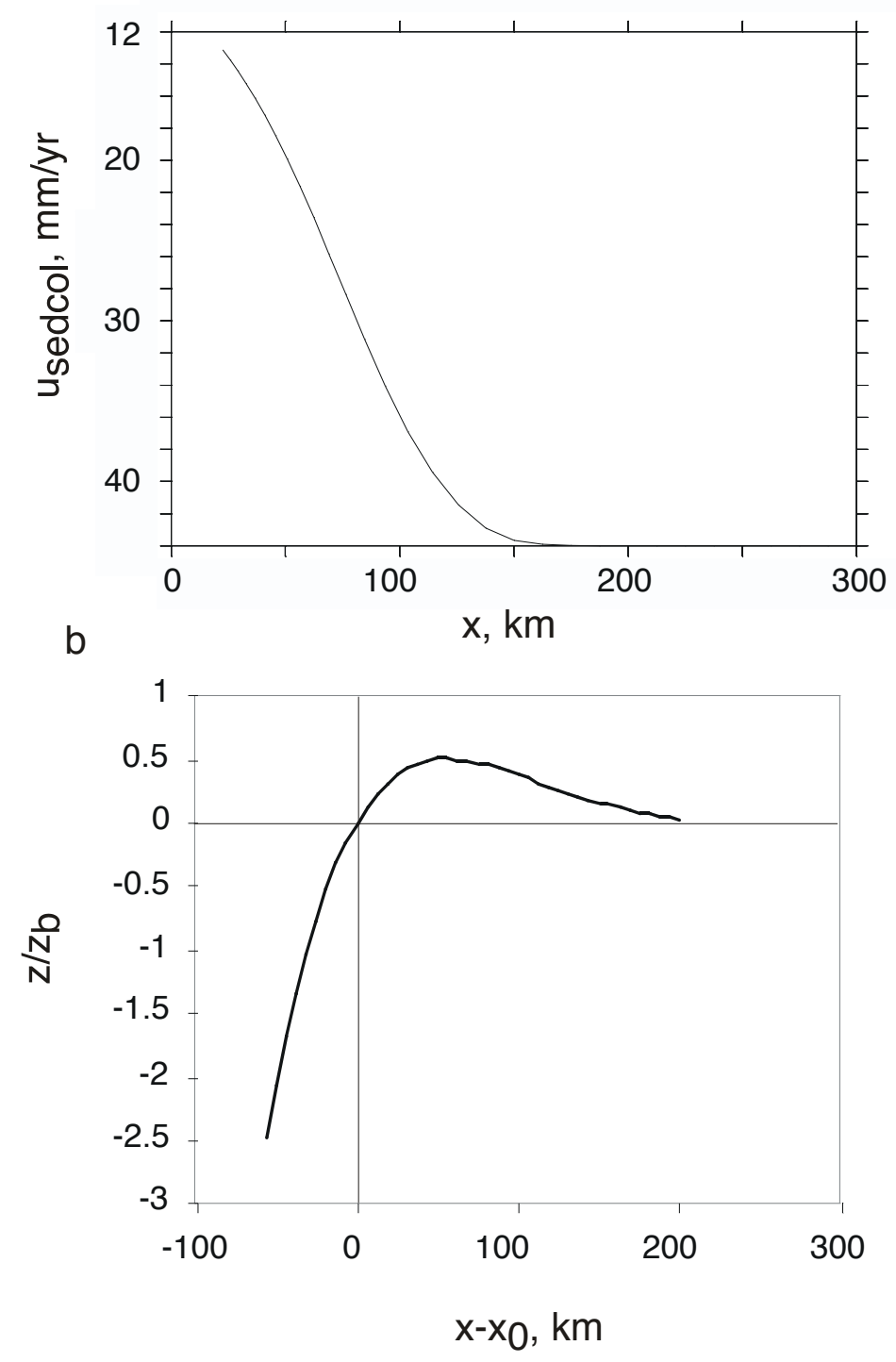

16. (A) The sediment column velocity (negative meaning from right to left) for the Base scenario of the Active margin simulation. (B) The solution to the plate flexure / isostasy balance near the subducting margin. 
a

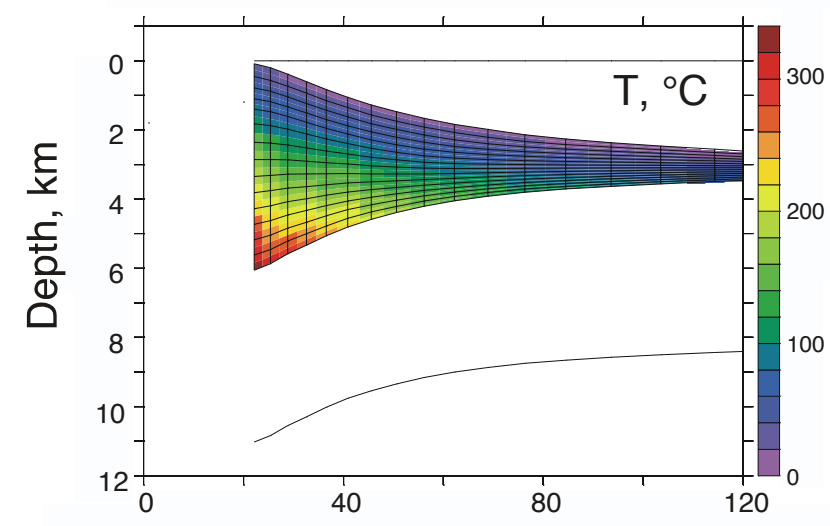

C

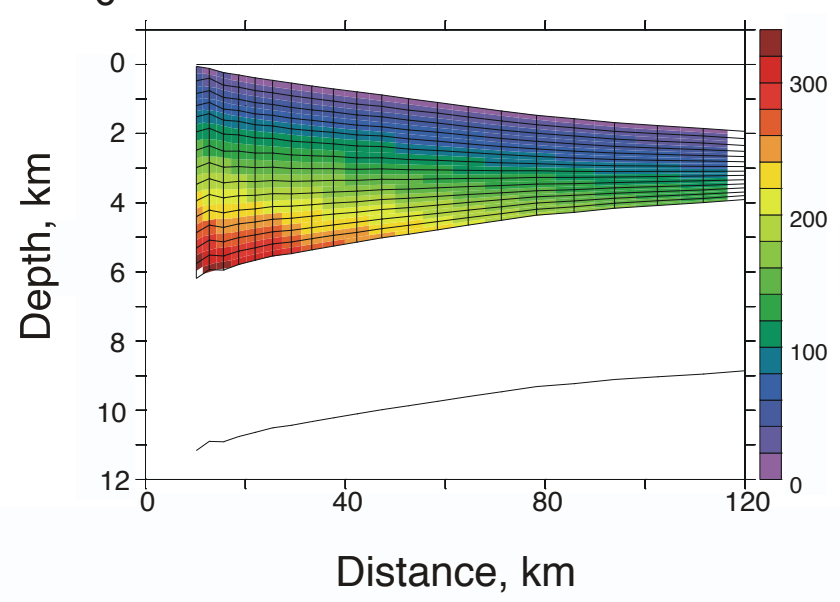

b

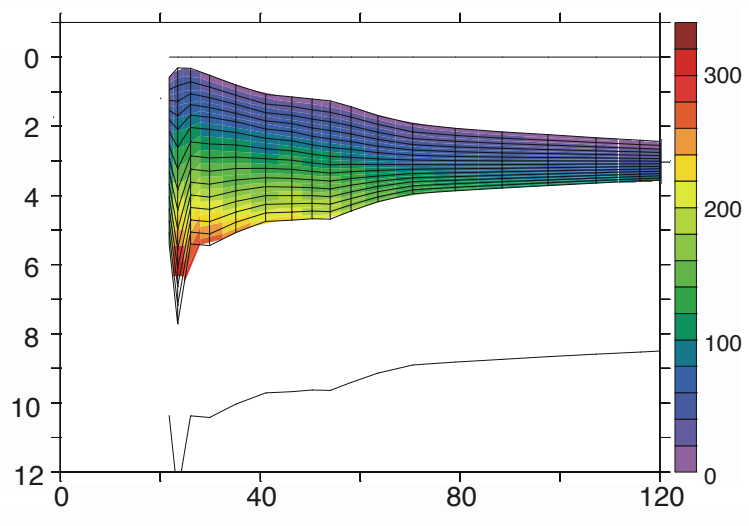

d

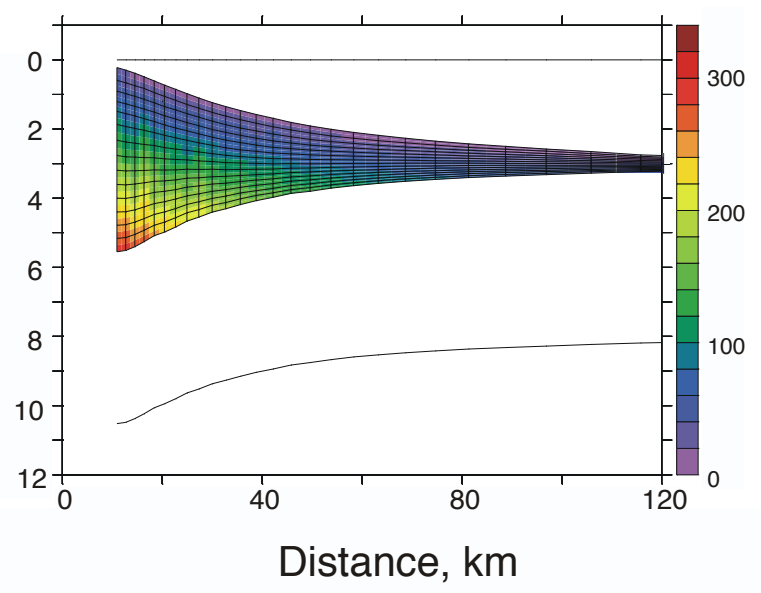

Figure 17. Grid, temperature, and isostasy results for (A) Base, (B) Bumpy, (C) Broad Slope, and (D) Fast Plate scenarios. A movie of the Base scenario can be seen at http://geosci.uchicago.edu/ archer/spongebob_active/fig2.active.movie.gif. 

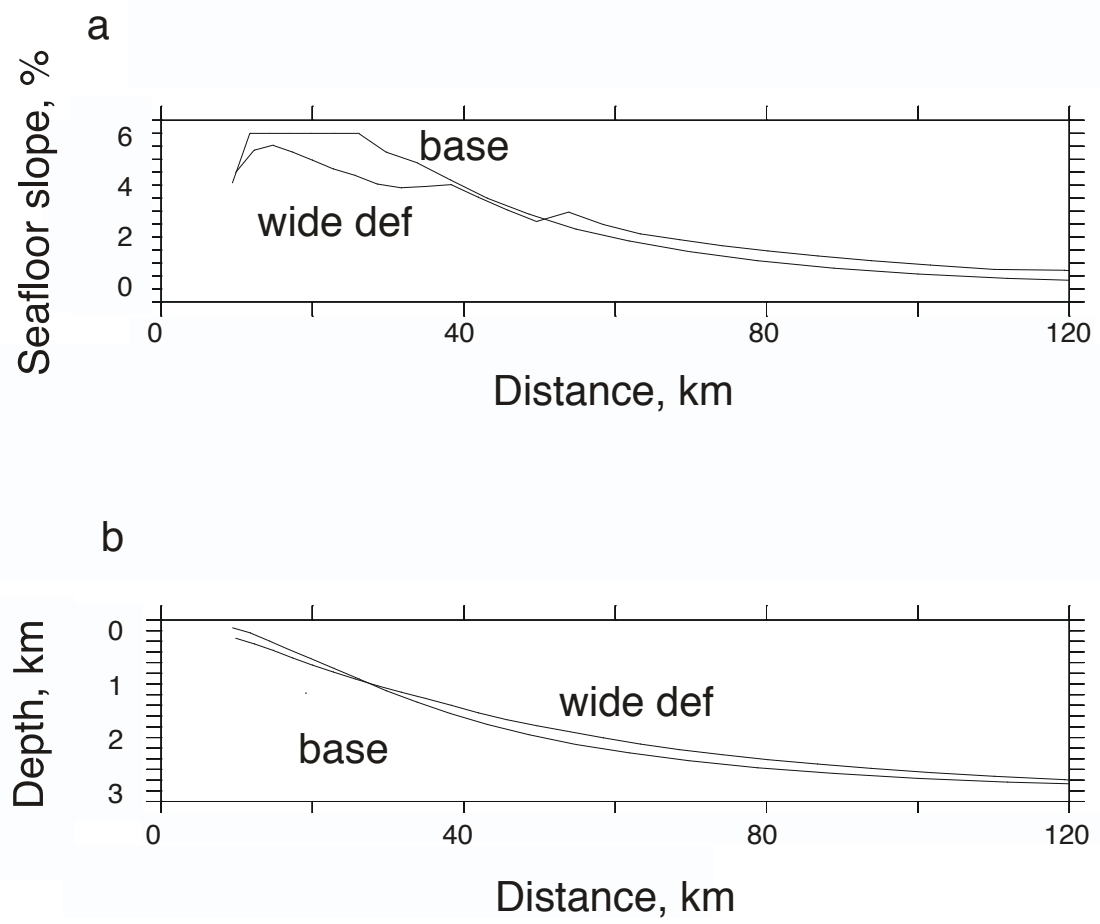

Figure 18. (A) Sea floor slope and (B) sea floor depth for the Base and Wide Def simulations. Wide Def never reaches the critical sea floor slope of 6\%, and so the slope gets monotonically steeper as the simulation approaches the shore. 
a

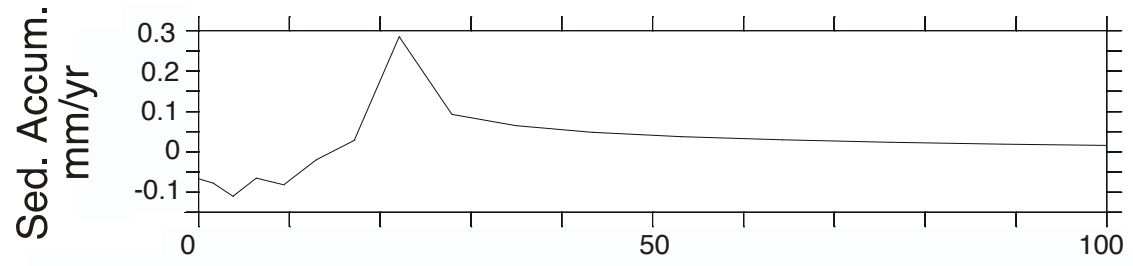

Distance, $\mathrm{km}$

b

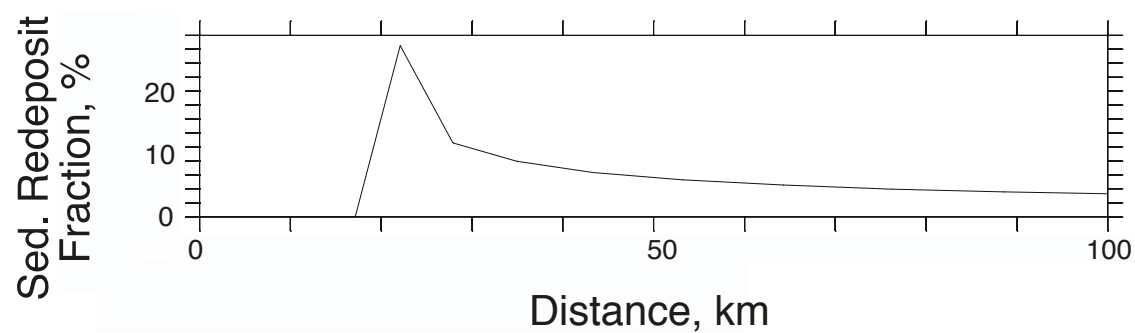

Figure 19. (A) Total sediment accumulation rate and (B) redeposition fraction for the Base scenario. 


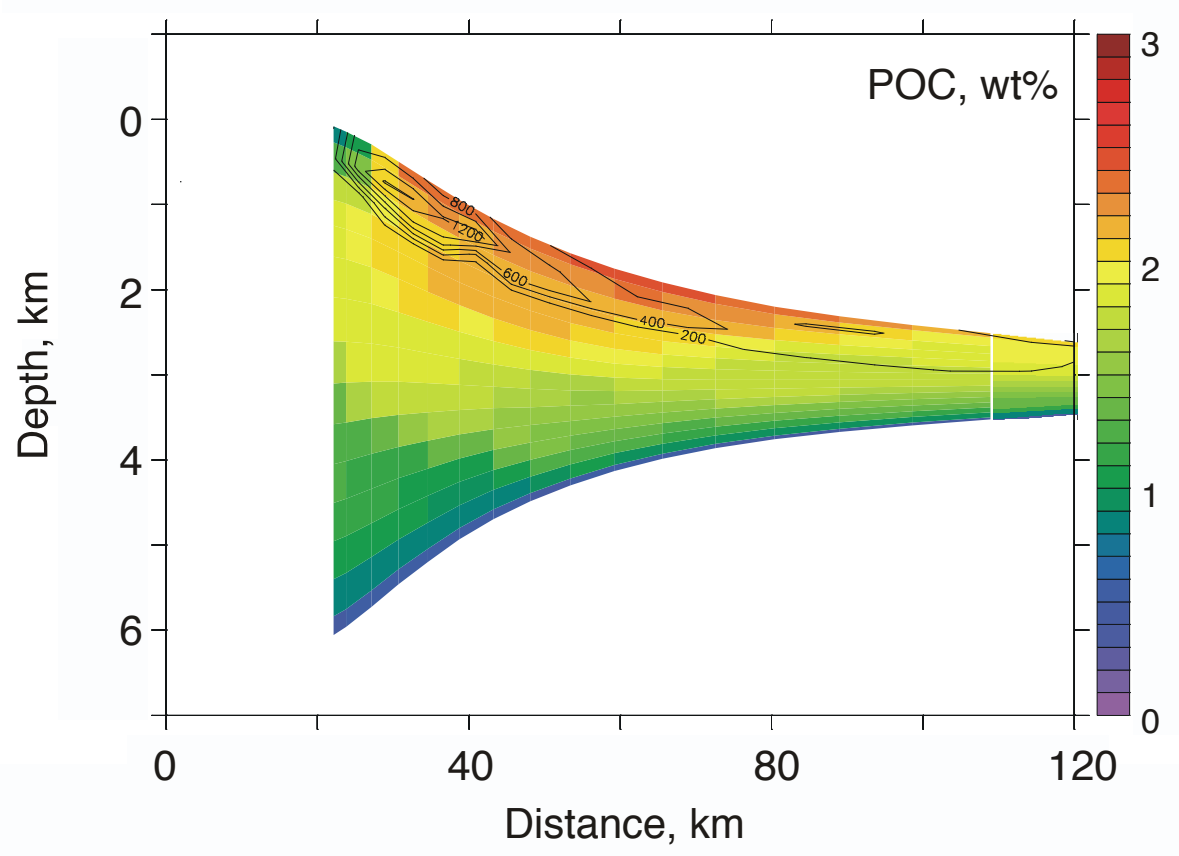

Figure 20. POC results from the base case. Contours are respiration rates. A movie of the Base and Bumpy simulations can be seen at http://geosci.uchicago.edu/ archer/spongebob_active/fig5.active.movie.gif. 


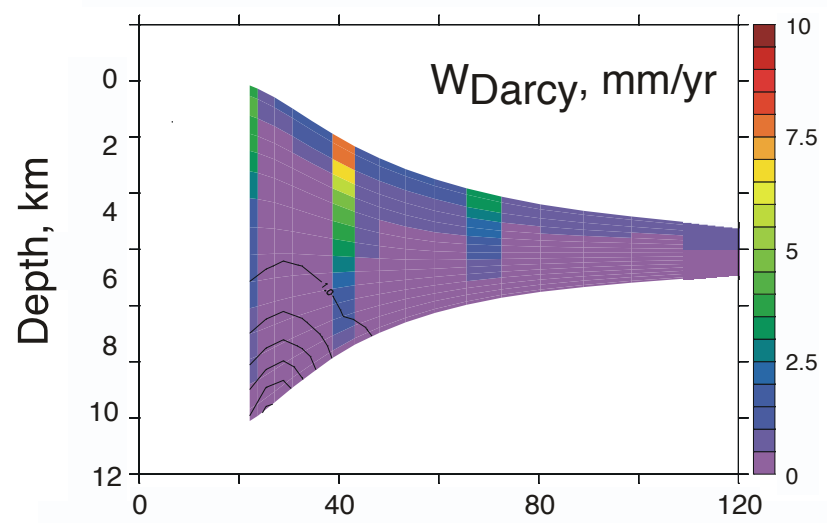

$\mathrm{b}$
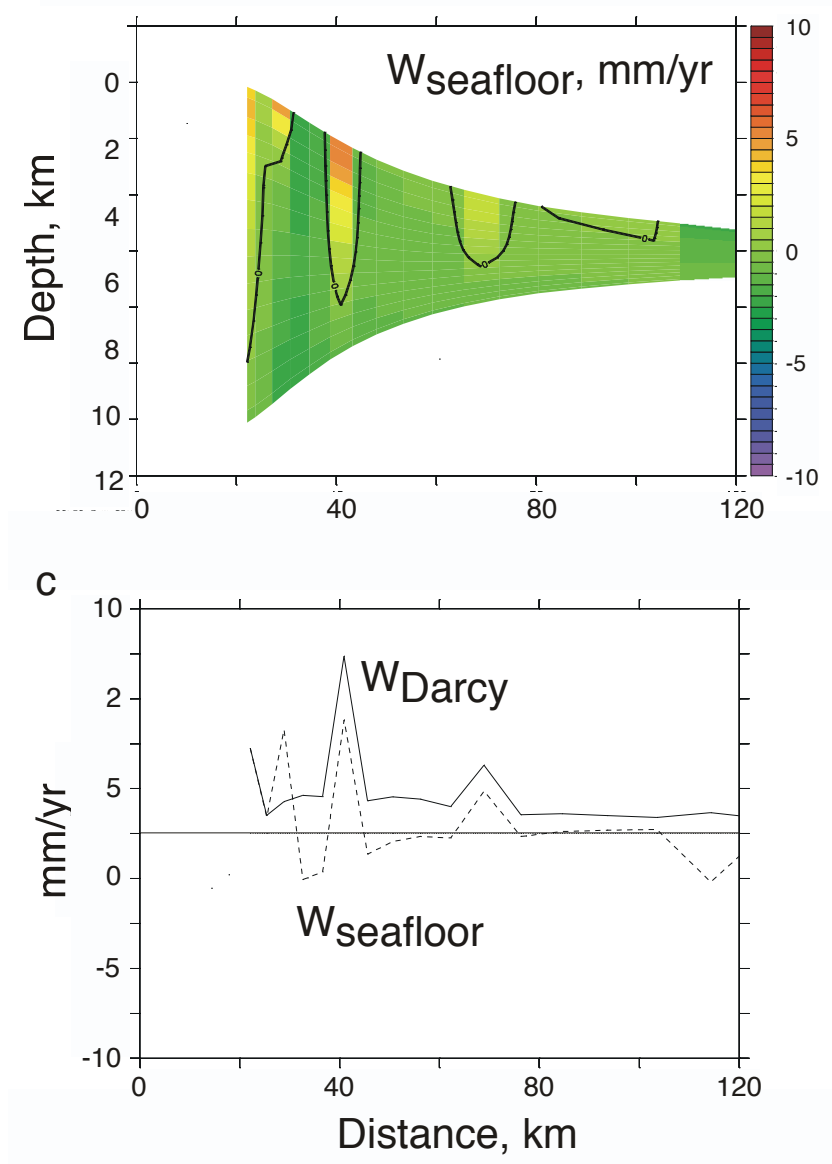

Figure 21. (A) Sections of Darcy vertical velocities (flow relative to the grains), and (B) velocities relative to the sea floor, and (C) plots of wDarcy and wseafloor at the sea floor, for the base scenario. Snapshots of other cases are shown in Figure 6 Suppl (Base, Bumpy, No Chan, and No Erod). Movies of wseafloor from the Base and Bumpy scenarios can be seen at http://geosci.uchicago.edu/ archer/spongebob active/fig6a.active.movie.gif and velocities at the sea floor at http://geosci.uchicago.edu/ archer/spongebob_active/fig6b.active.movie.gif . 

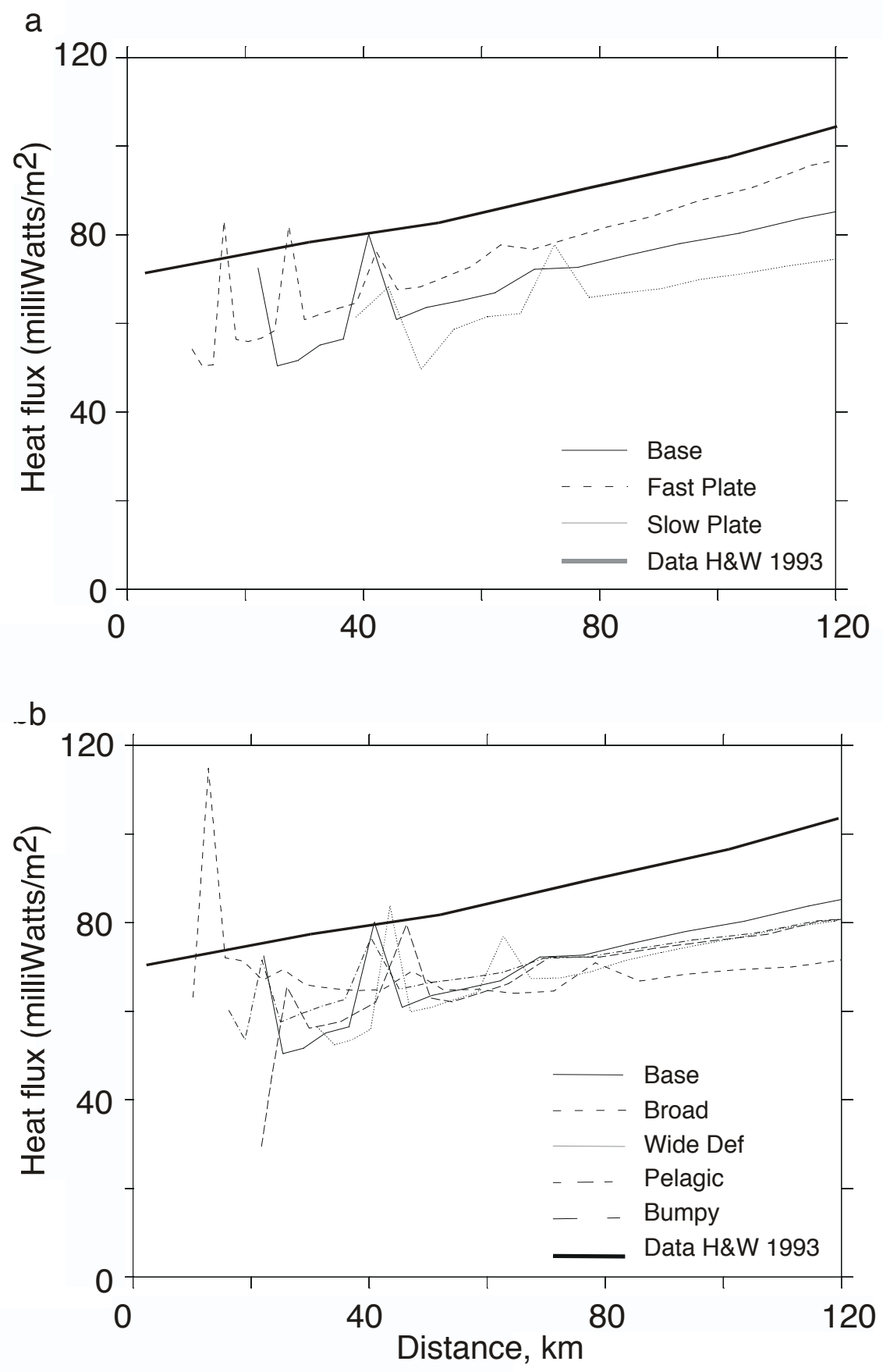

Figure 22. Diffusive heat flow results compared with data from Hyndman and Wang [1993]. (A) and (B) are various model scenarios as indicated. 


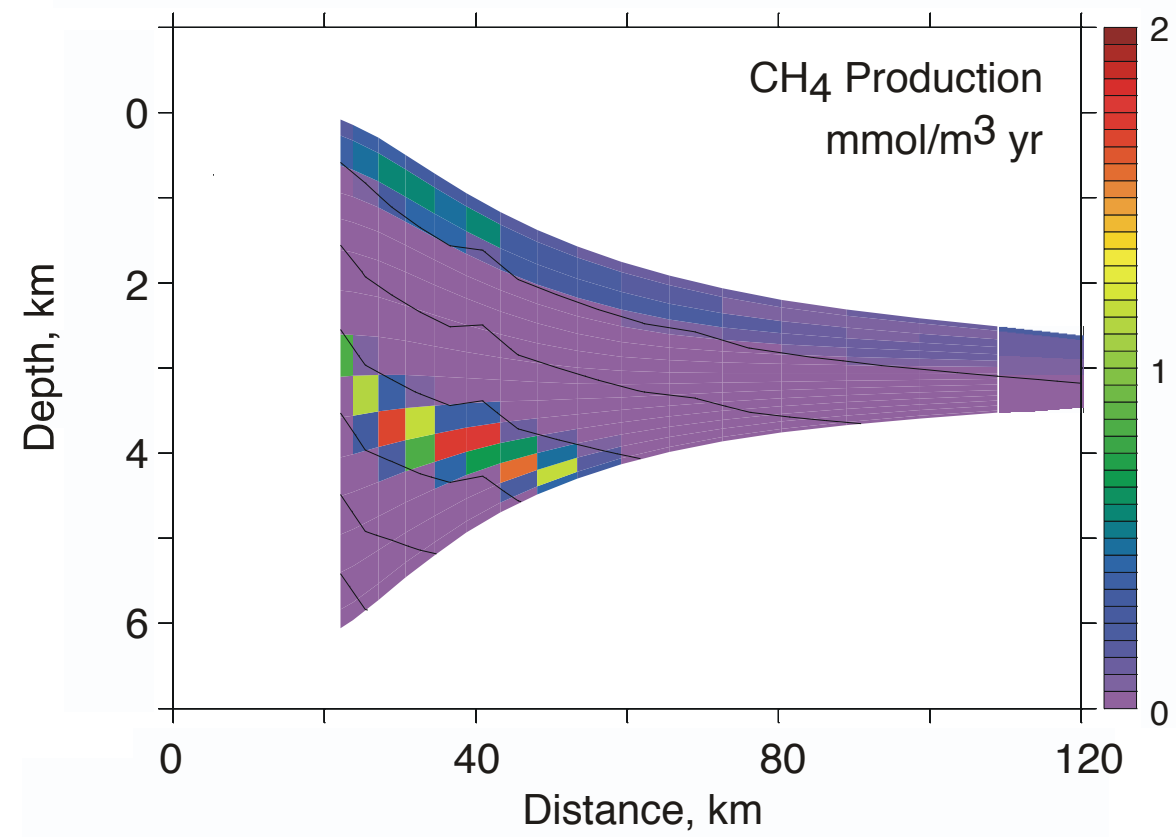

Figure 23. Methanogenesis rates in the base scenario. Shallow is from biological activity, deep is thermogenic methane production rates. Contours are temperature. An animation can be seen at http://geosci.uchicago.edu/ archer/spongebob active/fig8.active.movie.gif . 


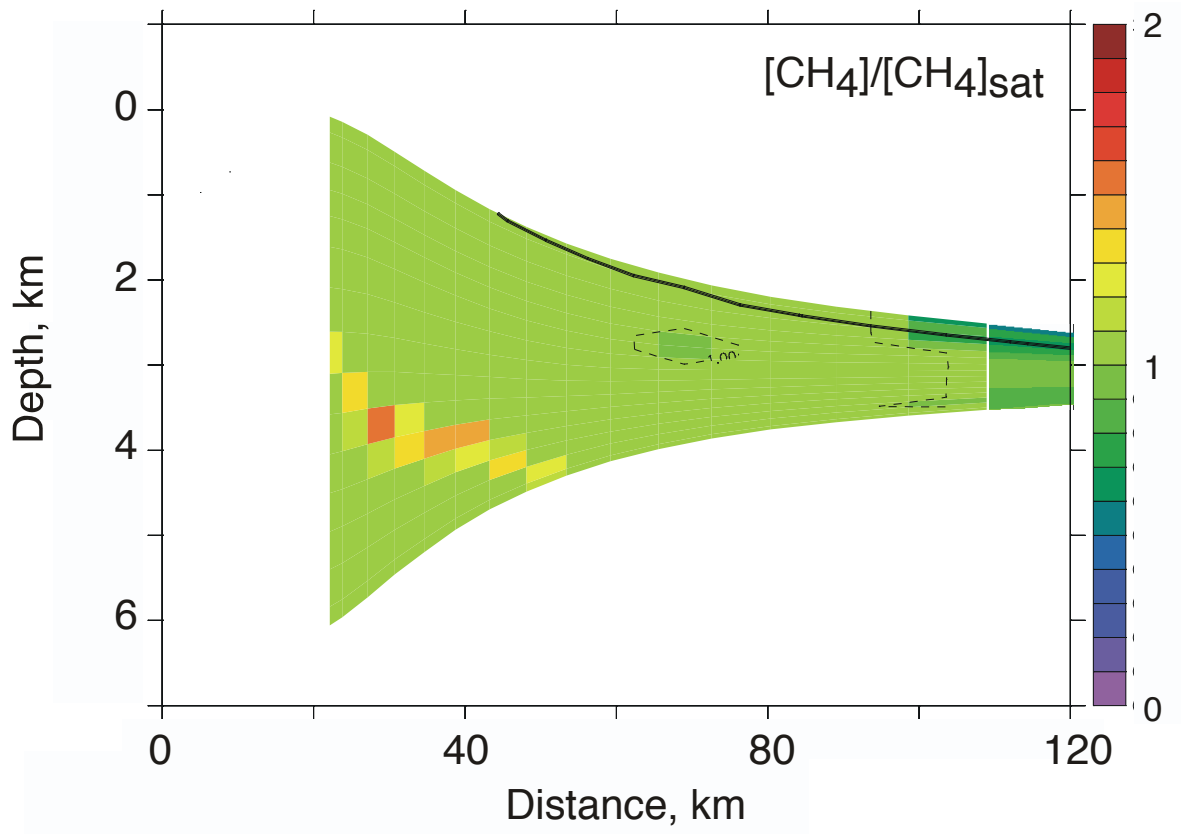

Figure 24. Dissolved methane concentration relative to equilibrium with respect to gas (below the stability horizon, solid black line) or hydrate (above the stability horizon), for the base scenario. An animation can be seen at http://geosci.uchicago.edu/ archer/spongebob_active/fig9.active.movie.gif . 


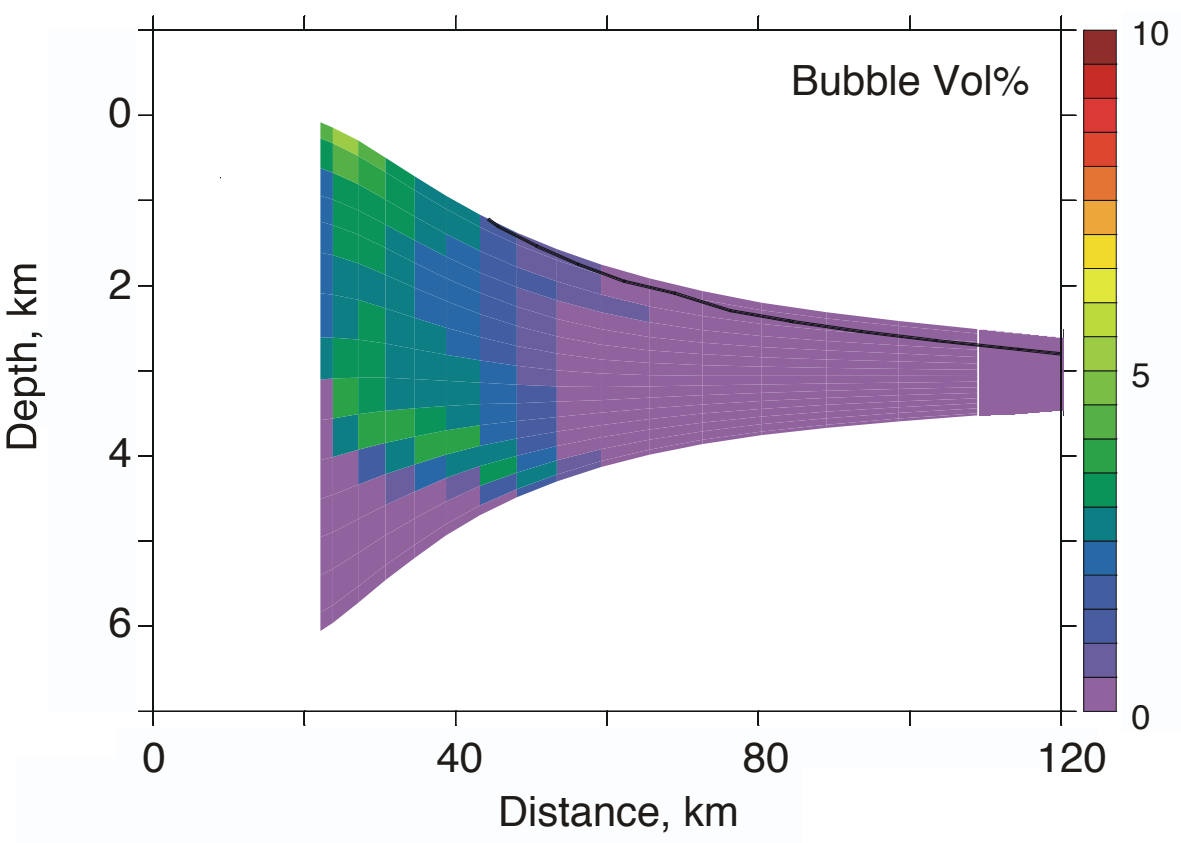

Figure 25. Bubble concentration (percent pore volume) for the base scenario. Solid black line is the hydrate stability boundary. An animation of the Base and Bumpy scenarios can be seen at http://geosci.uchicago.edu/ archer/spongebob active/fig10.active.movie.gif . 


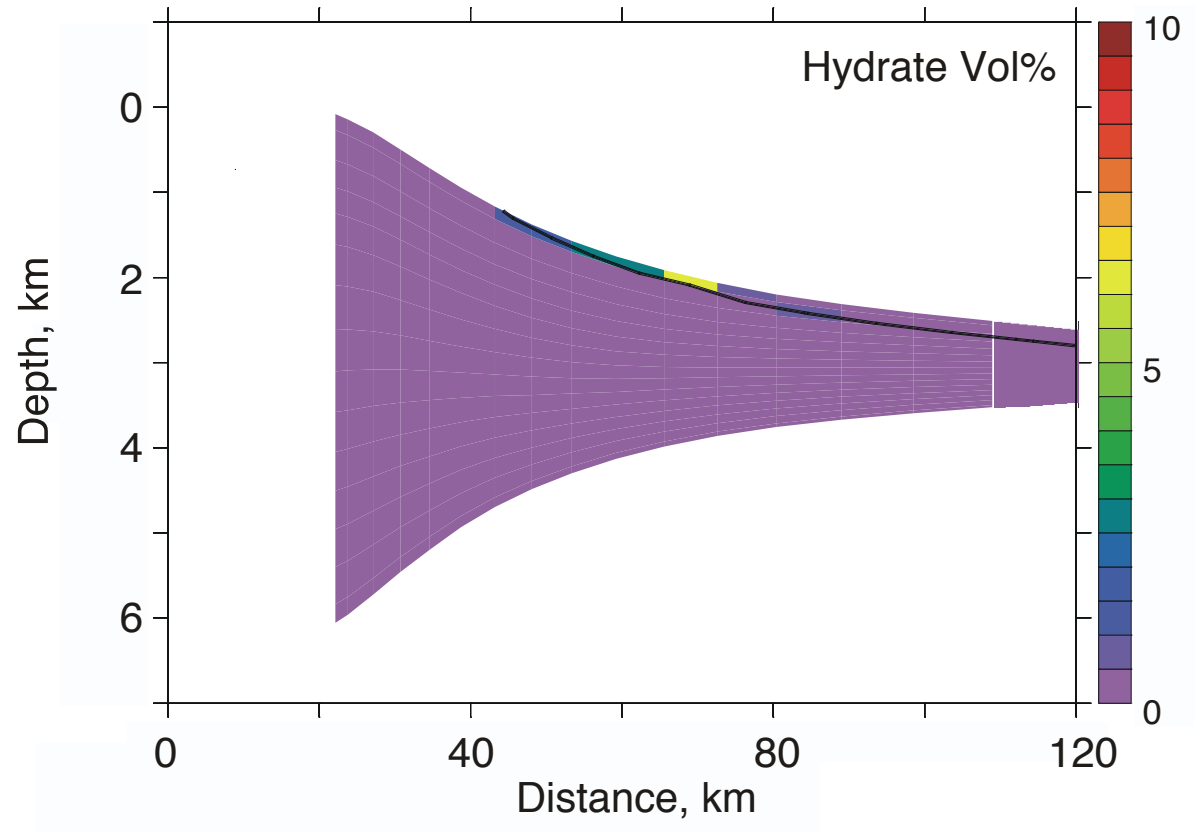

Figure 26. Methane hydrate concentration, percent pore volume, for the base scenario. Solid black line is the stability boundary. Animations of the Base and Bumpy scenarios can be seen at http://geosci.uchicago.edu/ archer/spongebob_active/fig11a.active.movie.gif . and of the three plate speed scenarios at http://geosci.uchicago.edu/ archer/spongebob_active/fig11b.active.movie.gif . 


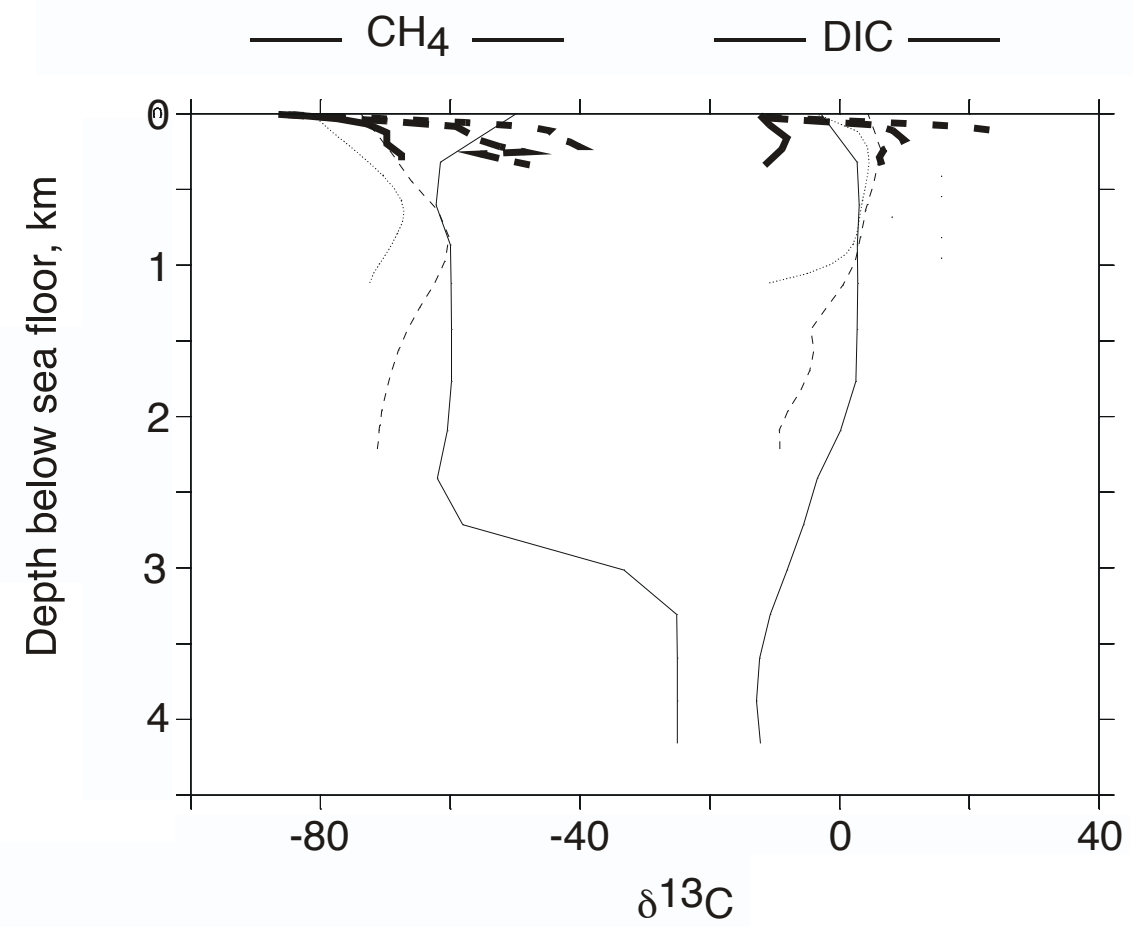

Figure 27. Carbon isotopic compositions compared with measurements from Pohlman et al [2009]. Short dashes are near the toe, long dashes intermediate, and solid lines are closest inshore. Heavy lines are data, thin lines are model results. 


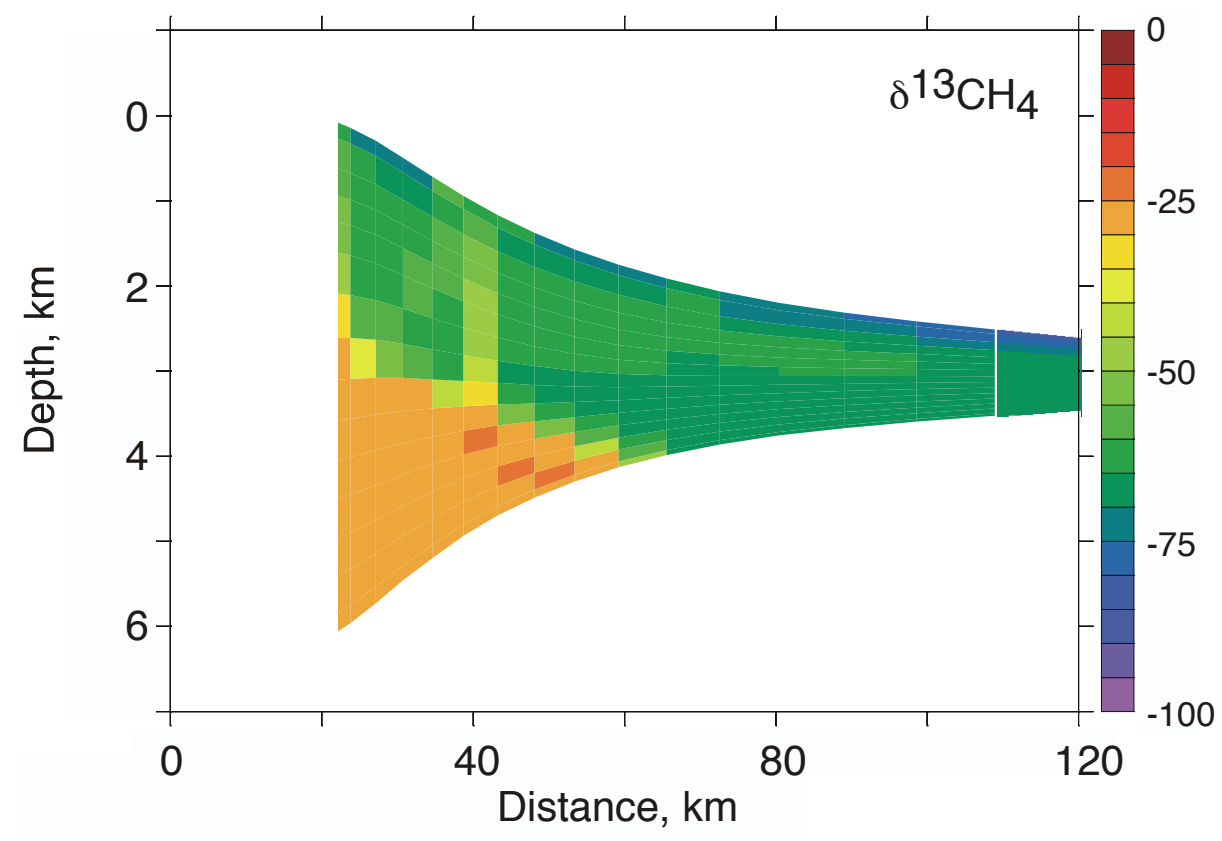

Figure 28. Carbon isotopic composition, $\delta 13 \mathrm{C}$, of dissolved methane, for the base scenario. An animation of $\delta 13 \mathrm{C}$ of methane and DIC (Figure 29) can be seen at http://geosci.uchicago.edu/ archer/spongebob active/fig13-14.active.movie.gif . 


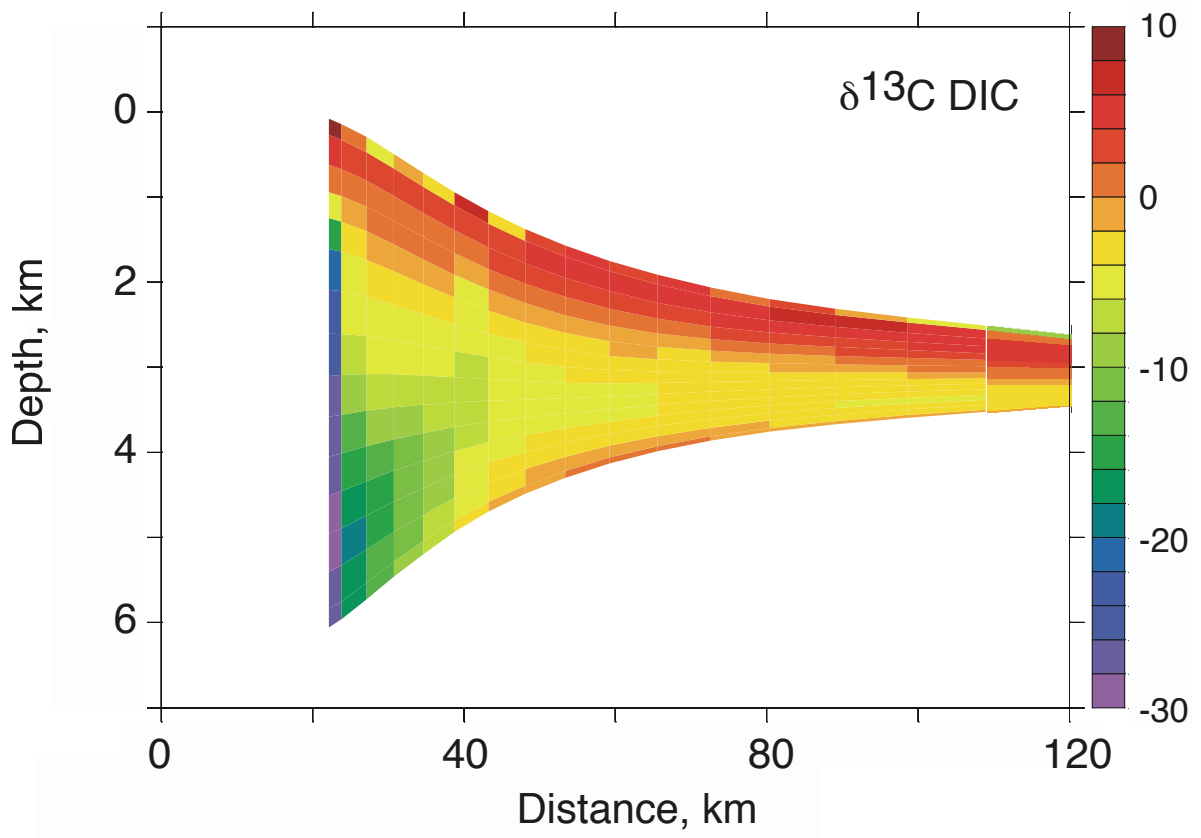

Figure 29. Carbon isotopic composition, $\delta 13 \mathrm{C}$, of dissolved inorganic carbon, for the base scenario. An animation of $\delta 13 \mathrm{C}$ of methane and DIC (Figure 28) can be seen at http://geosci.uchicago.edu/ archer/spongebob_active/fig13-14.active.movie.gif . 


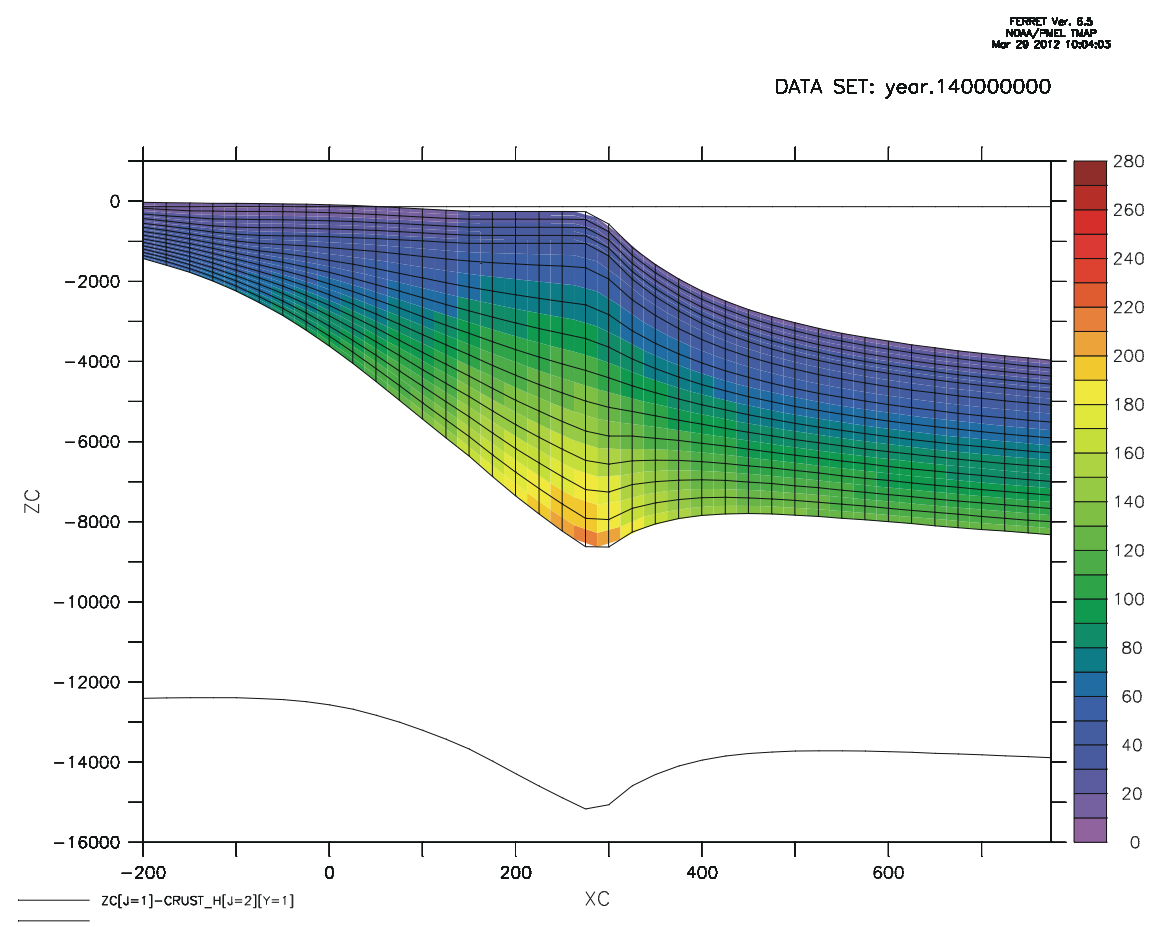

TEMPERATURE

Figure 30. Temperature in the Gulf of Mexico scenario.

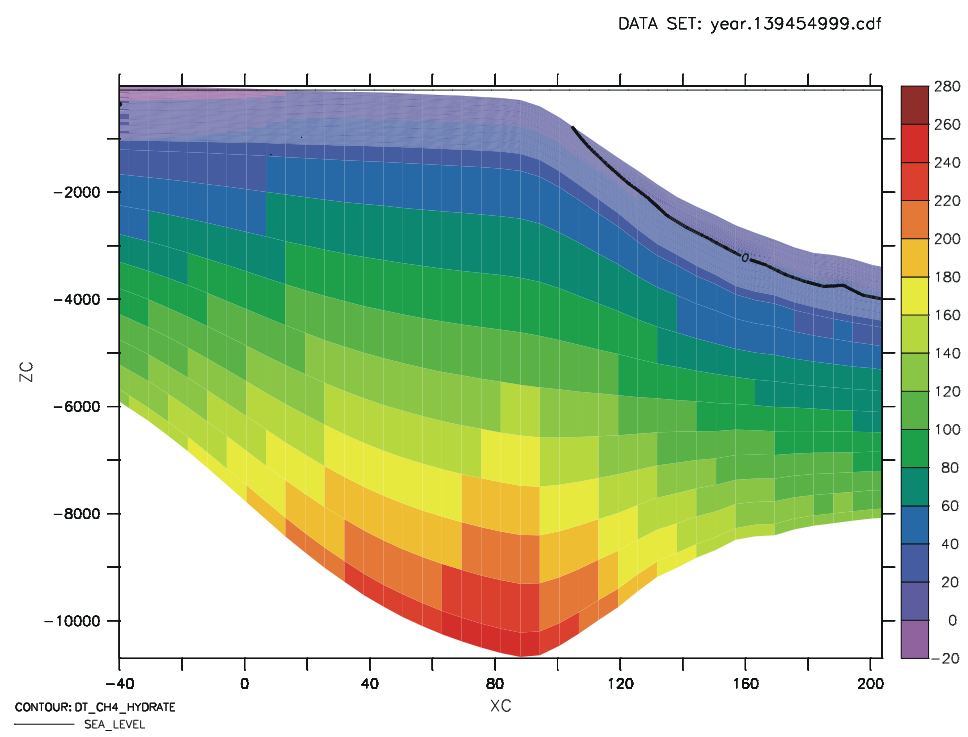

TEMPERATURE

Figure 31. Temperature in the Arctic scenario. 
a

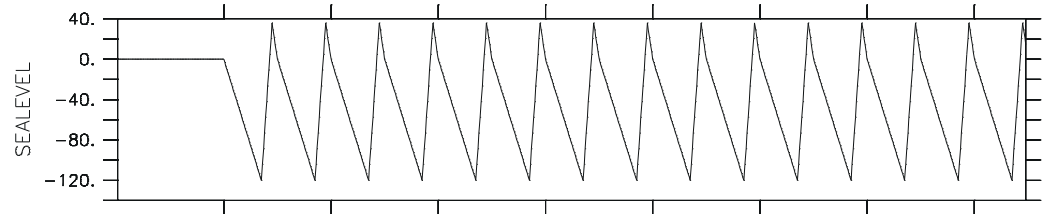

$b$

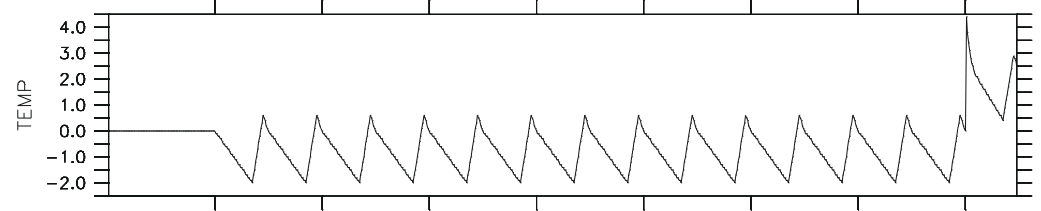

$C$

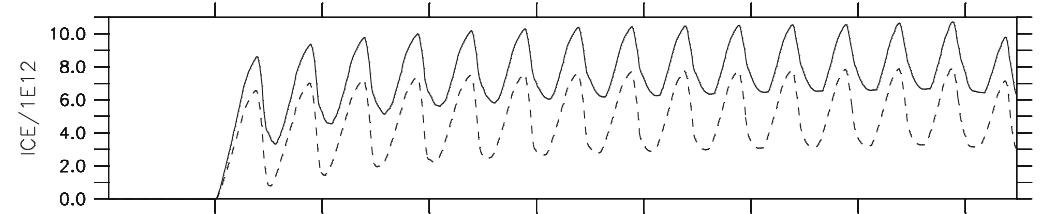

$d$

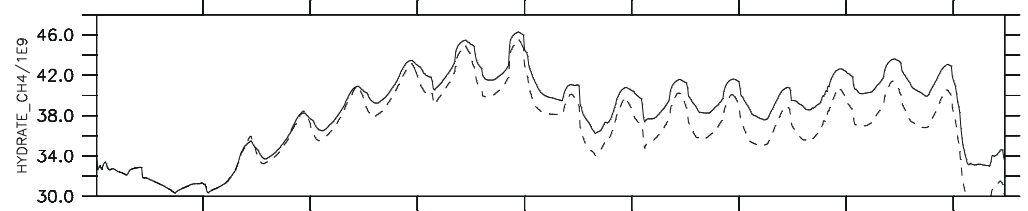

e

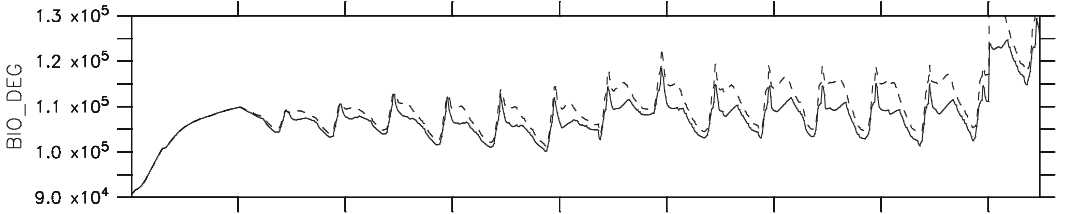

$f$

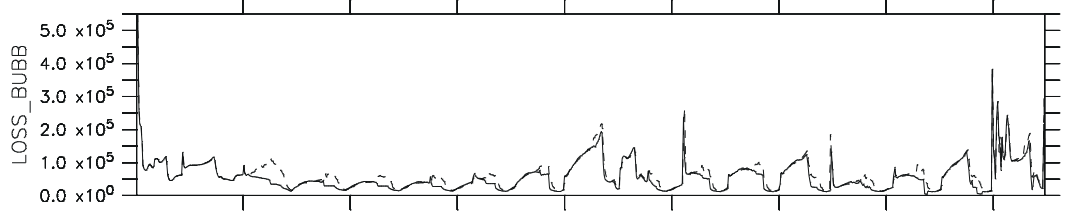

$g$

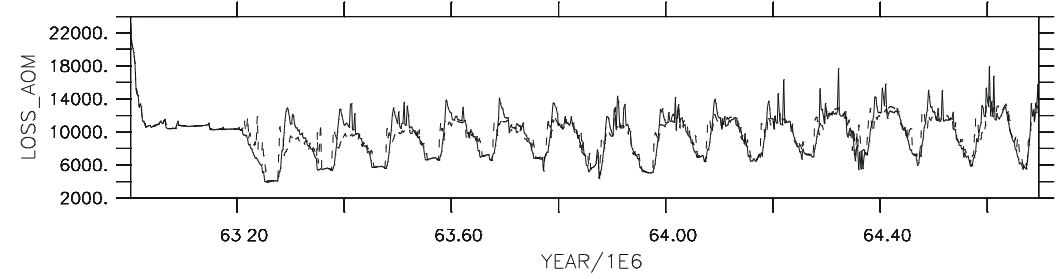

Figure 32. Time-dependent results from Laptev Sea margin simulation. Sea level 
a

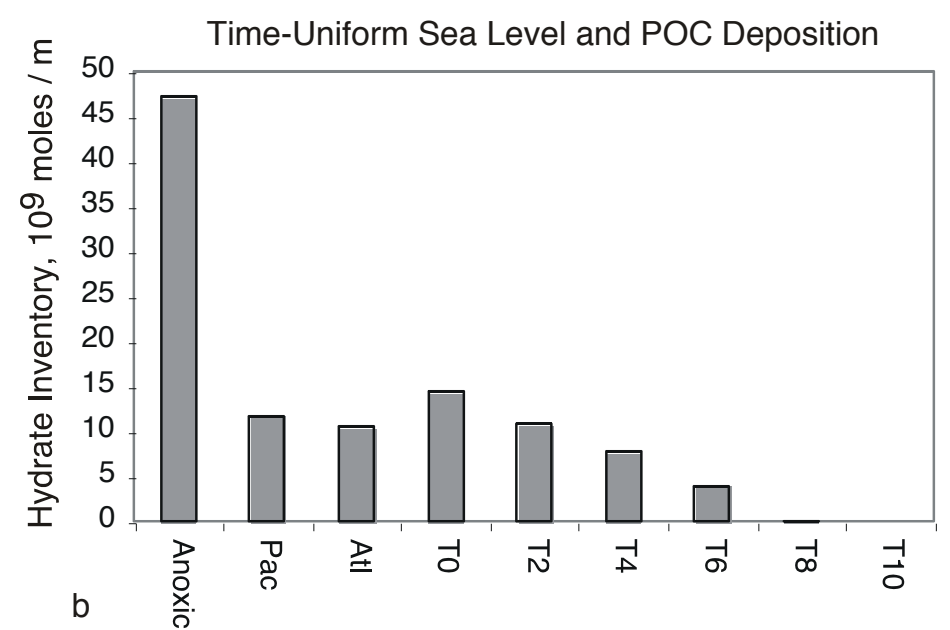

Time-Dependent Sea Level and POC Deposition

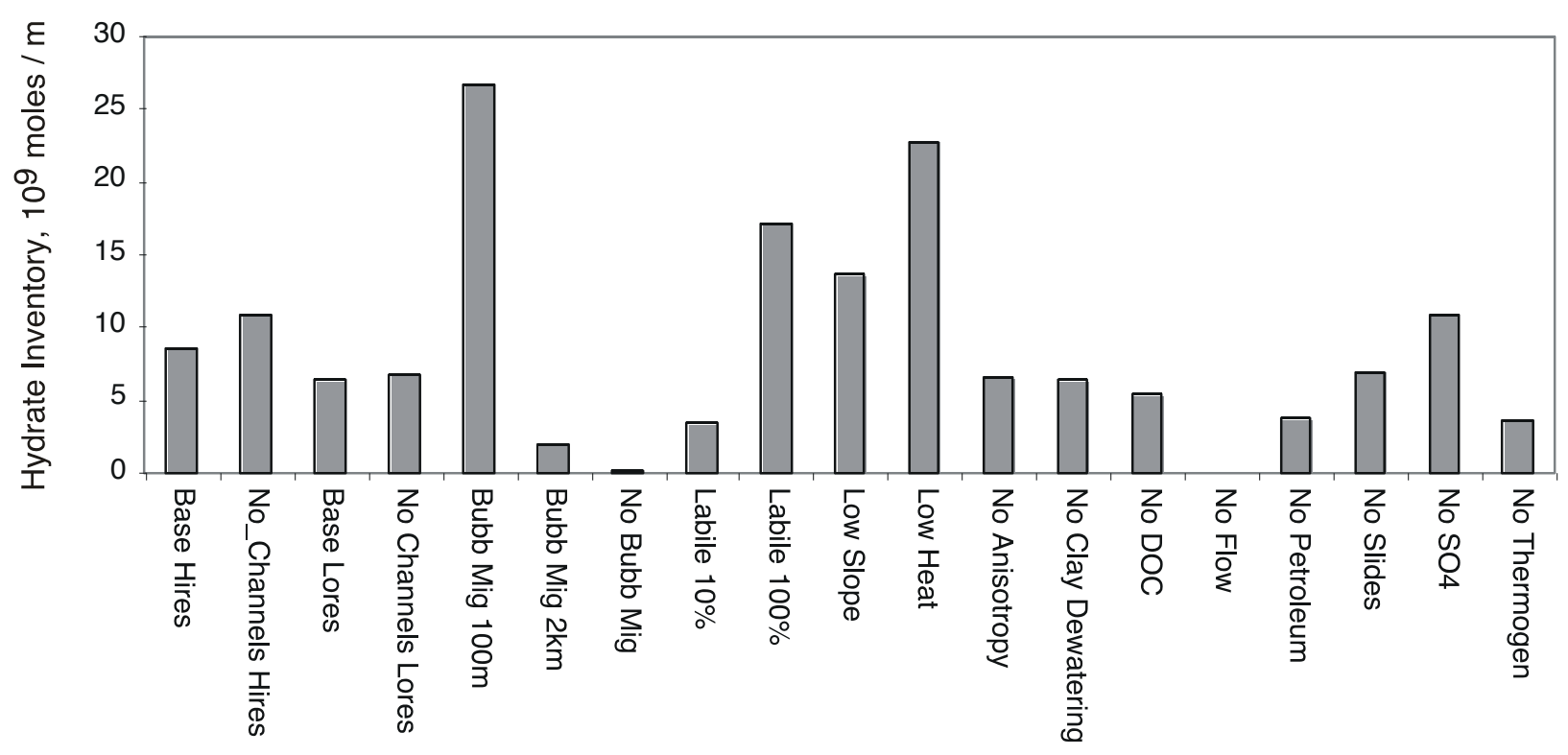

Figure 33. Results of model sensitivity runs. (A and B) Hydrate inventory at the end of the simulation, (A) for the time-uniform forcing runs and (B) for the time-varying forcing runs. (C) The time trajectory of hydrate inventory, Base (time-varying) vs. T0 (time-uniform).

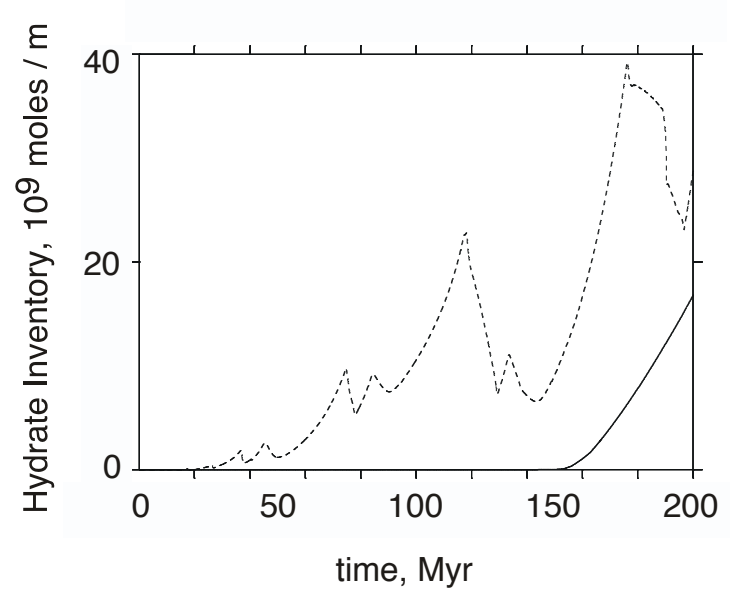




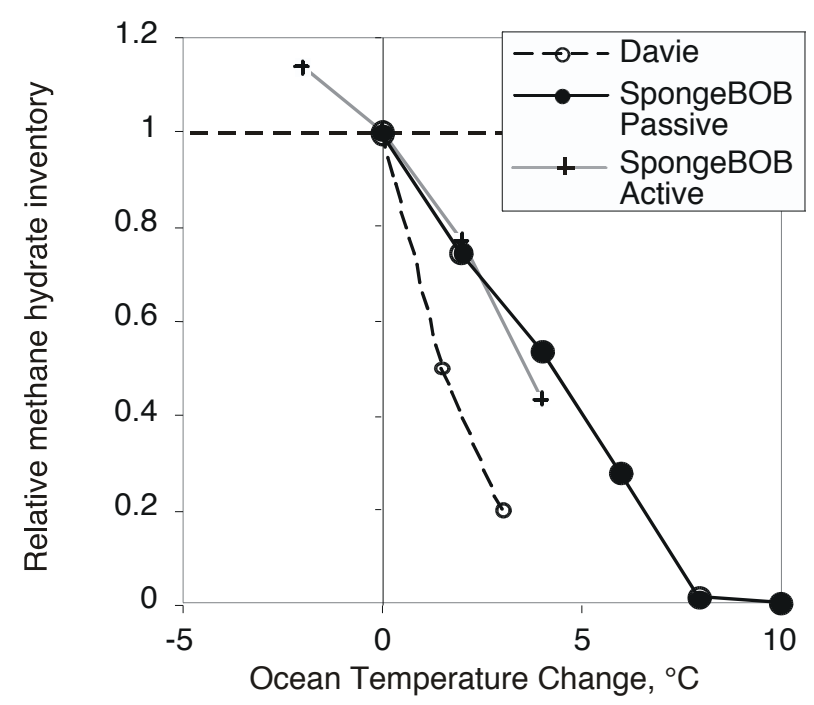

C

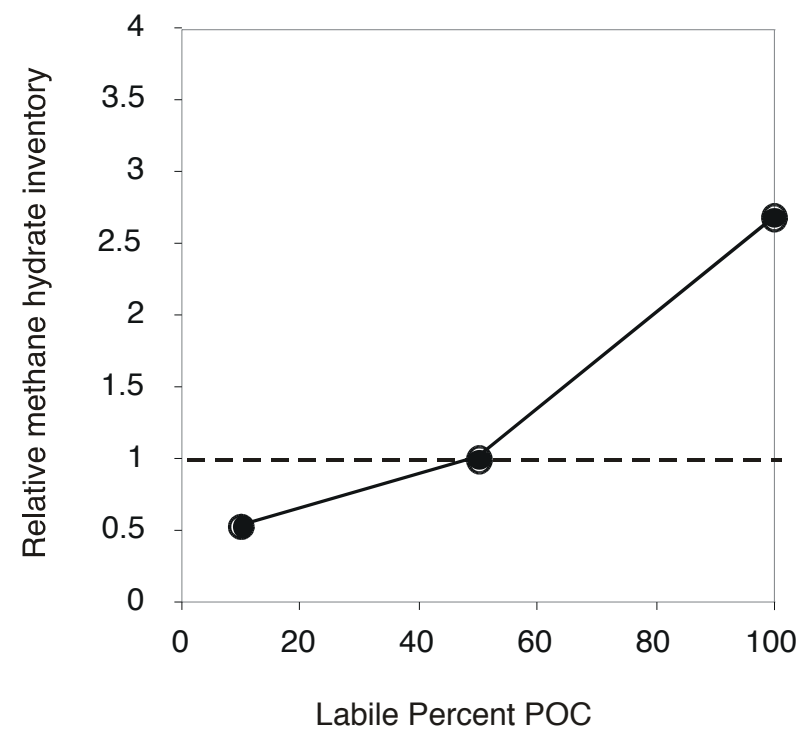

b
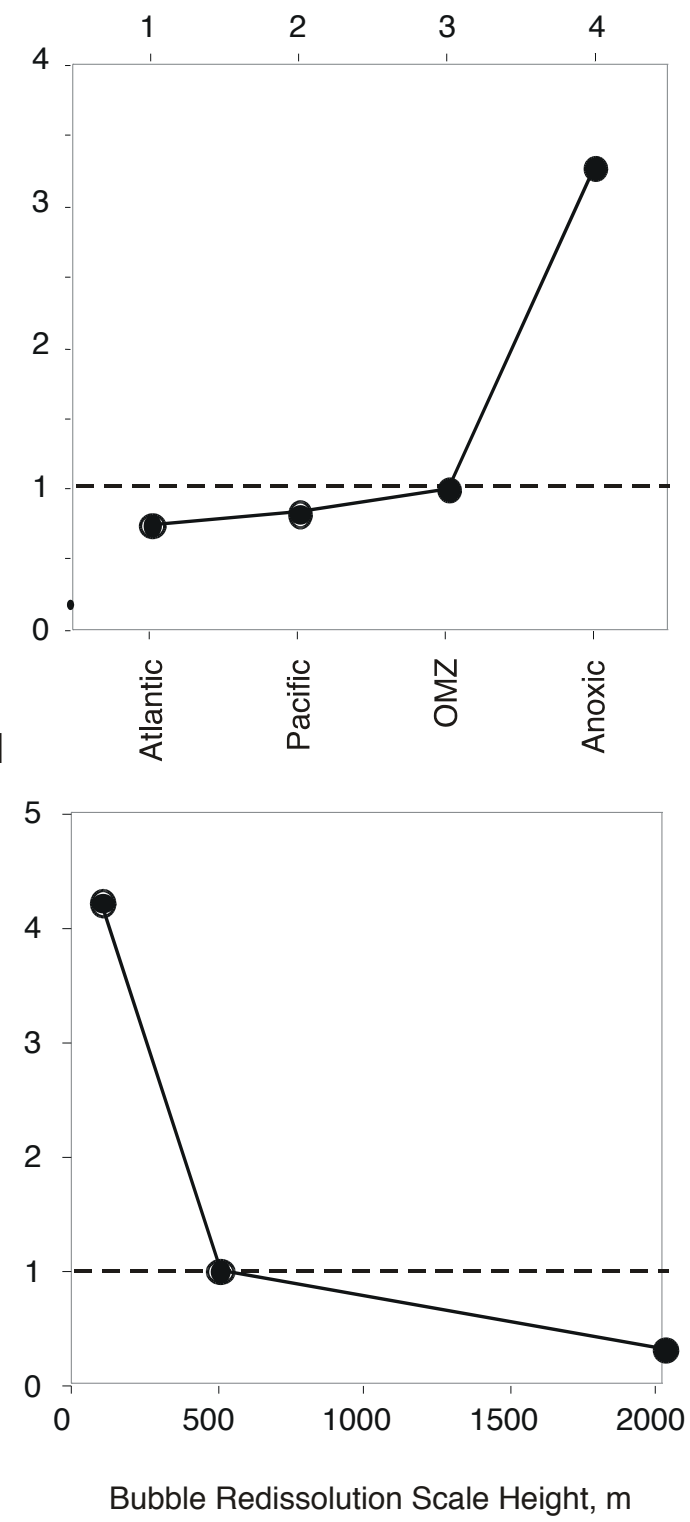

Figure 34. Summary of model sensitivities. Y-axis is the hydrate inventory relative to the appropriate base case $=1$. (A) Temperature,

(B) ocean oxic state (see Figure 3),

(C) percent labile fraction of depositing POC, and (D) migrating bubble redissolutution scale height. 16 . 
a

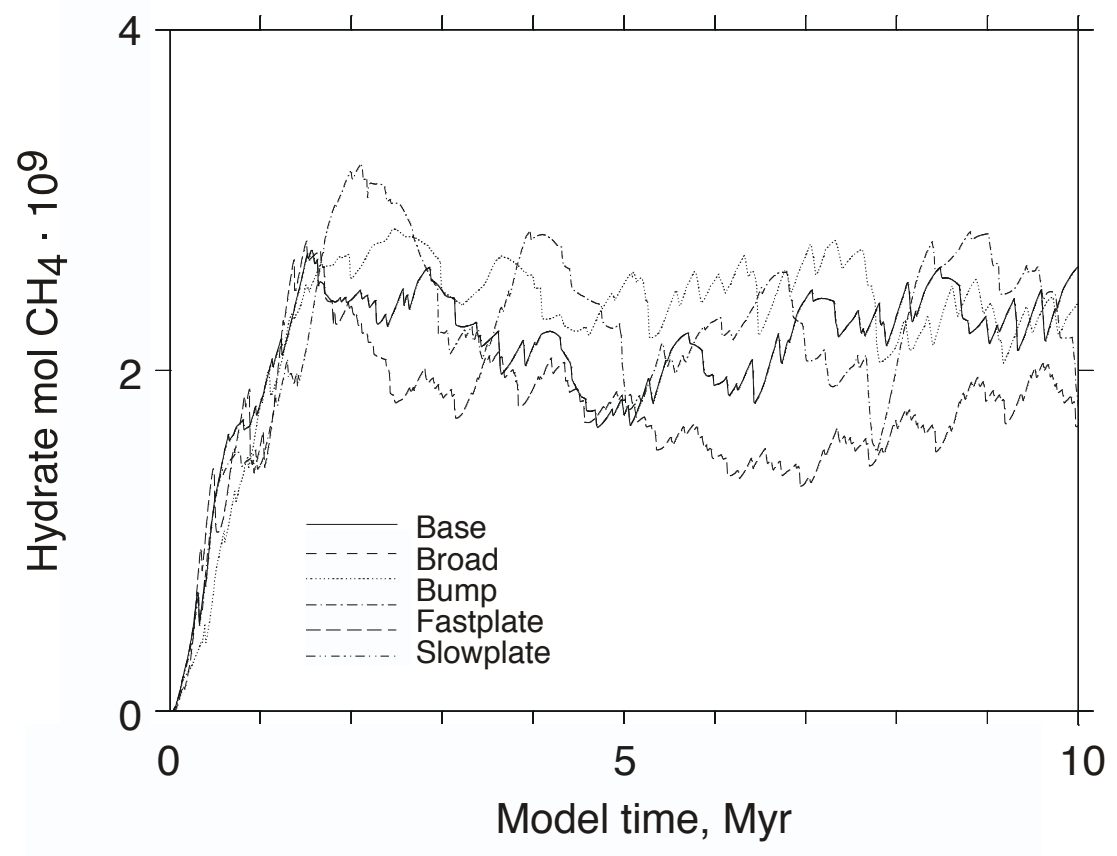

b

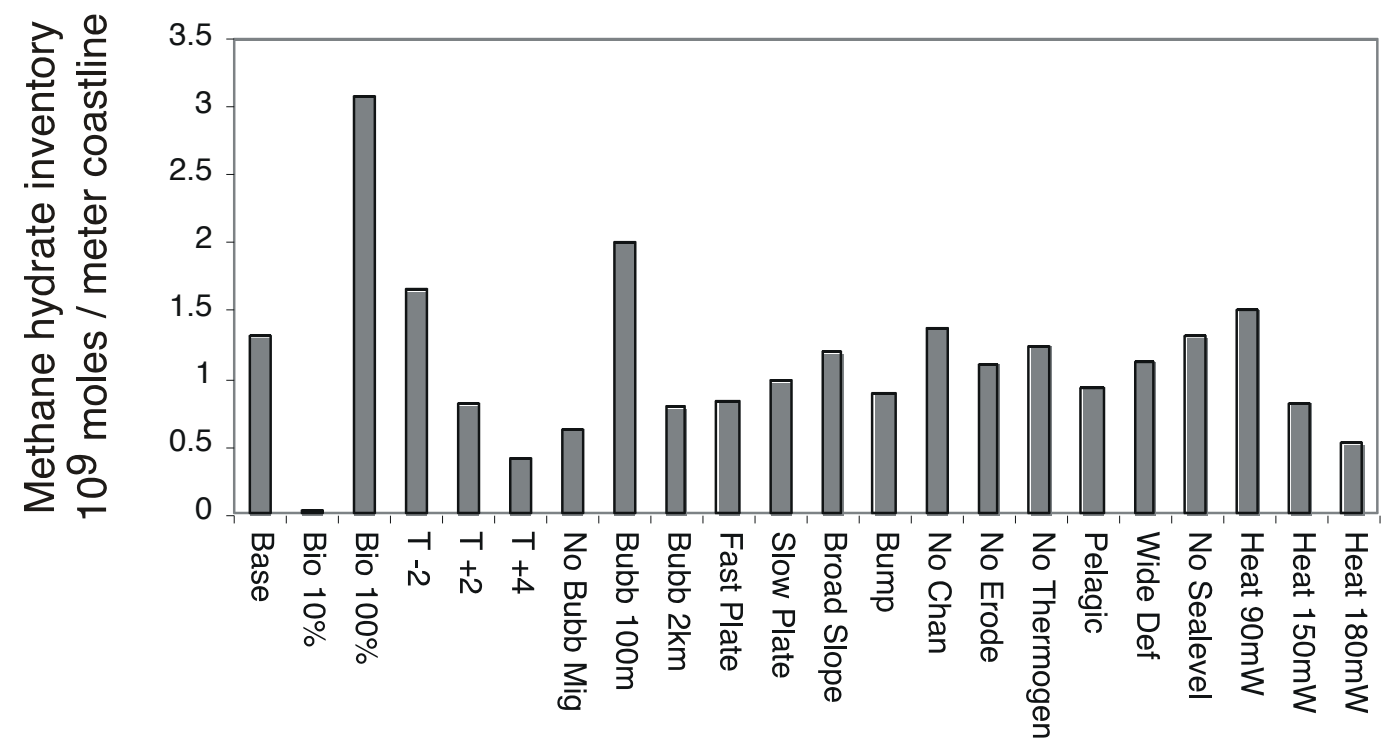

Figure 35. Results of model sensitivity runs for the active margin scenario. (A) Timedependent hydrate inventory. (B) Final hydrate inventories 

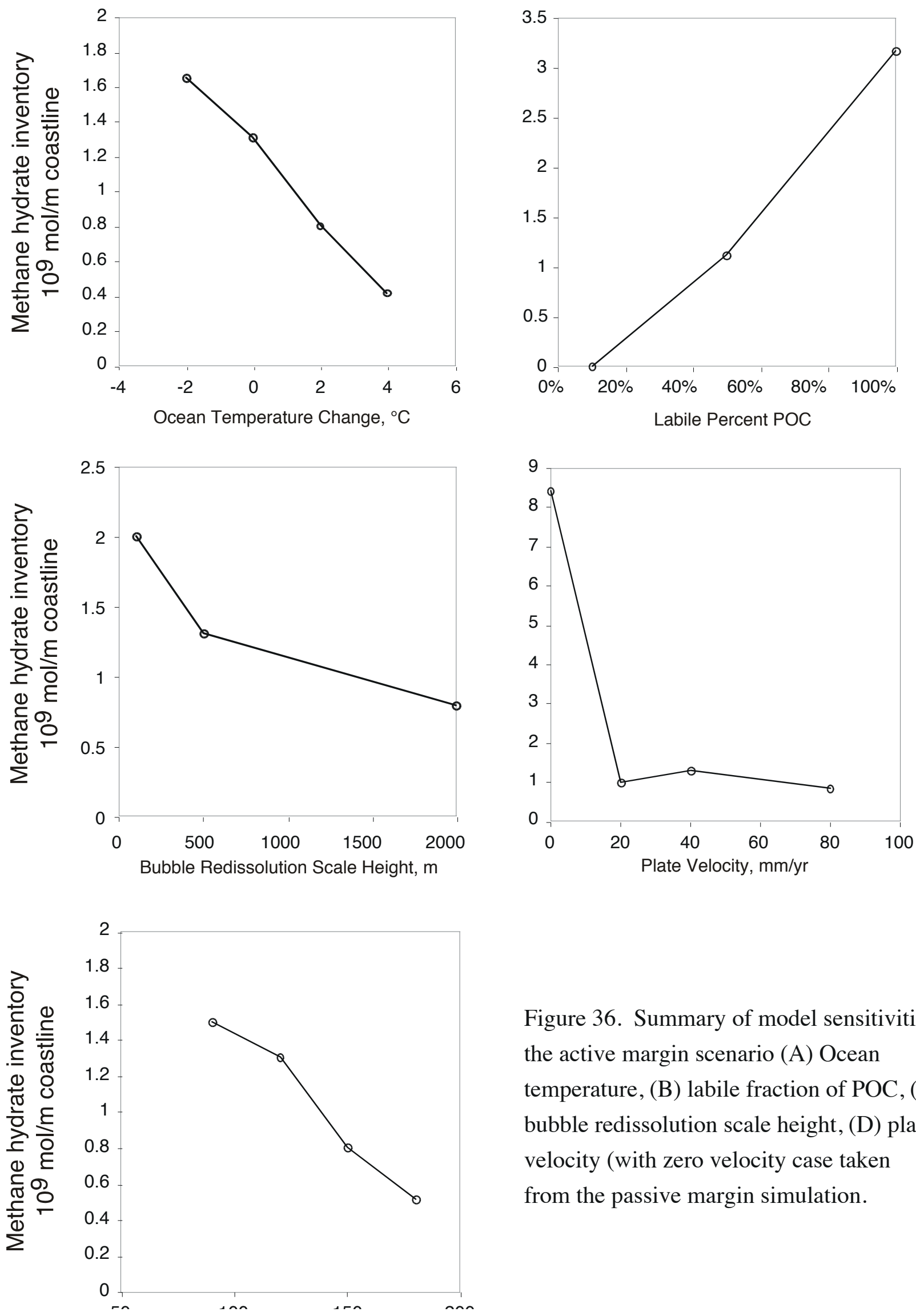

Figure 36. Summary of model sensitivities for the active margin scenario (A) Ocean temperature, (B) labile fraction of POC, (C) bubble redissolution scale height, (D) plate velocity (with zero velocity case taken from the passive margin simulation. 